\title{
The GRAS Protein SCL14 and TGA Transcription Factors Interact to Regulate Stress-Inducible Promoters
}

\author{
Dissertation \\ zur Erlangung des Doktorgrades \\ der Mathematisch-Naturwissenschaftlichen Fakultäten \\ der Georg-August-Universität zu Göttingen
}

vorgelegt von

Benjamin Fode

aus Hamburg

Göttingen 2008 
D7

Referent:

Prof. Dr. Christiane Gatz

Korreferent:

PD Dr. Wolfgang Dröge-Laser

Tag der mündlichen Prüfung:

08. Mai 2008 
Für dich, Joe 


\section{Contents}

\section{Abbreviations}

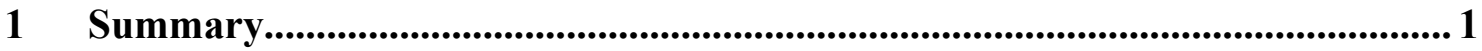

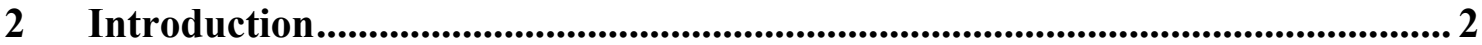

2.1 The role of plant hormones in stress responses ............................................... 2

2.2 The regulatory promoter element activating sequence 1 .................................. 5

2.3 The role of TGA transcription factors in defence signalling ........................... 6

$2.4 \quad$ Detoxification of xenobiotic compounds....................................................... 7

2.5 The GRAS protein SCL14 interacts with TGA transcription factors................ 9

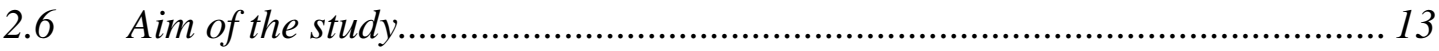

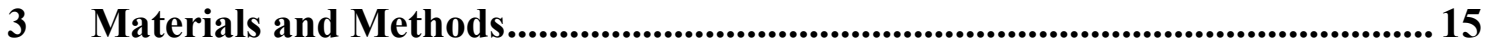

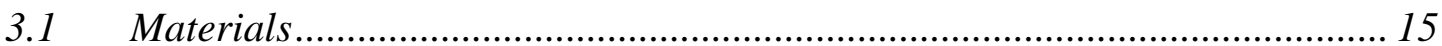

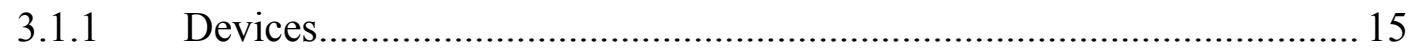

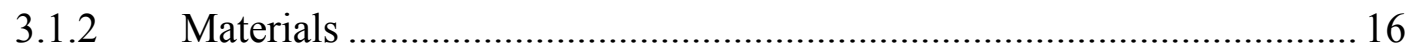

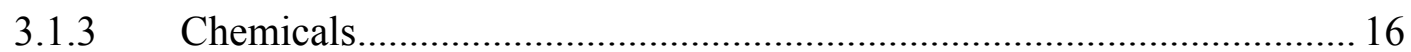

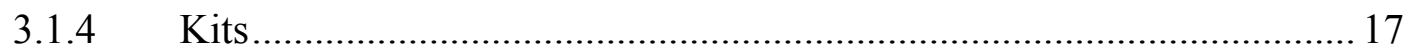

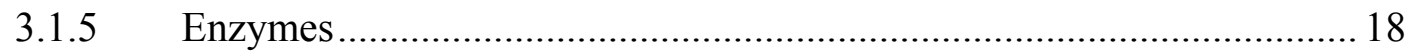

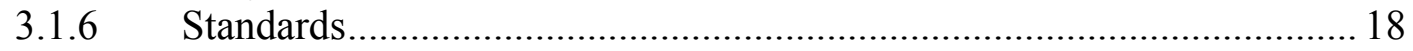

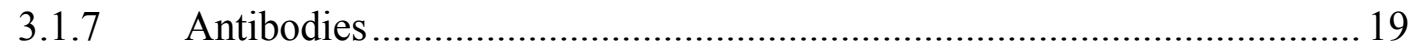

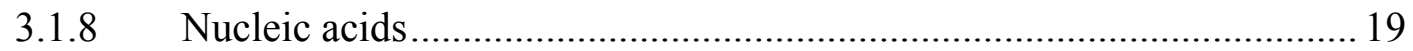

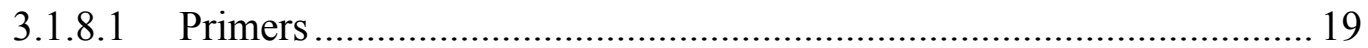

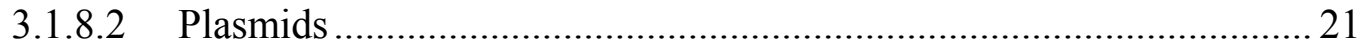

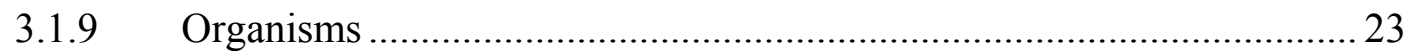

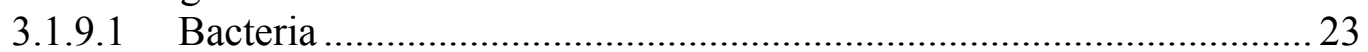

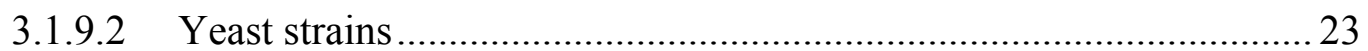

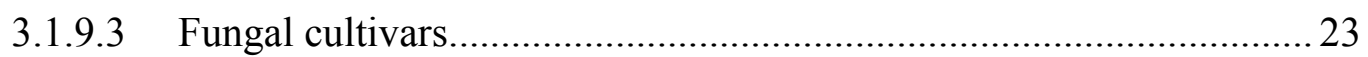

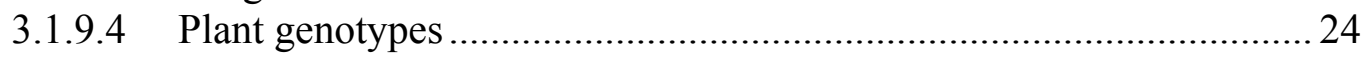

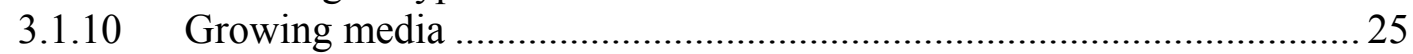

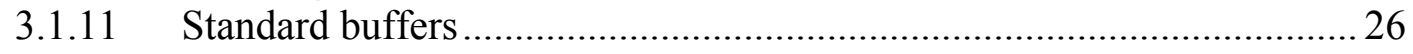

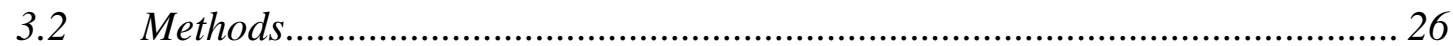

3.2.1 Standard molecular biology methods ................................................... 26

3.2.1.1 Isolation of plasmid DNA from E. coli........................................... 26

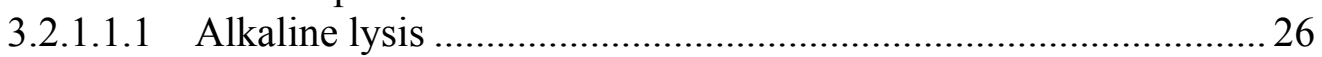

3.2.1.1.2 High-quality plasmid DNA isolation: Spinprep …...................... 27

3.2.1.2 Determination of DNA/ RNA concentrations .................................. 27

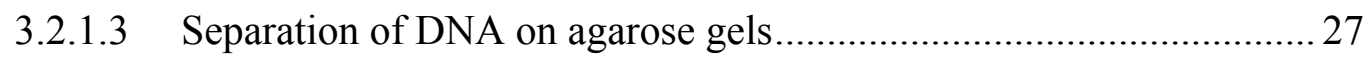

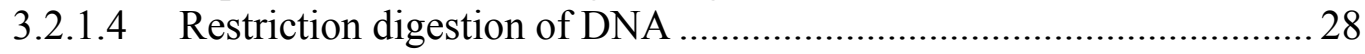

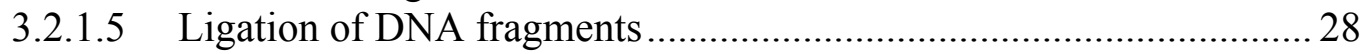




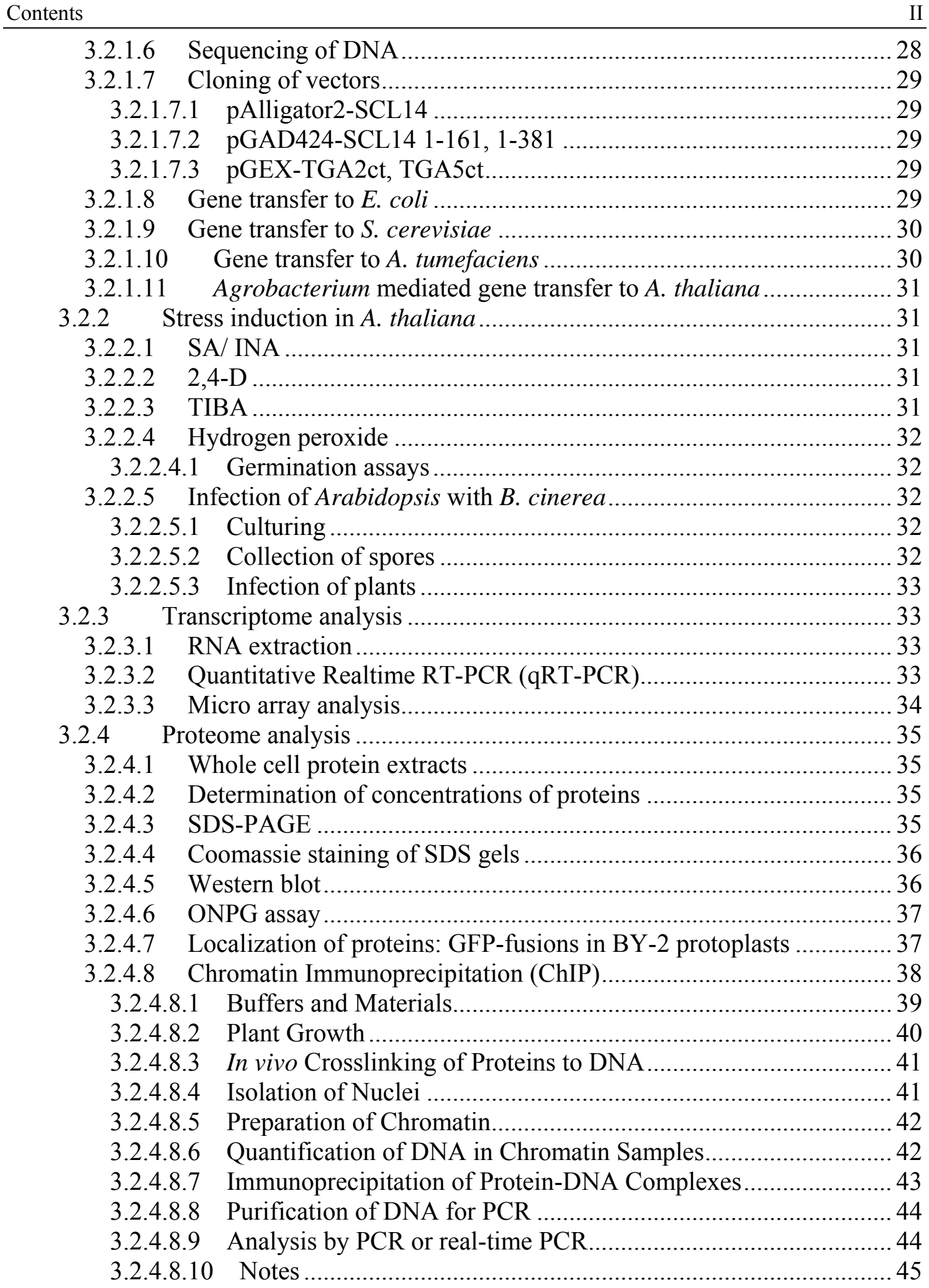

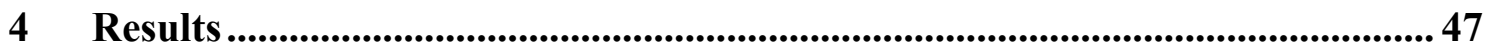

4.1 The N terminus of SCL14 is required for TGA interaction............................. 47

4.2 Intracellular localization of SCL14-GFP fusion proteins .............................. 48

4.3 Sequence analysis of endogenous genes activated by SCL14........................ 50 
4.4 Recruitment of SCL14 and TGA2 to target promoters .................................. 51

4.5 Expression pattern of SCL14 target genes ................................................. 55

4.5.1 The SA analogue 2,6-isonicotinic acid induces the SCL14 target genes in

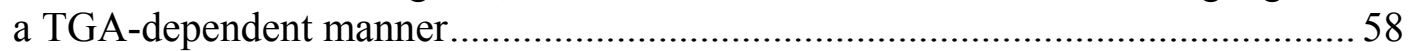

4.5.2 Hydrogen peroxide triggers the SCL14-dependent activation of

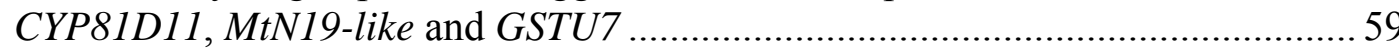

4.5.3 The chemical TIBA elicits SCL14 and TGA dependent expression of

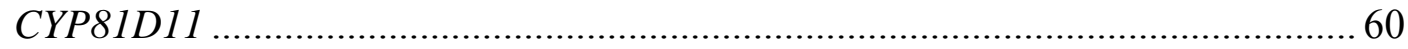

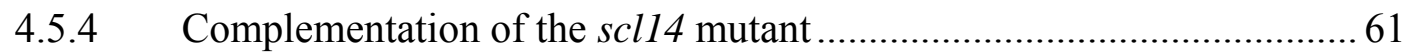

4.5.5 SCL14 binding to DNA is not influenced by TIBA ............................. 62

4.6 Influence of SCL14 protein levels on tolerance of Arabidopsis to xenobiotic

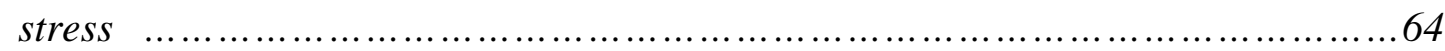

4.6.1 Complementation of the growth defect of scl14 mutants on xenobiotics

4.7 Identification of SCL14-dependent genes under inducing conditions............ 69

4.7.1 Verification of TIBA-induced SCL14 target genes ............................... 74

4.8 Overexpression of SCL14 leads to resistance against the necrotrophic fungus

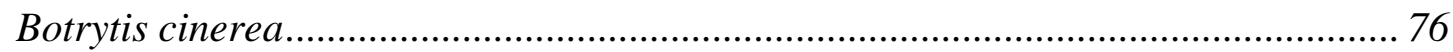

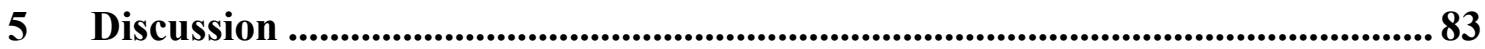

5.1 Functional role of the intracellular transport of SCL14 ............................... 83

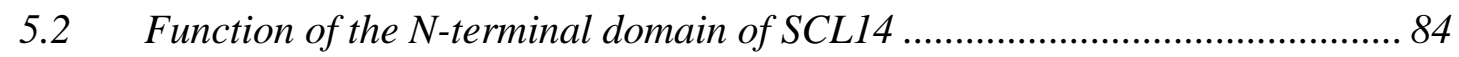

5.3 Genevestigator clustering analysis of SCL14 target genes ............................ 85

5.4 Functional role of SCL14 target genes.......................................................... 86

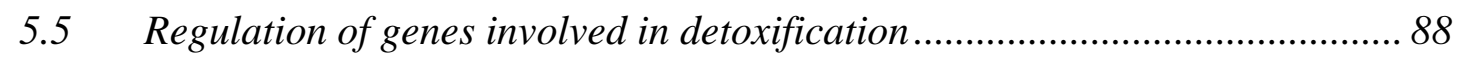

5.6 Role of SCL14 during infection with Botrytis cinerea .................................... 89

5.7 Direct regulation of target gene transcription by the TGA/ SCL14 complex at

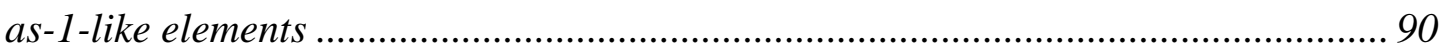

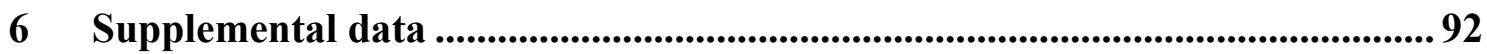

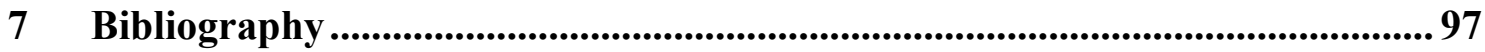




\section{Abbreviations}

2,4-D

aa

A

A

ABA

(Bc)ActinA

AD

ADE

ADH1

amp

APS

APX

as-1

AT

A. thaliana

(AT)MRP

A. tumefaciens

B. cinerea

bp

BSA

BY-2

bZIP

C

CaMV

CAT

cDNA

ChIP 2,4-dichlorophenoxyacetic acid

amino acids

Ampere

adenosine

abscisic acid

ActinA gene from B. cinerea

activation domain

marker gene for adenine prototrophy

alcohol dehydrogenase 1

ampicilin

ammoniumpersulfate

ascorbate peroxidase

activating sequence 1

marks a protein from Arabidopsis thaliana

Arabidopsis thaliana

multidrug resistance protein (from A. thaliana)

Agrobacterium tumefaciens

Botrytis cinerea

base pairs

bovine serum albumine

bright yellow-2

basic leucine zipper

cytosine

cauliflower mosaic virus

catalase

copy DNA

chromatin immunoprecipitation 


\begin{tabular}{|c|c|}
\hline CLB & crosslink buffer \\
\hline COI1 & CORONATINE INSENSITIVE 1 \\
\hline $\mathrm{C}_{\mathrm{T}}$ & threshold cycle \\
\hline C-terminal & carboxy-terminal \\
\hline CYP & cytochrome P450 \\
\hline $\mathrm{Da}$ & Dalton \\
\hline ddNTPs & didesoxy nucleotides \\
\hline Dex & dexamethasone \\
\hline DMSO & dimethylsulfoxide \\
\hline DNA & desoxyribonucleic acid \\
\hline DNase & desoxyribonuclease \\
\hline dNTP & desoxyribonucleotides \\
\hline dpi & days past infection \\
\hline $\mathrm{DOC}$ & sodium deoxycholate \\
\hline DTT & dithiotreitol \\
\hline EB & elusion buffer \\
\hline ECL (kit) & enhanced chemoluminescence (kit for western detection) \\
\hline E. coli & Escherichia coli \\
\hline EDTA & ethylenediaminetetraacetic acid \\
\hline ERF1 & ETHYLENE RESPONSE FACTOR 1 \\
\hline ET & ethylene \\
\hline et al. & et alii (and others) \\
\hline $\mathrm{EtOH}$ & ethanol \\
\hline $\mathrm{F}$ & Farad \\
\hline$g$ & gravitation \\
\hline$g$ & gram \\
\hline $\mathrm{G}$ & guanine \\
\hline GA & gibberellic acid \\
\hline$\beta-G a l$ & $\beta$-galactosidase \\
\hline GAL4-AD & activation domain of GAL4 transcription factor from yeast \\
\hline
\end{tabular}




\begin{tabular}{|c|c|}
\hline GB & gradient buffer \\
\hline GFP & green fluorescence protein \\
\hline GPX & glutathione peroxidase \\
\hline GR & glucocorticoid receptor \\
\hline GST (U) & glutathione-S-transferase ( $\tau$-class) \\
\hline GUS & glucuronidase \\
\hline $\mathrm{h}$ & hours \\
\hline HIS & marker gene for histidine prototrophy \\
\hline $\mathrm{H}_{2} \mathrm{O}_{2}$ & hydrogen peroxide \\
\hline hpi & hours past infection \\
\hline HR & hypersensitive response \\
\hline HSP & herring sperm DNA \\
\hline IAA & auxin \\
\hline INA & isonicotinic acid \\
\hline $\mathrm{JA}$ & jasmonic acid \\
\hline $\mathrm{k}$ & kilo $\left(10^{3}\right)$ \\
\hline $\mathrm{L}$ & litre \\
\hline lacZ & gene coding for $\beta$-galactosidase \\
\hline LB & left border \\
\hline LEU & marker gene for leucine prototrophy \\
\hline LOX1 & lipoxygenase 1 \\
\hline$\mu$ & micro $\left(10^{-6}\right)$ \\
\hline $\mathrm{m}$ & mili $\left(10^{-3}\right)$ \\
\hline $\mathrm{m}$ & meter \\
\hline M & molarity $[\mathrm{mol} / \mathrm{L}]$ \\
\hline Me-SA & methyl salicylate \\
\hline $\min$ & minutes \\
\hline MtN19-like & MAC9.6, Medicago truncatula N19-like \\
\hline mRNA & messenger RNA \\
\hline MS & Murahige and Skoog \\
\hline
\end{tabular}


$\mathrm{n}$

NEB

NES

NLS

NPR1

N-terminal

$\Omega$

OD

$\mathrm{o} / \mathrm{n}$

oNPG

OPDA

$\mathrm{p}$

PAA

PAGE

PCR

PCD

PDA

PDB

PDF1.2

$\mathrm{pH}$

PMSF

PR

PUFA

PVDF

RB

REN

RES

RNA

RNase

ROS nano $\left(10^{-9}\right)$

nuclei extraction buffer

nuclear export sequence

nuclear localization sequence

NON-EXPRESSOR of PR-GENES 1

amino-terminal

Ohm

optical density

over night

o-nitrophenyl- $\beta$-D-galactopyranoside

12-oxophytodienoic acid

pico $\left(10^{-12}\right)$

polyacrylamide

polyacrylamide gelelectrophoresis

polymerase chain reaction

programmed cell death

potato dextrose agar

potato dextrose broth

Plant defensin 1.2

negative $\log _{10}$ of proton concentration

phenyl-methyl-sulfonyl-fluoride

Pathogenesis related

poly unsaturated fatty acid

polyvinylidene fluoride

right border

restriction endonucleases

reactive electrophile species

ribonucleic acid

ribonuclease

reactive oxygen species 


$\begin{array}{ll}\text { rpm } & \text { rotations per minute } \\ \text { RT } & \text { room temperature } \\ \text { S } & \text { second } \\ \text { SA } & \text { salicylic acid }\end{array}$

SAR systemic acquired resistance

SB sonic buffer

S. cerevisiae Saccharomyces cerevisiae (bakers yeast)

SCL14 SCARECROW-LIKE 14

SD minimal yeast medium

SDS sodium dodecylsulfate

SOD superoxide dismutase

T thymine

TE tris-EDTA buffer

TEMED N,N,N',N'-tetraethylenediamine

TGA as-1 (TGACG motive) binding bZIP transcription factors

TIBA 2,3,5-triiodobenzoic acid

Tris tris-hydroxymethylamino methane

TRP marker gene for tryptophane prototrophy

$\mathrm{u} \quad$ unit (quantity for enzyme activity)

U uracil

UV ultra violet

V Volt

$\mathrm{v} / \mathrm{v} \quad$ volume per volume

W Watt

Wt, WT wildtype plants

w/v weight per volume

X-Gal 5-bromo-4-chloro-3-indolyl- $\beta$-D-galactopyranoside 


\section{Summary}

TGA factors are members of the leucine zipper family of transcription factors and play a role in the regulation of various stress defence genes in Arabidopsis. TGA factors bind specifically to the cis element as-1 (activating sequence-1). Previous studies have shown the inducibility of as-1-mediated transcription by salicylic acid (SA) and the synthetic auxin 2,4-D.

Tanja Siemsen has identified the GRAS protein family member Scarecrow-like 14 transcription factor (SCL14) as a TGA-interacting factor. SCL14 is able to activate transcription in yeast after complex formation with as-1-bound TGA2. In the absence of TGA2, no activation occurs, indicating that SCL14 is recruited to the promoter by its interaction with TGA2. In micro array experiments comparing wildtype and scl14 mutant plants, Tanja Siemsen identified several SCL14-dependent genes.

In this work, three genes (CYP81D11, MtN19-like and GSTU7) were verified as direct targets of SCL14 and TGA2 by ChIP experiments. SCL14 is not recruited to these promoters in the tga2,5,6 mutant. These results indicate that transcriptional regulators of the GRAS family can be recruited to specific promoters by DNA-bound transcription factors. Consistently, these genes are not expressed in the scl14 and tga2 tga5 tga6 mutants.

Micro array experiments comparing the RNA of wildtype and scl14 mutant plants under xenobiotic-induced conditions revealed additional target genes for SCL14 involved in detoxification. When associated with TGA factors, SCL14 functions as transcriptional co-activator mediating specific responses of Arabidopsis plants to electrophiles and xenobiotic stress. Consistently, xenobiotics like TIBA induce target genes of SCL14 in a TGA dependent manner and scl14 and tga2 tga5 tga6 mutant plants are more susceptible to xenobiotic substances.

In addition, overexpression of SCL14 leads to a high resistance against the necrotrophic fungal pathogen Botrytis cinerea. However, scl14 mutants showed no higher susceptibility, suggesting a minor role for SCL14 target genes in response to necrotrophic pathogens. 


\section{Introduction}

Plants have evolved a broad spectrum of defence responses in order to cope with stress conditions that might threaten their survival. Stress can be evoked either by abiotic changes in the environment like drought, high light intensities, salt, cold and heat or biotic stressors like bacteria, fungi, viruses and herbivores. In some cases the cell wall, the cuticula and the constitutive synthesis of basal levels of toxic compounds cannot provide sufficient defence. As the permanent establishment of a highly efficient defence status would require too many resources, plants have evolved inducible defence mechanisms (van Hulten et al., 2006).

\subsection{The role of plant hormones in stress responses}

Plant hormones (phytohormones) play a major role in defining the outcome and specificity of an inducible defence by activating signalling cascades to remodel gene expression. All phytohormones have distinct roles in stress adaptation but their signalling pathways can also influence each other either in a synergistic or an antagonistic manner. This crosstalk between the signalling pathways allows the plants to fine tune defence responses and thus react in a very specific way to different threatening situations. In particular, abscisic acid (ABA), ethylene (ET), jasmonic acid (JA) and salicylic acid (SA) have been shown to possess crucial functions in mediating or orchestrating responses to stress. When plants suffer from drought ABA regulates the water status of the plants by controlling stomatal closure and gene expression to adapt to low water conditions. Additionally, ABA plays a role in defence against different pathogens (Adie et al., 2007) e.g. by regulating callose deposition to prevent intrusion of necrotrophs (Ton and Mauch-Mani, 2004). The most dominant phytohormones in defence against pathogens are JA, ET and SA.

The enzymatically derived oxylipin JA is the key hormone for defence against necrotrophic pathogens and also against herbivores. The COI1 (CORONATINE INSENSITIVE 1) protein is required for all known JA dependent signalling events. The 
coi1-1 mutant is JA-insensitive and fails to activate JA dependent defence responses against herbivoral attack. Larvae of Pieris rapae perform much better on coi1-1 mutants due to the lack of JA-dependent defence (Reymond et al., 2004). The defence against necrotrophic pathogens like Alternaria brassicicola and Botrytis cinerea is also dramatically reduced in coi1-1 mutants (Stintzi et al., 2001). COI1, an F-Box protein, is integrated in the multi protein $\mathrm{SCF}^{\mathrm{COI}}$ (skip-cullin-F-box) complex which targets proteins for degradation. Proteins that are recognized by $\mathrm{SCF}^{\mathrm{COI}}$ are poly-ubiquitinated and shuttled to the $26 \mathrm{~S}$ proteasome. Most recent results show that COI1 binds the JA conjugate JA-isoleucine (JA-Ile). This interaction enables the $\mathrm{SCF}^{\mathrm{COI}}$ complex to recognize JAZ (JASMONATE ZIM-DOMAIN) family proteins (Chini et al., 2007; Thines et al., 2007; Yan et al., 2007). The JAZ proteins analyzed so far are negative regulators of the JA response and bind to activators of JA-dependent genes. Degradation of these repressors is required for the activation of JA responses (Staswick, 2008).

ET is required for defence responses against herbivores and necrotrophic pathogens as well. ET-dependent gene expression requires two central components, the transcription factor EIN3 (ETHYLENE INSENSITIVE 3) and the important regulator EIN2 (ETHYLENE INSENSITIVE 2) (Alonso et al., 1999). Both mediate integrated ET signals from a MAP-kinase (mitogen-activated protein) cascade including the Raf-like kinase CTR1 (ONSTITUTIVE TRIPLE-RESPONSE 1). CTR1 actively suppresses ET signalling in the absence of the hormone and is inactivated upon binding of ET to the CTR1/ET receptor complex (Gao et al., 2003). Subsequently, phosphorylation of EIN3 by the MAP-kinase cascade renders it insensitive to $\mathrm{SCF}^{\mathrm{EBF}}$ mediated proteasomal degradation, thus, allowing EIN3 to activate transcription. In addition, EIN2 is thought to influence the stability of EIN3 by interfering with the action of EBFs (Ethylenedependent F-Box proteins).

In Arabidopsis, synergistic crosstalk between the JA and ET signalling pathway regulates expression of defence genes like osmotins or the plant defensin PDF1.2. These genes code for proteins which are key players in defence against necrotrophic pathogens (Thomma et al., 1998) and have direct anti-microbial properties (Verburg and Huynh, 1991; Capelli et al., 1997). Defensins directly attack certain lipid stretches (sphingolipids) on the surface of fungal cells causing membrane permeabilization (Aerts et al., 2007). A key regulator in the JA/ET crosstalk is the transcription factor ERF1 
(ETHYLENE RESPONSE FACTOR1). Full expression of ERF1, which is of importance in resistance against necrotrophic fungal pathogens like Botrytis cinerea requires JA and ET activity. Overexpression of ERF1 can rescue resistance both in the ein2-1 (ethylene insensitive2) and the JA signalling mutant coi1-1 (Lorenzo et al., 2003) indicating that it acts downstream of these central regulators.

Beside JA and ET, other pathways like the SA-dependent gene expression (e.g. PR-1) are also active during necrotrophic pathogen attack pointing at a crosstalk between the SA and the JA/ET signalling pathways. During infection with Botrytis cinerea, systemic acquired resistance (SAR) is proposed to be important for restriction of fungal spread (Zimmerli et al., 2001). In addition, the production of the phytoalexin camalexin is absolutely required for resistance (Ferrari et al., 2007) and one of the camalexin synthesis genes PAD3 (PHYTOALLEXIN DEFICIENT 3) is activated by oligogalacturonides (OGs) independently of SA, JA and ET. Those OGs are released from plant cell walls by fungal polygalacturonases during attack contributing to basal defence of the plant.

$\mathrm{SA}$ is the key hormone for defence responses against biotrophic pathogens. Biotrophic pathogens, in contrast to necrotrophs, require living host cells to gain nutrients and water. Plants have developed defence programs to limit the spread of the pathogen. After recognition of a pathogen, plants mount a hypersensitive response (HR), including accumulation of reactive oxygen species (ROS, oxidative burst), an increase of salicylic acid (SA) and programmed cell death (PCD) of the infected cells (Lam et al., 2001). In addition, defence genes like PR-1 (Pathogenesis Related-1) or the glutathione-Stransferase GSTF8 are expressed. This local response can be followed by the establishment of a systemically heightened level of defence against secondary infections, called systemic acquired resistance (SAR). The SAR is efficient against a broad spectrum of pathogens. For tobacco it has been shown that systemic movement of methyl salicylate from the infected tissue is required to establish an SAR (Park et al., 2007). Methyl salicylate is converted into SA in the systemic leaves and subsequently induces expression of the defence-related genes including $P R-1$. One key regulator of SA-dependent defence including SAR is NPR1 (NON EXPRESSOR OF $\underline{P R}$-GENES 1) which is translocated into the nucleus upon pathogen recognition (Mou et al., 2003). Mutants lacking NPR1 (npr1-1) are impaired in SAR. npr1-1 mutants fail to activate PR 
gene expression in the local and the systemic leaves (Dong, 2004). Lacking a DNA binding domain NPR1 was proposed to regulate $P R$ gene expression as a cofactor of DNA-binding transcription factors. Interaction between NPR1 and TGA transcription factors could be demonstrated in yeast and in planta (Subramaniam et al., 2001). Consistently, several of the stress related genes contain a TGA factor binding motif in their promoter. This regulatory element is called activating sequence-1 (as-1).

\subsection{The regulatory promoter element activating sequence 1}

The regulatory element as-1 was originally described as a functional cis element in the Cauliflower Mosaic Virus (CaMV) 35S promoter (Benfey and Chua, 1990). The consensus as-1-like element typically contains two copies of the TGAC/GTCA palindrome spaced by 12 bps (Qin et al., 1994). However, the stringency of the binding requirement is quite low and two sequences with only low homology can serve as a functional as-1-like sequences if the spacing between the palindromic centres is $12 \mathrm{bp}$ (Krawczyk et al., 2002). Regulatory sequences related to the as-1 element are found in a number of stress-responsive plant promoters including the pathogen-inducible $P R-1$ gene promoter (Lebel et al., 1998). Induction of this promoter by pathogens requires SA as well as one of the redundant as-1-binding proteins TGA2, TGA5 or TGA6 (Zhang et al., 2003) and the TGA-interacting ankyrin repeat protein NPR1 (Cao et al., 1997; Ryals et al., 1997). Other SA-inducible genes that contain a functional as-1-like element (Chen and Singh, 1999) are expressed in an NPR1-independent manner (Uquillas et al., 2004b; Blanco et al., 2005). Many of these genes encode glutathione S-transferases (GSTs). In contrast to PR-1, most of the GST genes are not only activated by SA, but also by the auxin analogue 2,4-dichlorophenoxyacetic acid (2,4-D) (Wagner et al., 2002). Likewise, synthetic promoters or promoter deletions that contain either one or multiple as-1 elements as the only regulatory upstream sequences are 2,4-D- and SAinducible (Redman et al., 2002) in the absence of NPR1 (Butterbrodt et al., 2006). 


\subsection{The role of TGA transcription factors in defence signalling}

The TGA transcription factor family comprises ten members in A. thaliana (Jakoby et al., 2002). They are named after their ability to bind TGACG motifs (as-1-like elements) (Johnson et al., 2001; Rochon et al., 2006). TGA factors are basic leucine zipper transcription factors clustering into six subclasses based on their sequence homology. TGA1 and TGA4 belong to class I, TGA2, TGA5 and TGA6 to class II, TGA3 and AtbZIP50 to class III, PERIANTHIA to class IV, AtbZIP21 to class V and AtbZIP65 to class VI.

TGA factors are involved in several signalling pathways including the NPR1-dependent SA signal transduction. The ability to interact with NPR1 has been demonstrated for the members of the first three classes of TGA factors (Xiang et al., 1997; Kesarwani et al., 2007). TGA1 and TGA4 only interact with NPR1 after SA stimulus, whereas the others can interact with NPR1 under non-inducing conditions. It was shown that reduction of cysteine residues in TGA1 and TGA4 is required to allow interaction with NPR1 (Despres et al., 2003). Mutants lacking all class II TGA transcription factors (tga2 tga5 tga6 mutants or tga2,5,6 mutants) are compromised in establishment of SAR after pathogen attack showing the importance of the TGA factors for SA-dependent defence signalling (Zhang et al., 2003). Moreover, TGA factors can act as both negative and positive regulators of gene expression (Kesarwani et al., 2007).

TGA factors are also necessary for the SA-mediated inhibition of the JA/ET pathway influencing the repression of JA/ET induction of the defensin PDF1.2 by SA (Ndamukong et al., 2007).

As unphysiological high concentrations of 2,4-D are required for TGA/as-1 mediated activation of transcription in tobacco (Pascuzzi et al., 1998), TGA factors are believed to participate in stress response to so called xenobiotics. Consistent with this idea, GSTs are involved in the detoxification of harmful substances and radicals (Hayes and McLellan, 1999) and several of the GSTs contain TGA binding motifs in their promoters. 


\subsection{Detoxification of xenobiotic compounds}

Xenobiotics ("life-foreign substances") are compounds which do not occur naturally in the respective organisms or at least occur in much lower concentrations. Chemical arms race between plants and pathogens or competing plants might have led to the establishment of efficient detoxification mechanisms in the plants. These detoxification processes are induced after recognition of xenobiotic substances and include alteration of gene expression. The influence of xenobiotic substances on gene expression was first described in animals (Prestera et al., 1993a). In plants, regulation of gene expression by xenobiotics occurs at least partly independent of possible hormone functions as xenobiotic-mediated induction of the $P R-4$ gene $(H E L)$ is insensitive to interruptions in ET, JA and SA hormone signalling pathways (Almeras et al., 2003). Likewise, 2,4-D promotes responses at least partially distinct from the auxin signalling pathway although 2,4-D is a functional analogue of IAA (Rahman et al., 2006). Actually, several xenobiotics exhibit electrophilic properties, suggesting that they activate electrophiledependent signalling pathways leading to their detoxification.

Reactive electrophile species (RES) are formed in the cells under oxidative stress conditions. Oxidation caused by reactive oxygen species (ROS) can lead to formation of such RES. ROS like superoxide $\left(\mathrm{O}_{2}{ }^{-}\right)$, hydrogen peroxide $\left(\mathrm{H}_{2} \mathrm{O}_{2}\right)$ and hydroxyl radicals are formed under biotic (oxidative burst during hypersensitive response) and abiotic stress conditions (Alvarez et al., 1998). They accumulate during pathogen attack due to the repression of ROS-scavenging enzyme activity by SA or nitric oxide (NO) (Klessig et al., 2000). The rising concentrations of hydrogen peroxide lead to activation of defence responses including programmed cell death (PCD) to restrict the spread of invading biotrophic pathogens. Thus, ROS act as secondary messengers for the plant during stress conditions leading to changes in gene expression but they also cause severe damage to cell compounds by denaturing proteins and oxidizing lipids. Because of this dual function (Bailey-Serres and Mittler, 2006) ROS scavenging is highly controlled by the cell. Nevertheless, interaction of ROS with proteins, nucleic acids and lipids cannot be totally avoided. In this case spreading damage of the respective cellular compounds must be restricted otherwise it leads to formation of further ROS and 
harmful compounds with oxidative potential like RES (Montillet et al., 2005; Grun et al., 2007). Stress-induced oxylipins for example can exhibit reactive electrophile properties. Characteristically for many plant-pathogen interactions is the production of such oxylipins and other lipid-derived compounds in the plants (Howe and Schilmiller, 2002). Lipid peroxidation either enzymatically or non-enzymatically leads to the generation of these compounds in stressed or diseased plants (Imbusch and Mueller, 2000). Many of these lipid-derived products contain a carbonyl group in their molecular context (e.g. hexanal) contributing to an electrophilic character. In case of a subgroup of compounds containing an $\alpha / \beta$-unsaturated carbonyl group the electrophilic properties are even increased. Several studies could show the ability of these highly reactive substances to alter gene expression in animals (Prestera et al., 1993b). In plants electrophiles mainly induce the expression of genes related to stress and detoxification like glutathione-Stransferases. Studies demonstrated the activation of the GSTF6 gene by electrophiles like malonaldehyde (Vollenweider et al., 2000). The primary function of GSTs is the detoxification of RES by catalysing the conjugation of glutathione to the electrophilic core of such lipophilic compounds.

Additionally, the precursor of JA, 12-oxo-phytodienoic acid (OPDA) is an enzymatically derived electrophilic oxylipin. Endogenous OPDA plays a role in plantinsect interaction and resistance to fungal pathogens (Stintzi et al., 2001). Additionally, gene expression induced by exogenously applied OPDA differs from JA-induced gene expression as most OPDA induced genes are COI1 independent. The differences in electrophilic properties between JA and OPDA contribute to this different induction pattern (Mueller et al., 2008). The OPDA-induced genes are predominantly coding for proteins involved in detoxification processes (Cytochrome P450s and glutathione-Stransferases). Likewise, some classes of plant isoprostanes (phytoprostanes) also alter gene expression with respect to their electrophilic potential. These phytoprostanes are derived from peroxidation of polyunsaturated fatty acids (PUFAs) (Sattler et al., 2006). During oxidation of PUFAs several lipid derived radicals are formed (lipid peroxyl radicals) which propagate their own formation by attacking neighbouring PUFAs. This chain reaction leads to the accumulation of lipid radicals, which spontaneously form phytoprostanes. Scavenging of those reactive radicals involves the reduction of lipid peroxyls by tocopherol (vitamine E). Thus, RES can activate or modulate plant defence 
responses but are also harmful as oxidative stressors (Almeras et al., 2003). To reduce this oxidative stress, plants mainly activate detoxification pathways (induction of glutathione-S-transferases) after recognition of RES.

As many RES and xenobiotic induced glutathione-S-transferase genes contain as-1 regulatory elements in their promoter regions, a role for as-1 binding TGA transcription factors was assumed. In addition, gene expression induced by electrophilic phytoprostanes includes a variety of GSTs and this induction largely depended on TGA2, TGA5 and TGA6 (Mueller et al., 2008). However, most of the GSTs are activated independently of the known TGA-interacting protein NPR1 (Uquillas et al., 2004a) suggesting an alternative TGA-dependent pathway for regulation of RES/ xenobiotic-detoxification associated genes.

\subsection{The GRAS protein SCL14 interacts with TGA transcription factors}

As compared to the NPR1-dependent pathway, the NPR1-independent activation of as1-containing promoters is far less explored. Assuming that TGA2 interacts with a different regulatory protein for activation of NPR1-independent pathways, a yeast protein interaction screen was performed by Tanja Siemsen using Arabidopsis TGA2 as bait.

The yeast two hybrid (YTH) screen has successfully been applied to isolate protein interaction partners (Fields and Song, 1989). However, fusion of the bait protein with a heterologous DNA binding domain or fusion of the prey protein with an activation domain might hamper certain interactions. In the screen done by Tanja Siemsen (2002), this potential drawback was circumvented by cloning three copies of the as- 1 element (3x as-1) upstream of the HIS3 selectable marker gene (Weigel et al., 2005) and expressing TGA2 in trans. As as-1-bound TGA2 proteins do not activate transcription in yeast, growth on selective medium is compromised. A cDNA expression library (Minet et al., 1992) was transformed into this strain and screening for prototrophic growth was performed. Five clones out of $1 \times 10^{6}$ yeast transformants were identified on selective media. One of the clones encoded an open reading frame of 769 amino acids 
and was identical to the GRAS protein SCL14 (At1g07530, AtGRAS-2) (Bolle, 2004; Tian et al., 2004).

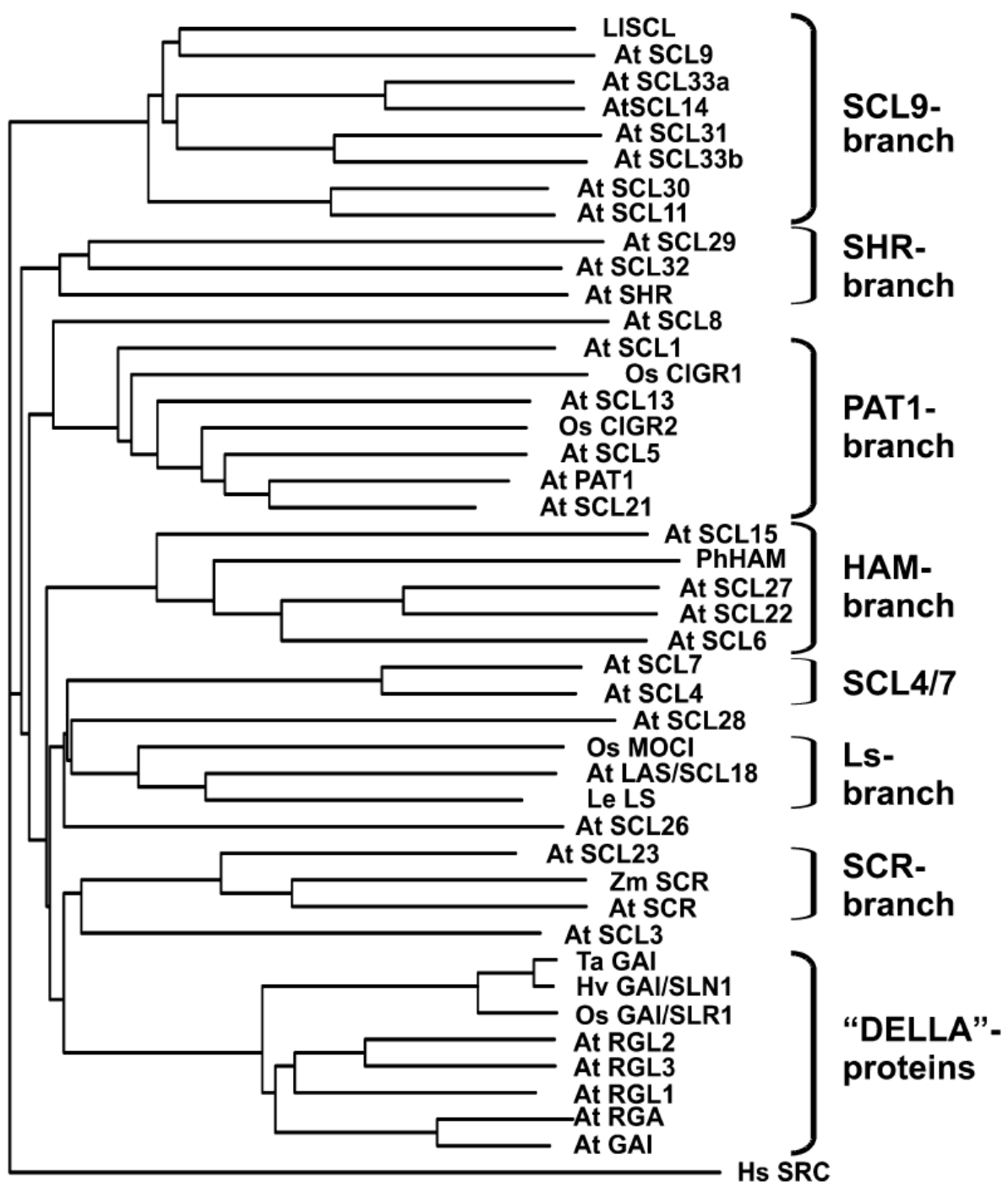

Figure 2-1 Phylogenetic tree of the GRAS protein family (Bolle, 2004)

The family of GRAS proteins is divided into 9 sub-classes including the DELLA proteins involved in GA signalling. SCL14 belongs to the "SCL9" branch and shows relatively high homology to LISCL from Lily.

Based on sequence analysis, SCL14 belongs to the plant-specific GRAS protein family that comprises 33 members in Arabidopsis (Bolle, 2004). GRAS proteins have been shown to be involved in gibberellic acid (GA) and phytochrome signalling, root and axillary shoot development, and maintenance of the shoot apical meristem. 
The acronym GRAS was coined after identification of the founding members GAI

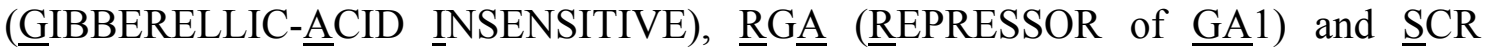
( SCARECROW) (Pysh et al., 1999). GAI and RGA have important roles in gibberellic acid dependent signal transduction processes (Silverstone et al., 1998), whereas SCR was isolated in a screen for mutations that affect root development. GAI, RGA, SCR and SCL (SCARECRROW-LIKE) proteins contain several conserved amino acid signatures in the so called GRAS domain at the $\mathrm{C}$ terminus. In contrast, the amino acid sequence of the N-terminal domain is more variable (Di Laurenzio et al., 1996).

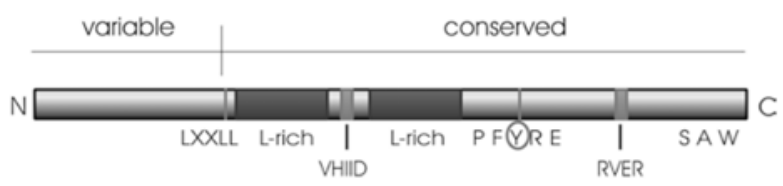

Figure 2-2 Domain structure of the GRAS proteins (Bolle, 2004)

GRAS proteins have a conserved C-terminal region with characteristic amino acid sequence stretches and two leucine rich repeat regions probably involved in protein-protein interaction. The N-terminal region is quite variable among the GRAS proteins probably contributing to their different functions.

Like all the other members of the family, SCL14 contains a unique $\mathrm{N}$ terminus and a conserved C-terminal GRAS domain. The roughly 380 amino acid long GRAS domain is characterized by two leucine-rich regions (LHRI and LHRII) and three separate conserved amino acid signatures: VHIID, PFYRE, and SAW (Pysh et al., 1999). Only two studies have addressed its function. The VHIID domain of a GRAS protein from Brassica napus interacts with a histone deacetylase supporting the notion that GRAS proteins function in regulating gene expression at the level of transcription (Gao et al., 2004). The GRAS domain of the regulator of GA signalling GAI contributes to the interaction with the F-box protein SLEEPY1 (Dill et al., 2004), which is of major importance for the control of protein abundance as a function of GA. Though direct DNA binding to a specific target sequence has never been reported, GRAS proteins are classified as transcriptional regulators (Riechmann et al., 2000; Zentella et al., 2007).

The yeast data suggested an activating function for SCL14 as histidine prototrophy was restored only in the presence of TGA2, indicating that SCL14-mediated activation of the $3 x$ as-1:HIS3 construct requires TGA2. These data were confirmed in a yeast strain 
harbouring three copies of the as- 1 element upstream of the $\beta$-galactosidase (lacZ) gene (Siemsen, 2005).

To obtain independent evidence for the formation of a TGA2/SCL14 complex, an in vitro pull-down assay with recombinant proteins was performed by Ulrike Süthoff (2006). Crude E. coli extracts containing either SCL14 fused to a glutathione Stransferase (GST-SCL14) or His-tagged TGA2 (His 6 -TGA2) were combined and loaded onto glutathione-sepharose affinity beads. After washing and subsequent elution under denaturing conditions, eluates were analyzed for the presence of $\mathrm{His}_{6}{ }^{-T G A 2}$. Though GST-SCL14 was subject to protein degradation in E. coli and during subsequent processing steps, sufficient amounts of the protein were bound to the glutathione matrix to retain $\mathrm{His}_{6}$-TGA2. In contrast, equivalent amounts of unfused GST protein were unable to interact with $\mathrm{His}_{6}$-TGA2. This experiment supports the initial yeast data that implicate an interaction between SCL14 and TGA2.

To analyze the in vivo effect of SCL14 on as-1-mediated gene expression, the SCL14 cDNA was cloned into a binary vector designed to express $\mathrm{HA}_{3}$-tagged proteins under the control of the Cauliflower Mosaic Virus (CaMV) 35S promoter (pAlligator2-SCL14). Arabidopsis plants encoding the ß-glucuronidase gene (GUS) downstream of the "truncated" Cauliflower Mosaic Virus (CaMV) 35S promoter (as-1:GUS) (Redman et al., 2002) were used for transformation. Transcription from this promoter fragment $(+1$ to -90 ), which contains as- 1 as the only regulatory sequence, can be induced by SA and 2,4-D. Out of 48 primary transformants, only two plants showed expression of $\mathrm{HA}_{3}$ SCL14 as revealed by Western blot analysis of crude extracts performed with an aSCL14 antiserum (Siemsen, 2005; line \#5 was used in this work). Expression of 35S:SCL14 led to an increased basal expression of the GUS gene and an increased induction after treatment with SA or 2,4-D.

The Arabidopsis mutant SALK_126931, carries a T-DNA insertion in the 5'UTR of SCL14. Homozygous mutant plants showed no detectable SCL14 mRNA and SCL14 protein levels (Figure 2-3) as revealed by Northern and Western blot analysis, respectively. Those plants were crossed with wildtype plants carrying the as-1:GUS construct and lines homozygous for the mutated SCL14 gene were selected. In these transgenic mutants transcript of the GUS reporter gene was no longer inducible by 2,4D or SA (Siemsen, 2005; line \#14 was used in this work as scl14 mutant). However, 
transcript levels of the NPR1-dependent PR-1 gene and the NPR1-independent GSTF8 gene showed no difference to those found in wildtype plants after SA treatment and 2,4D-induced expression of GSTF8 was also not affected. The $H A_{3}-S C L 14$ line also responded like wildtype with respect to these genes, implicating that $P R-1$ and GSTF8 are not subject to SCL14-dependent regulation.

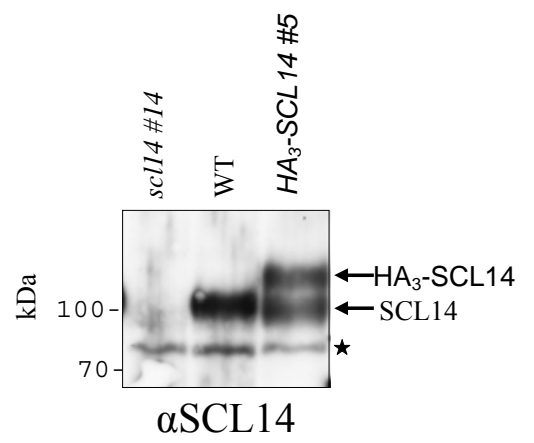

Figure 2-3 Western blot analysis of SCL14 protein in different genotypes

Five-wee-old wildtype plants (WT; encoding the wildtype SCL14 allele and the as-1:GUS transgene), plants transformed with the CaMV 35S:HA - SCL14 construct and scl14 mutant plants were compared regarding their SCL14 protein levels. The $\alpha$ SCL14 antiserum was used in a 1:1000 dilution. The asterisk marks an unspecific band.

Additionally, SCL14 transcription was found to be induced under abiotic stress conditions like ozone treatment or dark-induced senescence suggesting a role for SCL14 during oxidative stress. In addition, micro array analysis revealed a subset of endogenous genes, which requires SCL14 protein for full expression (Siemsen, 2005). Many of the identified genes (e.g. CYP81D11 and GSTU7) are putatively involved in detoxification processes. Thus, SCL14 is a good candidate as a co-regulator of TGAdependent gene expression mediating detoxification of electrophilic/ xenobiotic compounds.

\subsection{Aim of the study}

This study is based on results of the $\mathrm{PhD}$ thesis of Tanja Siemsen, who identified SCL14 as a TGA-interacting protein. Moreover, she identified putative SCL14 target genes by comparing the transcriptome of wildtype plants with that of scl14 mutants and 
transgenic plants ectopically expressing SCL14. Cluster analysis revealed induction of these genes under conditions of oxidative/ xenobiotic stress.

The aim of this study was to verify whether these candidate genes were induced in an SCL14- and TGA-dependent manner under different stress conditions. Moreover, chromatin immunoprecipitation experiments should answer the question, whether the TGA/ SCL14 complex is formed in vivo on promoters that contain an as-1 element. In addition, the biological function of SCL14 should be elucidated by applying different forms of biotic and abiotic stress and subsequent monitoring of growth of different plant genotypes. As the previous transcriptome profiling experiment had been performed under non-inducing conditions, a second profiling experiment should be done to identify more SCL14-dependent genes likely to play a role in response to the stress applied. 


\section{$3 \quad$ Materials and Methods}

\subsection{Materials}

\subsubsection{Devices}

\begin{tabular}{l|l|l}
\hline Device & Model & Source \\
\hline Autoclave & 3870 ELV & Tuttnauer \\
\hline Automatic pipettes & & Gilson \\
\hline Blotting device & & University of Göttingen \\
\hline $\begin{array}{l}\text { Chambers for gel } \\
\text { electrophoreses }\end{array}$ & & University of Göttingen \\
\hline Cooling centrifuge & Sorvall RC 5B Plus & DuPont \\
\hline $\begin{array}{l}\text { Cooling micro centrifuge } \\
\text { with overhung rotor }\end{array}$ & & Hettich \\
\hline Counting chamber & Fuchs-Rosenthal & \\
\hline Counting chamber, spores & Thomma & Brand \\
\hline Electroporator & Gene Pulser ${ }^{\circledR}$ II & \\
\hline Fluorescence microscope & & BioRad \\
\hline Fluorometer & CytoFluorII Plate Reader & PerSeptive \\
\hline Gel documentation device & & MWG Biotech \\
\hline Heat block & & Boekel Scientific \\
\hline Heated stirrer & RCT basic & IKA Labortechnik \\
\hline Heated shaker & Thermomixer 5436 & Eppendorf \\
\hline Locker for incubations & & WTC binder; Memmert \\
\hline Micro centrifuge & Biofuge pico & Heraeus Christ \\
\hline Micro centrifuge, cooled & 5403 & Eppendorf \\
\hline PCR cycler & MiniCyclerTM PTC-150 & MJ Research \\
\hline pH-Meter & HI 9321 & Hanna Instruments \\
\hline Photometer & Unikon 720 LC & Kontron \\
\hline $\begin{array}{l}\text { Photometer for microtiter } \\
\text { plates }\end{array}$ & MRX Dynex Plate Reader & Dynex \\
\hline Realtime PCR cycler & iCycler & \\
\hline RNA-/DNA-Calculator & GeneQuant II & BioRad \\
\hline Rotation platform & IntelliMixer & \\
\hline Scanner & ScanJet 4c & Hewlett Packard \\
\hline Scanner for array slides & G2505B & Agilent Technologies \\
\hline Sequencer & ABI PRISM 3100 & Perkin-Elmer \\
\hline Sonication device & Soniprep 150 & Nunc \\
\hline Sterile bench & Microflow Laminar & \\
\hline & & \\
\hline
\end{tabular}




\begin{tabular}{l|l|l}
\hline Device & Model & Source \\
\hline Sterile bench & Microflow Biohazard & Nunc \\
\hline UV transilluminator & FLX-20 M & Vilber Lourmat \\
\hline Water deionization device & Option 4, Maxima & ELGA \\
\hline Vacuum pump & Cyclo 1 & Roth \\
\hline Vortex & L46 & Labinco BV, Niederlande \\
\hline
\end{tabular}

\subsubsection{Materials}

\begin{tabular}{l|l}
\hline Product & Source \\
\hline Electroporation cuvettes & BioRad \\
\hline Filter paper Miracloth & Calbiochem \\
\hline Flow paper 3MM & Whatman \\
\hline Microtiter plates & Roth \\
\hline Para-film M & American National Can ${ }^{\mathrm{TM}}$ \\
\hline Plastics one-way material & $\begin{array}{l}\text { Biozym; Eppendorf; Greiner; Roth; } \\
\text { Sarstedt }\end{array}$ \\
\hline PVDF membrane Immobilon ${ }^{\mathrm{TM}}-\mathrm{P}$ & Millipore \\
\hline X-ray films Cronex 4, Cronex 10T & Agfa, Belgium \\
\hline
\end{tabular}

\subsubsection{Chemicals}

\begin{tabular}{l|l}
\hline Chemical & Source \\
\hline $\begin{array}{l}30 \%(w / v) \text { Acrylamide: } \mathrm{N}, N^{\prime}- \\
\text { Methylenebisacrylamide }(37,5: 1)\end{array}$ & Roth \\
\hline Agarose SeaKem LE & Biozym \\
\hline Ampicillin & AGS \\
\hline APS (Ammonium persulfate) & Biometra \\
\hline Bradford-Reagent & Roth \\
\hline Bromophenol blue & Roth \\
\hline BSA & Serva \\
\hline Coomassie Brilliant Blue G-250 & BioRad \\
\hline 2,4-Dichlorophenoxyacetic acid (2,4-D) & Sigma \\
\hline Diethylpyrocarbonat (DEPC) & Roth \\
\hline N,N-Dimethyl formamide (DMF) & J.T. Baker Chemicals B.V. \\
\hline Dimethyl sulfoxide (DMSO) & Sigma \\
\hline Dithiothreitol (DTT) & Sigma \\
\hline dNTPs & MBI; Roth \\
\hline Ethylene diaminetetraacetate (EDTA) & AppliChem \\
\hline Ethidiumbromide & Roth \\
\hline Gentamycine & Duchefa \\
\hline PIPES & Roth \\
\hline Hydrogen peroxide & Roth \\
\hline
\end{tabular}




\begin{tabular}{l|l}
\hline Chemical & Source \\
\hline Herring sperm DNA (HSP) & Sigma \\
\hline Isonicotinic acid (INA) & ABCR \\
\hline Isopropylthiogalactosid (IPTG) & Bio Tech Trade \\
\hline Kanamycine & Sigma \\
\hline Leptomycine B & LC Laboratories ${ }^{\circledR}$ \\
\hline Powdered milk & Glücksklee \\
\hline B-Mercaptoethanol & Roth \\
\hline Murashige and Skoog medium & Duchefa \\
\hline Orange G & Sigma \\
\hline Percoll & Sigma-Aldritch \\
\hline Phenol & Sigma \\
\hline Phenylmethane sulfonylchloride (PMSF) & Fluka \\
\hline Ponceau S & Sigma \\
\hline Rifampicine & Duchefa \\
\hline X-ray developer LX24 & Kodak \\
\hline X-ray fixer AL4 & Kodak \\
\hline Salicylic acid (SA) & Merck \\
\hline Select Agar & Life Technologies \\
\hline Select Yeast Extract & GIBCO BRL \\
\hline TEMED & Roth \\
\hline 2,3,5-triiodobenzoic acid (TIBA) & Sigma \\
\hline Triton X-100 & Roth \\
\hline Trypton & Oxoid \\
\hline Tween20 & Roth \\
\hline X-Gal & Bio Tech Trade \\
\hline X-Gluc & Roth \\
\hline Xylene cyanol FF & Roth \\
\hline Yeast Nitrogen Base w/o amino acids & Difco \\
\hline & \\
\hline & \\
\hline
\end{tabular}

\subsubsection{Kits}

\begin{tabular}{|c|c|}
\hline Kit & Source \\
\hline BCA Protein Assay Kit & Thermo Scientific \\
\hline $\begin{array}{l}\text { BigDye }{ }^{\mathrm{TM}} \text { Terminator Cycle Sequencing } \\
\text { Ready Reaction Kit v.3.1 }\end{array}$ & Perkin-Elmer Corporation \\
\hline $\begin{array}{l}\text { Enhanced Chemiluminescence Plus }{ }^{\mathrm{T}} \text { Kit } \\
(\mathrm{ECL}+)\end{array}$ & GE Healthcare \\
\hline HiDi-Mix & ABI PRISM $^{\mathrm{TM}}$ \\
\hline Invisorb $^{\circledR}$ Spin Plant RNA Mini Kit & Invitek \\
\hline
\end{tabular}




\begin{tabular}{l|l}
\hline Megaprime ${ }^{\mathrm{TM}}$ DNA Labelling Systems & Amersham Life Science \\
\hline Nucleo Spin ${ }^{\circledR}$ Extract II & Macherey-Nagel \\
\hline Nucleo Spin ${ }^{\circledR}$ Plasmid & Macherey-Nagel \\
\hline $\begin{array}{l}\text { Qiagen Plasmid Preparation Kits (Midi, } \\
\text { Maxi) }\end{array}$ & Qiagen \\
\hline QIAprep Spin Miniprep Kit & Qiagen \\
\hline QIAquick Gel Extraction Kit & Qiagen \\
\hline QIAquick PCR Purification Kit & Qiagen \\
\hline
\end{tabular}

\subsubsection{Enzymes}

\begin{tabular}{l|l}
\hline Enzyme & Source \\
\hline Biotaq DNA polymerase & Bioline \\
\hline Cellulase "Onozuka R-10" & Serva \\
\hline Immolase DNA polymerase & Bioline \\
\hline iProof high fidelity DNA polymerase & BioRad \\
\hline Klenow DNA polymerase exo- & MBI Fermentas \\
\hline Lyticase & Sigma \\
\hline Macerozyme R-10 & Serva \\
\hline Reverse transcriptase H- & MBI Fermentas \\
\hline Restriction enzymes & MBI Fermentas, New England Biolabs \\
\hline RNase A (DNase-free) & Qiagen \\
\hline RNase inhibitor & MBI Fermentas \\
\hline T4 DNA-Ligase & MBI Fermentas \\
\hline
\end{tabular}

\subsubsection{Standards}

\begin{tabular}{l|l}
\hline Standard & Source \\
\hline GeneRuler DNA Ladder Mix & MBI Fermentas \\
\hline Prestained Protein Ladder & MBI Fermentas \\
\hline
\end{tabular}




\subsubsection{Antibodies}

\begin{tabular}{l|l|l|l}
\hline Antibody & Specificity & Properties & Reference \\
\hline$\alpha$ HA-tag & $\begin{array}{l}\text { polyclonal from } \\
\text { rabbit (1:1000) }\end{array}$ & $\begin{array}{l}\text { Santa Cruz } \\
\text { Biotechnology }\end{array}$ \\
\hline$\alpha-$ rabbit Ig & $\begin{array}{l}\text { Rabbit- } \\
\text { Immunoglobulin }\end{array}$ & $\begin{array}{l}\text { polyclonal from } \\
\text { donkey, coupled to } \\
\text { peroxidase (1:25000) }\end{array}$ & Amersham \\
\hline $\begin{array}{l}\text { aSCL14 (serum) } \\
\text { (SA 2495) }\end{array}$ & SCL14 full length & $\begin{array}{l}\text { polyclonal from } \\
\text { rabbit (final bleeding) } \\
(1: 1000)\end{array}$ & $\begin{array}{l}\text { Tanja Siemsen, } \\
\text { 2005 }\end{array}$ \\
\hline $\begin{array}{l}\text { aTGA2/5 (serum) } \\
\text { (SA 4364) }\end{array}$ & $\begin{array}{l}\text { TGA2 and TGA5 } \\
\text { C-terminal region } \\
\text { including the zipper } \\
\text { domain }\end{array}$ & $\begin{array}{l}\text { polyclonal from } \\
\text { rabbit (final bleeding) } \\
(1: 1000)\end{array}$ & This work \\
\hline
\end{tabular}

\subsubsection{Nucleic acids}

\subsubsection{Primers}

Primers were synthesized by Operon or Invitrogen as indicated in the last line. QuantiTect Primer Assays from Qiagen contain both, forward and reverse primer. They are indicated as "QPA" and are described on:

http://www1.qiagen.com/Products/Pcr/QuantiTect/PrimerAssays.aspx

False QuantiTect primers (FQ) are designed on basis of sequence analysis of a cloned PCR fragment after amplification with the original primer assays. These primers were diluted and mixed to $4 \mu \mathrm{M}$ stock solution containing forward and reverse primer.

\begin{tabular}{l|l|l}
\hline Primer & Sequence $\mathbf{5}^{\prime} \rightarrow \mathbf{3}^{\prime}$ & Source/ Application \\
\hline Actin8 forward & $\begin{array}{l}\text { GGT TTT CCC CAG TGT TGT } \\
\text { TG }\end{array}$ & Operon/ ChIP \\
\hline Actin 8 reverse & $\begin{array}{l}\text { CTC CAT GTC ATC CCA GTT } \\
\text { GC }\end{array}$ & Operon/ ChIP \\
\hline AlKeprsen & $\begin{array}{l}\text { AGT TCT GTC TTC TGT GAT } \\
\text { ACG TG }\end{array}$ & Operon/ ChIP \\
\hline AlKeprant & $\begin{array}{l}\text { ACT AGC TAT TAA AGG GTG } \\
\text { AGA AG }\end{array}$ & Operon/ ChIP \\
\hline At_At1g07530_1_SG & SCL14 & QPA \\
\hline At_ATGSTU7_1_SG & GSTU7/ GST25 & QPA \\
\hline At_At5g61820_2_SG & MAC9.6/MtN19-like & QPA \\
\hline At_At3g28740_1_SG & CYP81D11 & QPA \\
\hline At_At1g77450_1_SG & NAC32 & QPA \\
\hline At_ADH1_1_SG & ADH1 & QPA \\
\hline At_ATMRP2_1_SG & ATMRP2 & \\
\hline
\end{tabular}




\begin{tabular}{|c|c|c|}
\hline At_LOX1_1_SG & $L O X 1$ & QPA \\
\hline At_ATGSTU1_1_SG & GSTU1 & QPA \\
\hline At_PR1_1_SG & $P R-1$ & QPA \\
\hline At_LCR70/PDF2.1_1_SG & PDF1.2 & QPA \\
\hline BcActAfwd & $\begin{array}{l}\text { CTT CGT GTA GCA CCA GAG } \\
\text { GA }\end{array}$ & $\begin{array}{l}\text { Operon/ qRT PCR, } \\
\text { (Gronover et al., } \\
\text { 2001) }\end{array}$ \\
\hline BcActArevalt & TCA ACA CGA GCA ATG GCG & Operon/ qRT PCR \\
\hline Cyp81sen & $\begin{array}{l}\text { AAA GTA GGT TTG TTG GTT } \\
\text { TCA AG }\end{array}$ & Operon/ ChIP \\
\hline Cyp81ant & $\begin{array}{l}\text { CTG ATT TTA TAG TGC ATT } \\
\text { TGG AAG }\end{array}$ & Operon/ ChIP \\
\hline FQCypfwd & $\begin{array}{l}\text { TTA TGA TAC TTG CCG GGA } \\
\text { CTG }\end{array}$ & $\begin{array}{l}\text { FQ (false QPA), } \\
\text { Operon }\end{array}$ \\
\hline FQCyprev & TCG ATT TCG GTC TTT GCC & $\begin{array}{l}\text { FQ (false QPA), } \\
\text { Operon }\end{array}$ \\
\hline FQGst25sen & $\begin{array}{l}\text { GAA GAC CGG AAA AGA GAG } \\
\text { AG }\end{array}$ & $\begin{array}{l}\text { FQ (false QPA), } \\
\text { Operon }\end{array}$ \\
\hline FQGst25ant & CAA AGT CGC CAC AAT ATC C & $\begin{array}{l}\text { FQ (false QPA), } \\
\text { Operon }\end{array}$ \\
\hline FQMtn19sen & $\begin{array}{l}\text { CGA TTC GTT CTC ACG AGA } \\
\text { TG }\end{array}$ & $\begin{array}{l}\text { FQ (false QPA), } \\
\text { Operon }\end{array}$ \\
\hline FQMtn19ant & TTG GCT CGG CGA TAT GC & $\begin{array}{l}\text { FQ (false QPA), } \\
\text { Operon }\end{array}$ \\
\hline Gst25prsen & $\begin{array}{l}\text { CTA AGA CCC CCA GTA ATT } \\
\text { AAT TC }\end{array}$ & Operon/ ChIP \\
\hline Gst25prant & $\begin{array}{l}\text { TGG ACT AAG GTT AAT AGG } \\
\text { TTA TG }\end{array}$ & Operon/ ChIP \\
\hline Mtn19prsen & $\begin{array}{l}\text { TGG TCG TCT ATC TAC TTT } \\
\text { TGT TTG }\end{array}$ & Operon/ ChIP \\
\hline Mtn19prant & $\begin{array}{l}\text { ATT CGG GAG TTG TCT ATT } \\
\text { TAA TAC }\end{array}$ & Operon/ ChIP \\
\hline PP2a sense & AAG CAG CGT AAT CGG TAG G & FQ/ qRT PCR \\
\hline PP2a anti & $\begin{array}{l}\text { GCA CAG CAA TCG GGT ATA } \\
\text { AAG }\end{array}$ & FQ/ qRT PCR \\
\hline Rev23 & $\begin{array}{l}\text { TTC ACA CAG GAA ACA GCT } \\
\text { ATG ACC }\end{array}$ & Invitrogen/ cloning \\
\hline SCL14woHArev & $\begin{array}{l}\text { ACC TGA ACA AGA ACC GTC } \\
\text { AGG GCT ATC AC }\end{array}$ & Invitrogen/ cloning \\
\hline SCL14woHAub & $\begin{array}{l}\text { CGC TGA CAA GCT GAC TCT } \\
\text { AGT AAA AAT GGG TTC TTA } \\
\text { TCC GGA TGG ATT CC }\end{array}$ & Invitrogen/ cloning \\
\hline TGA2anti & $\begin{array}{l}\text { CCA ATG AAT TCT CAC TCT } \\
\text { CTG GGTCGA GCA AGC }\end{array}$ & Invitrogen/ cloning \\
\hline
\end{tabular}




\begin{tabular}{l|l|l}
\hline TGA2sense & $\begin{array}{l}\text { CCT AAG GAT CCG CTT ATG } \\
\text { TTC AGC AGC TAG AGA AC }\end{array}$ & Invitrogen/ cloning \\
\hline Uni24 & $\begin{array}{l}\text { ACG ACG TTG TAA AAC GAC } \\
\text { GGC CAG }\end{array}$ & Invitrogen/ cloning \\
\hline
\end{tabular}

\subsubsection{Plasmids}

\begin{tabular}{|c|c|c|}
\hline Plasmid & Description & Reference \\
\hline pAlligator2 & $\begin{array}{l}\text { Gateway }{ }^{\mathrm{TM}} \text { vector for plant } \\
\text { transformation, contains the } \\
\text { CaMV 35S promoter, the nos } \\
\text { terminator, a 3x HA-tag (N- } \\
\text { terminal), and a GFP selection } \\
\text { marker under control of a seed } \\
\text { specific promoter At2S3, spn }\end{array}$ & $\begin{array}{l}\text { Parcy, } \\
\text { http://www.isv.cnrs- } \\
\text { gif.fr/JG/alligator/intro.html }\end{array}$ \\
\hline pAlligator2/SCL14 & $\begin{array}{l}\text { pAlligator2 derivative, } \\
\text { contains the CDS of SCL14- } \\
\text { cDNA under control of the } \\
\text { CaMV 35S promoter, } s p n^{r}\end{array}$ & This work \\
\hline pAlligator2/SCL14-HA & $\begin{array}{l}\text { pAlligator2 derivative, } \\
\text { contains the CDS of SCL14- } \\
\text { cDNA fused to the } 3 \text {-end of } \\
\text { the } 3 \times \text { HA-tag under control of } \\
\text { the CaMV 35S promoter, spn }\end{array}$ & Siemsen, 2005 \\
\hline pGAD424 & $\begin{array}{l}\text { Vector for expression of GAD } \\
\text { fusion proteins under control } \\
\text { of the } A D H 1 \text { promoter in } \\
\text { yeast, GAL4 } 4_{(768-881)} \text { activation } \\
\text { domain, } L E U 2, a m p^{r}\end{array}$ & Clontech \\
\hline pGAD424/SCL14 & $\begin{array}{l}\text { pGAD424 derivative, contains } \\
\text { the CDS of the SCL14-cDNA } \\
\text { and 3'UTR fused to the } 3 \text { '-end } \\
\text { of the GAL4-AD, LEU2, amp }\end{array}$ & Siemsen, 2005 \\
\hline pGAD424/SCL14 1-161 & $\begin{array}{l}\text { pGAD424 derivative, contains } \\
\text { a truncated CDS of the SCL14- } \\
\text { cDNA (1-479) fused to the } 3{ }^{\prime}- \\
\text { end of the GAL4-AD, LEU2, } \\
\text { amp }{ }^{r}\end{array}$ & This work \\
\hline pGAD424/SCL14 1-381 & $\begin{array}{l}\text { pGAD424 derivative, contains } \\
\text { a truncated CDS of the SCL14- } \\
\text { cDNA (1-1139) fused to the } \\
3^{\prime} \text {-end of the GAL4-AD, } \\
L E U 2, a m p^{r}\end{array}$ & This work \\
\hline
\end{tabular}




\begin{tabular}{|c|c|c|}
\hline pGBT9 & $\begin{array}{l}\text { Vector for expression of GBD } \\
\text { fusion proteins under control } \\
\text { of the } A D H 1 \text { promoter in } \\
\text { yeast, } G A L 4_{(1-147)} \text { DNA } \\
\text { binding domain, TRP1, amp } \\
\end{array}$ & Clontech \\
\hline pGBT9/TGA2 & $\begin{array}{l}\text { pGBT9 derivative, contains the } \\
\text { CDS of the TGA2-cDNA fused } \\
\text { to the } 5 \text {-end of the GAL4- } \\
\text { DNA-BD under control of the } \\
\text { ADH1 promoter, TRP1, amp }\end{array}$ & (Weigel et al., 2001) \\
\hline $\mathrm{pGEX} / 2.1 \mathrm{ct}$ & $\begin{array}{l}\text { pGEX-4T1 derivative, contains } \\
\text { the truncated CDS of the } \\
\text { TGA2.1-cDNA from tobacco } \\
\text { (only the C-terminus), for } \\
\text { expression of GST fusion } \\
\text { proteins }\end{array}$ & \\
\hline pGEX/TGA2ct & $\begin{array}{l}\text { pGEX-4T1 derivative, contains } \\
\text { the C-terminal part (plus } \\
\text { zipper region) of the CDS of } \\
\text { the TGA2-cDNA ( } 817 \mathrm{bp})\end{array}$ & This work \\
\hline pGEX/TGA5ct & $\begin{array}{l}\text { pGEX-4T1 derivative, contains } \\
\text { the C-terminal part (plus } \\
\text { zipper region) of the CDS of } \\
\text { the TGA5-cDNA }\end{array}$ & This work \\
\hline pHBT & $\begin{array}{l}\text { Vector for transient expression } \\
\text { in plant cells, pHBTL-sGFP } \\
\text { derivative, deletion of sGFP } \\
\text { gene by NcoI / NotI restriction, } \\
\text { Klenow fill in and religation, } \\
a m p^{r}\end{array}$ & (Heinekamp et al., 2002) \\
\hline pHBTL-sGFP & $\begin{array}{l}\text { pHBT-sGFP derivative (Sheen, } \\
\text { 1993), contains the sGFP- } \\
\text { S65T gene between the HBT } \\
\text { promoter and the nos } \\
\text { terminator, additional KpnI } \\
\text { and EcoRI restriction sites in } \\
\text { front of the BamHI site, } a m p^{r}\end{array}$ & (Nickolov, 2003) \\
\hline pHBTL/SCL14-sGFP & $\begin{array}{l}\text { pHBTL derivative, contains } \\
\text { the CDS of the SCL14-cDNA } \\
\text { fused to the } 5^{\prime} \text {-end of the SGFP } \\
\text { under control of the HBT } \\
\text { promoter, } a m p^{r}\end{array}$ & (Siemsen, 2005) \\
\hline pSK-T & $\begin{array}{l}\text { Vector for cloning and } \\
\text { sequencing, } l a c Z \alpha, a m p^{r}\end{array}$ & Kriete, unpublished \\
\hline
\end{tabular}




\subsubsection{Organisms}

\subsubsection{Bacteria}

\begin{tabular}{|c|c|c|}
\hline Species & Properties & Reference \\
\hline $\begin{array}{l}\text { Agrobacterium tumefaciens } \\
\text { GV3101 }\end{array}$ & $\begin{array}{l}\text { PMP90RK } \\
\text { rif }^{r}, g^{r}\end{array}$ & (Koncz and Schell, 1986) \\
\hline Escherichia coli DB3.1 & $\begin{array}{l}\mathrm{F}^{-}, \text {gyr } \mathrm{A} 462, \text { end } 1, \mathrm{D}(\text { sr1- } \\
\text { recA }), \text { mcrB, mrr, hsdS20 } \\
\left(\mathrm{r}_{\mathrm{B}}^{-} \mathrm{m}_{\mathrm{B}}^{-}\right), \text {supE } 44, \text { ara-14, } \\
\text { galK2, lac } 1, \text { proA } 2 \\
\left.\text { rpsL20( } \mathrm{Sm}^{\mathrm{r}}\right), \text { xyl-S, } \lambda-\mathrm{leu}, \\
\text { mtl-1 }\end{array}$ & (Bernard et al., 1993) \\
\hline Escherichia coli DH5 $\alpha$ & $\begin{array}{l}\mathrm{F}^{-}, \text {gyrA } 96 \text { (Nalr), recA1, } \\
\text { endA1, thi-1, hsdR17 (rk- } \\
\text { mk+), glnV44, deoR, D } \\
\text { (lacZYA-argF) U169 } \\
\text { [p80dD(lacZ)M15] }\end{array}$ & (Hanahan, 1983) \\
\hline
\end{tabular}

\subsubsection{Yeast strains}

\begin{tabular}{l|l|l}
\hline Strain & Properties & Reference \\
\hline PJ69-4a & MAT $\alpha$, trp1-901, & (James et al., 1996) \\
& leu2-3,112, ura3-52, & \\
& his3-200, gal4d, gal804, & \\
& GAL2-ADE2, & \\
& LYS2 ::GAL1-HIS3, & \\
& met2::GAL7-lacZ & \\
\hline
\end{tabular}

\subsubsection{Fungal cultivars}

\begin{tabular}{l|l|l}
\hline Strain & Properties & Reference \\
\hline B. cinerea BH/1 & Infects A. thaliana Col-0 & $\begin{array}{l}\text { Kindly provided by Brigitte } \\
\text { Mauch-Mani, University of } \\
\text { Neuchatel }\end{array}$ \\
\hline B. cinerea B1.26 & Infects A. thaliana Col-0 & $\begin{array}{l}\text { Kindly provided by Andreas } \\
\text { von Tiedemann, University } \\
\text { of Göttingen }\end{array}$ \\
\hline
\end{tabular}




\subsubsection{Plant genotypes}

\begin{tabular}{|c|c|c|}
\hline Genotype & Description & Reference \\
\hline Columbia, Col-0 & Wildtype & $\begin{array}{l}\text { NASC Stock Nr. N1092, } \\
\text { NASC } 2002\end{array}$ \\
\hline Col-0/as-1:GUS & $\begin{array}{l}\text { Plants expressing the GUS } \\
\text { reporter gene under control } \\
\text { of the truncated CaMV } 35 S \\
(-90) \text { promoter, used as } \\
\text { "wildtype" control in this } \\
\text { work }\end{array}$ & (Redman et al., 2002) \\
\hline coi1-1 mutant & $\begin{array}{l}\text { Knock out line, lacking } \\
\text { COI1, impaired in most JA } \\
\text { dependent responses }\end{array}$ & $\begin{array}{l}\text { (Feys et al., 1994) (Xie et } \\
\text { al., 1998) }\end{array}$ \\
\hline npr1-1 mutant & $\begin{array}{l}\text { Knock out line lacking } \\
\text { NPR1 }\end{array}$ & (Cao et al., 1994) \\
\hline $\begin{array}{l}\text { as-1:GUS/ 35S:SCL14 } \\
\text { expressing plants }\end{array}$ & $\begin{array}{l}\text { Over-expression line, } \\
\text { expressing the SCL14 gene } \\
\text { under control of the CaMV } \\
35 S \text { promoter, expresses } \\
\text { GFP in seeds for selection }\end{array}$ & This work \\
\hline $\begin{array}{l}\text { as-1:GUS/ 35S:SCL14-HA } \\
\text { expressing plants }\end{array}$ & $\begin{array}{l}\text { Over-expression line, } \\
\text { expressing the SCL14 gene } \\
\text { fused to an HA-tag (N- } \\
\text { terminal) under control of } \\
\text { the CaMV } 35 S \text { promoter, } \\
\text { expresses GFP in seeds for } \\
\text { selection, line } \# 5 \text { was used } \\
\text { in this work }\end{array}$ & Siemsen, 2005 \\
\hline $\begin{array}{l}\text { scl14 mutant } \\
\left(\mathrm{SALK} \_126931\right)\end{array}$ & $\begin{array}{l}\text { Knock out line, expressing a } \\
\text { T-DNA insertion } 55 \mathrm{bp} \\
\text { upstream of the ATG from } \\
\text { SCL14 gene, } \mathrm{km}^{r}\end{array}$ & $\begin{array}{l}\text { SALK Stock Centre, } \\
\text { Nottingham }\end{array}$ \\
\hline as-1:GUS/ scl14 & $\begin{array}{l}\text { scl14 mutant, expressing } \\
\text { GUS reporter gene under } \\
\text { control of truncated CaMV } \\
35 S \text { promoter, line \#14 }(\sim 5 \\
\text { as-1:GUS insertions) was } \\
\text { used during this work, } \mathrm{km}^{r}\end{array}$ & Siemsen, 2005 \\
\hline $\begin{array}{l}\text { as-1:GUS/ scl14/ } \\
\text { 35S:SCL14 }\end{array}$ & $\begin{array}{l}\text { scl14 mutant (\#14) } \\
\text { complemented with SCL14 } \\
\text { under control of the CaMV } \\
\text { 35S promoter, expresses } \\
\text { GFP in seeds for selection, } \\
\mathrm{km}^{r}\end{array}$ & This work \\
\hline
\end{tabular}




\begin{tabular}{l|l|l}
\hline as-1:GUS/ scl14/ & $\begin{array}{l}\text { scl14 mutant (\#14) } \\
\text { complemented with SCL14 } \\
\text { fused to a HA-tag under } \\
\text { control of the CaMV 35S } \\
\text { promoter, expresses GFP in } \\
\text { seeds for selection, } \mathrm{km}^{r}\end{array}$ & \\
\hline $\begin{array}{l}\text { as-1:GUS/ scl14/ SCL31 } \\
\text { RNAi }\end{array}$ & $\begin{array}{l}\text { scl14 mutant (\#14) also } \\
\text { expressing a RNAi } \\
\text { construct targeting SCL31 } \\
\text { mRNA, } \mathrm{km}^{r}\end{array}$ & Fode, unpublished \\
\hline tga2 tga5 tga6 triple mutant & $\begin{array}{l}\text { Knock out line lacking all } \\
\text { three class II TGA }\end{array}$ & Zhang et al., 2003 \\
tga2,5,6 mutant) & $\begin{array}{l}\text { transcription factors, } \\
\text { impaired in SAR, kindly } \\
\text { provided by Y. Zhang }\end{array}$ & \\
\hline
\end{tabular}

\subsubsection{Growing media}

\begin{tabular}{|l|l|}
\hline $\begin{array}{l}\text { dYT medium } \\
\text { for bacteria }\end{array}$ & $20 \mathrm{~g} / \mathrm{L}$ Tryptone; $10 \mathrm{~g} / \mathrm{L}$ Yeast extract; $10 \mathrm{~g} / \mathrm{L} \mathrm{NaCl}$ \\
\hline $\begin{array}{l}\text { LB medium for } \\
\text { bacteria }\end{array}$ & $10 \mathrm{~g} / \mathrm{L}$ Tryptone; $5 \mathrm{~g} / \mathrm{L}$ Yeast extract; $10 \mathrm{~g} / \mathrm{L} \mathrm{NaCl}$ \\
\hline $\begin{array}{l}\text { Malt extract } \\
\text { medium for } \\
\text { fungi }\end{array}$ & $48 \mathrm{~g} / \mathrm{L}$ Malt extract agar (Merck), $2 \mathrm{~g} / \mathrm{L}$ Yeast extract \\
\hline $\begin{array}{l}\text { MS medium for } \\
\text { plants }\end{array}$ & $4.4 \mathrm{~g} / \mathrm{L}$ MS medium; $\mathrm{pH} 5.7$ with KOH \\
\hline $\begin{array}{l}\text { PDA medium } \\
\text { for fungi }\end{array}$ & $4 \mathrm{~g} / \mathrm{L}$ Potato dextrose agar (Fluka) \\
\hline $\begin{array}{l}\text { PDB medium } \\
\text { for fungi }\end{array}$ & $12 \mathrm{~g} / \mathrm{L}$ Potato dextrose broth (Sigma) \\
\hline $\begin{array}{l}\text { SD medium for } \\
\text { yeast }\end{array}$ & $\begin{array}{l}6.7 \mathrm{~g} / \mathrm{L} \text { Yeast nitrogen base without amino acids, } \mathrm{pH} 5.8 ; 100 \mathrm{~mL} / \mathrm{L} \\
\mathrm{DROP} \text { OUT-Stock }(10 \mathrm{x}) ; 50 \mathrm{~mL} / \mathrm{L} \mathrm{Glucose}(40 \%) ; \text { amino acids } \\
\text { (for solid medium: } 14 \mathrm{~g} / \mathrm{L} \text { Select agar) }\end{array}$ \\
\hline $\begin{array}{l}\text { YPAD medium } \\
\text { for yeast }\end{array}$ & $\begin{array}{l}20 \mathrm{~g} / \mathrm{L} \text { Tryptone } / \text { Peptone; } 10 \mathrm{~g} / \mathrm{L} \text { Select Yeast extract; } 50 \mathrm{~mL} / \mathrm{L} \\
\mathrm{Glucose}(40 \%) ; 20 \mathrm{~mL} / \mathrm{L} \text { Adenine }(\mathrm{Hemi} \text { sulfate })(0.2 \%) ; \mathrm{pH} 5.8 \\
\text { (for solid medium: } 14 \mathrm{~g} / \mathrm{L} \text { Select agar) }\end{array}$ \\
\hline
\end{tabular}




\subsubsection{Standard buffers}

\begin{tabular}{|l|l|}
\hline PBS (10 x) & $1.4 \mathrm{M} \mathrm{NaCl}, 27 \mathrm{mM} \mathrm{KCl}, 100 \mathrm{mM} \mathrm{Na}_{2} \mathrm{HPO}_{4}, 18 \mathrm{mM} \mathrm{KH}_{2} \mathrm{PO}_{4}, \mathrm{pH} 7.3$ \\
\hline PBS-T (1 x) & 1 x PBS with $0.05 \%(\mathrm{v} / \mathrm{v})$ Tween-20 \\
\hline TAE (20 x) & $0.8 \mathrm{M}$ Tris, $2.3 \%(\mathrm{v} / \mathrm{v})$ acetic acid, $20 \mathrm{mM}$ EDTA \\
\hline TE & $10 \mathrm{mM}$ Tris, $1 \mathrm{mM}$ EDTA, $\mathrm{pH} 7.5$ \\
\hline
\end{tabular}

\subsection{Methods}

\subsubsection{Standard molecular biology methods}

\subsubsection{Isolation of plasmid DNA from $E$. coli}

\subsection{Alkaline lysis}

Small amounts of plasmid DNA for analytical purposes were isolated from E. coli using a modification of the alkaline lysis method. E. coli overnight culture (stationary phase) of $1.5 \mathrm{~mL}$ was collected by centrifugation at $13000 \mathrm{rpm}$ for 1 minute. The supernatant was removed and the cells were resuspended in $100 \mu \mathrm{L}$ of buffer I for plasmid DNA isolation (50 mM Tris-HCl, $\mathrm{pH} 8.0 ; 10 \mathrm{mM}$ EDTA; $100 \mu \mathrm{g} / \mu \mathrm{L}$ RNase A). The cell suspension was lysed for 5 minutes on ice using $200 \mu \mathrm{L}$ of buffer II $(0.2 \mathrm{M} \mathrm{NaOH} ; 1 \%$ (w/v) SDS). The suspension was neutralized with $150 \mu \mathrm{L}$ of buffer III $(29.4 \mathrm{~g}$ potassium acetate; $5 \mathrm{~mL}$ formic acid and water till $100 \mathrm{~mL}$ ). The solution was mixed well by inverting 6-8 times and the suspension was centrifuged for 10 minutes at $13000 \mathrm{rpm}$ at room temperature. The aqueous solution $(\sim 400 \mu \mathrm{L})$ was transferred into a new microcentrifuge tube containing $1 \mathrm{~mL}$ of $96 \%(\mathrm{v} / \mathrm{v})$ ethanol. The DNA was left to precipitate for $20 \mathrm{~min}$ at $-20^{\circ} \mathrm{C}$. Plasmid DNA was collected by centrifugation for 10 minutes at $13000 \mathrm{rpm}$ and $4^{\circ} \mathrm{C}$. The pellet was washed with $70 \%(\mathrm{v} / \mathrm{v})$ ethanol and airdried for 10 minutes at $37^{\circ} \mathrm{C}$. The DNA was dissolved in $20 \mu \mathrm{L}$ of EB buffer $(10 \mathrm{mM}$ Tris-HCl, $\mathrm{pH} 8.5$ ). 


\subsection{High-quality plasmid DNA isolation: Spinprep}

For sequencing and yeast transformation purposes, high-purity plasmid DNA was isolated using QIAprep (Qiagen) or Nucleospin Mini kit (Machery\&Nagel) following the manufacturer's instructions. Optional steps were always followed according to the manufacturer's recommendation. A $3 \mathrm{~mL}$ overnight culture was used to isolate plasmid and the isolated DNA was eluted with $50 \mu \mathrm{L}$ (high copy) or $30 \mu \mathrm{L}$ (low copy) EB buffer or water (ultra pure).

Larger amounts of plasmid DNA from E. coli with high purity were isolated using Qiagen or Macherey-Nagel Midi and Maxi kit depending upon the required end concentration. Manufacturer's protocol including the optional recommendations was followed and final elution volume depended on the plasmid copy number, size of the DNA pellet to be eluted and final concentration required.

\subsubsection{Determination of DNA/ RNA concentrations}

The concentration of nucleic acids was estimated by measuring their absorption in a spectrophotometer at a wavelength of $260 \mathrm{~nm}$ (maximum nucleic acid absorption value; due to the $\pi$-electron systems of the heterocycles of the nucleotides). In a cuvette having $10 \mathrm{~mm}$ path-length where $\mathrm{OD}_{260}$ reading is 1 corresponds to 50 and $40 \mu \mathrm{g} / \mathrm{mL}$ doublestranded DNA and RNA, respectively. Absorption at $280 \mathrm{~nm}$ (for the presence of aromatic rings from amino acids and phenol compounds) was used to give information about the purity of the DNA or RNA sample, where an optimal ratio $\mathrm{OD}_{260} / \mathrm{OD}_{280}$ is in the range of 1.9-2.0 for RNA and 1.8 for DNA. DNA concentrations lower than $100 \mathrm{ng} /$ $\mu \mathrm{L}$ were measured on an agarose gel using the Gene Ruler Ladder Mix.

\subsubsection{Separation of DNA on agarose gels}

The electrophoretic separation of DNA for analytical and preparative purpose was done in a horizontal agarose gel $(10 \mathrm{~cm} \times 7 \mathrm{~cm} \times 0.3 \mathrm{~cm}, 16$ lanes $)$ with $1 \times$ TAE as running buffer. DNA fragments ranging between $500 \mathrm{bp}$ and $14 \mathrm{~kb}$ were run in an agarose gel concentration of $1 \%$ where DNA fragments with lower size were run in a $2 \%$ agarose gel. DNA samples were mixed with 1/10 volume of 10x DNA loading buffer, loaded in separate lanes and run at $120 \mathrm{~V}$ for $40-45 \mathrm{~min}$. Ethidiumbromide solution $(0.1 \% \mathrm{w} / \mathrm{v})$ was used to stain the DNA fragments. The detection of DNA was done under UV light $(260 \mathrm{~nm})$. When a preparative gel was run and particular band fragments were needed to cut out, detection was done using larger wavelength UV light $(320 \mathrm{~nm})$. Before exposure to the UV light, the gel was rinsed briefly in $\mathrm{H}_{2} \mathrm{O}$ to reduce background staining. In a gel-documentation station, gels were visualized on a UV-transilluminator and documented. The sizes and amount of the DNA fragments were determined using DNA standards.

The elution of DNA fragments from agarose gel was done using the QIAquick or Nucleospin Extract II Gel Extraction kit following the manufacturer's instructions. The eluted fragments were verified by electrophoresis as described above. 


\subsubsection{Restriction digestion of DNA}

Type II endonucleases were used to digest a double stranded DNA molecule for analytical and cloning purposes. The enzymes cut the DNA either as 5' or 3' "sticky" overhangs or as blunt ends. The digestion reactions were incubated in a buffer system optimized for the used enzyme and in the case of double digestion a universal buffer system was used. The activity of the restriction enzymes was estimated in "units" (U), where $1 \mathrm{U}$ was defined as that amount of enzyme cutting completely $1 \mu \mathrm{g}$ of $\lambda$ DNA in 60 minutes at optimal conditions. The minimal amount of enzyme necessary for each restriction was determined according to the following formula:

$\mathrm{U}=(\mathrm{bp}[\lambda] \mathrm{x}$ No. of restriction sites in target DNA) / (No. of restriction sites in $[\lambda] \mathrm{x} b \mathrm{p}$ of target DNA) with $\lambda=48500 \mathrm{bp}$

The incubation temperature was $37^{\circ} \mathrm{C}$ unless otherwise mentioned for particular restriction enzyme. Due to the adverse effect of high glycerol concentration, the total volume of restriction enzymes should not extend more than $10 \%$ in the restriction mix.

\subsubsection{Ligation of DNA fragments}

The conventional cloning of a DNA fragment into a selected plasmid was performed using the T4-DNA ligase enzyme, which is able to catalyze the formation of a phosphodiesther chemical bond between free $5^{\prime}$-phosphate and 3 '-OH groups of double stranded DNA fragments and vectors. The donor DNA fragment (10x accesses over the vector) was incubated with the vector DNA, $2 \mu \mathrm{L}$ of ligation buffer and $1 \mu \mathrm{L}$ of T4DNA ligase for 2 hours at room temperature. The ligation of DNA fragments with blunt ends was performed in the presence of $5 \%(\mathrm{w} / \mathrm{v})$ PEG 4000 with the ligation mix described above. Ligase activity was destroyed by heating at $65^{\circ} \mathrm{C}$ for $10 \mathrm{~min}$ before using the ligated DNA for transformation.

\subsubsection{Sequencing of DNA}

The DNA sequencing was done using the BigDye Terminator RR Mix Cycle Sequencing kit. The principle of DNA sequencing is based on the chain-termination method (Sanger et al., 1977). In the chain-termination method, dideoxynucleotides (terminators) are incorporated into a newly synthesized complementary chain that will lead to stop its elongation in a PCR reaction. Each of dideoxynucleotides is labeled with a specific fluorescent dye and the terminated chains can be specifically detected using an ABI Prism 3100 Capillary Sequencer (Applied Biosystems). The PCR sequencing reaction was performed using 500-1000 ng plasmid DNA, 5 pmol primer, $2 \mu \mathrm{L}$ RR mix (ready reaction) and $\mathrm{H}_{2} \mathrm{O}$ up to $10 \mu \mathrm{L}$. The samples were subjected to 25 cycles of: 10 seconds at $95^{\circ} \mathrm{C}, 5$ seconds at $50^{\circ} \mathrm{C}, 4$ minutes at $60^{\circ} \mathrm{C}$ in a thermocycler. The DNA product was precipitated using $9.5 \mu \mathrm{L}$ water and $30.5 \mu \mathrm{L}$ of absolute ethanol and left for 1 hour. The DNA was collected by centrifugation for 20 minutes at $13000 \mathrm{rpm}$. The pellet was washed using $125 \mu \mathrm{L} \mathrm{70 \%} \mathrm{ethanol} \mathrm{and} \mathrm{then} \mathrm{centrifuged} \mathrm{for} 10$ minutes at $13000 \mathrm{rpm}$. The pellet was dried at $95^{\circ} \mathrm{C}$ for one minute and resuspended in $10 \mu \mathrm{L}$ of 
HiDi-reagent. The samples were placed on ice. The reactions were loaded on an ABIPrism 3100 capillary electrophoresis sequencing station for analysis.

\subsubsection{Cloning of vectors}

\subsubsection{1 pAlligator2-SCL14}

This vector was constructed by overlapping PCR from pAlligator2-SCL14-HA and pUCA7. Primers for first fragment: SCL14woHAub and SCL14woHArev on pAligator2-SCL14-HA. Primers for second fragment: Rev23 and Alligator-ohneHA on pUCA7 (provided by C. Thurow). The PCR on both fragments (15 ng) was performed with primers Rev23 and SCL14woHA antisense. This product was cut with EcoRV and BspHI and ligated into pAlligator-SCL14-HA cut with EcoRV and BspHI.

\subsubsection{2 pGAD424-SCL14 1-161, 1-381}

Deletion derivatives of SCL14 were created in the pGAD424-SCL14 plasmid.

SCL14 (aa 1-161): pGAD424-SCL14 plasmid was cut with REN NheI and religated without the cut-off (middle part) of SCL14 (bp 479 - bp 1996).

SCL14 (aa 1-381): pGAD424-SCL14 plasmid was cut with REN BcuI and religated without the cut-off (C terminus) of SCL14 (bp 1139 - bp 2716:3'-UTR).

\subsubsection{3 pGEX-TGA2ct, TGA5ct}

To express GST-fused TGA proteins for antibody generation the C-terminal parts (including zipper) of TGA2 and TGA5 were cloned into pGEX-2.1C-term plasmids.

TGA5: pGBT9-TGA5 was cut with RENs NdeI and SalI and the TGA5 fragment was ligated into the equally cut pGEX-2.1C-term.

TGA2: PCR with primers TGA2sense and TGA2anti produced a TGA2ct fragment with addition of a BamHI (5') and an EcoRI (3') restriction site. This product was cut with RENs BamHI and EcoRI and ligated into the equally cut vector pGEX-2.1C-term. These vectors were used to produce TGA2ct-GST and TGA5ct-GST fusion proteins, which were sent to Eurogentec as antigens for antibody production.

\subsubsection{Gene transfer to $E$. coli}

E. coli cells have no competent nature, i.e. they are not able to accept foreign DNA molecules from the environment. To enable the bacterial cells to take up circular vector DNA they have to be made competent using special treatments. Two transformation methods were used to transform competent bacteria cells: The heat shock and the electroporation. The heat shock method was used only to transform E. coli chemical 
competent cells (Hanahan, 1983). In brief, $200 \mu \mathrm{L}$ competent E. coli cells were thawed on ice for $20 \mathrm{~min}, 50 \mathrm{ng}$ of plasmid DNA was added to the cells and mixed gently. The mixture was incubated on ice for 30 minutes. The cells were heat shocked for $90 \mathrm{~s}$ at $42^{\circ} \mathrm{C} .700 \mu \mathrm{L}$ of LB medium were added to the tube and the suspension was mixed on a roller for $45-60 \mathrm{~min}$ at $37^{\circ} \mathrm{C}$ depending on selectable antibiotic resistance marker. Different volumes of the culture were plated on plates containing LB medium supplemented with antibiotics. The plates were incubated overnight at $37^{\circ} \mathrm{C}$.

The transformation using electroporation was done for $E$. coli cells according to a slight modification of (Dower et al., 1988). The electroporation was done using a Gene Pulser II. Bacterial competent cells were thawed on ice slowly before adding $2 \mu \mathrm{L}$ of plasmid DNA. The mixture was transferred into an ice-cooled electroporation cuvette $(2 \mathrm{~mm}$ electrode distance). The cuvette was subjected to electroporation at $25 \mu \mathrm{F}, 2.5 \mathrm{kV}, 200$ $\Omega$. The cells were suspended immediately with $1 \mathrm{~mL} \mathrm{LB}$ medium and incubated for 45 $60 \mathrm{~min}$ at $37^{\circ} \mathrm{C}$. Different volumes of the culture were plated on LB media supplemented with antibiotics and incubated overnight (12-16 hours) at $37^{\circ} \mathrm{C}$.

\subsubsection{Gene transfer to $S$. cerevisiae}

Competent yeast cells were used for transformation. For generation of competent cells a yeast colony (Strain PJ69-4a) from a plate was used to inoculate $10 \mathrm{~mL}$ of YPAD medium. Subsequently, the medium was incubated $\mathrm{o} / \mathrm{n}$ at $30^{\circ} \mathrm{C}$. Cells were harvested the next day by centrifugation (3000 rpm for $5 \mathrm{~min}$ ). After removal of supernatant, cells were resuspended in residual medium and transferred to $200 \mathrm{~mL}$ YPAD medium. Growing of cells at $30^{\circ} \mathrm{C}$ was extended until the culture reached $\mathrm{OD}_{600}=0.6$. Cells were pelleted as 4 x $50 \mathrm{~mL}$ aliquots by centrifugation like before and supernatant was discarded. Subsequently, cells were resuspended in each $10 \mathrm{~mL}$ Solution A $(10 \mathrm{mM}$ Bicine $\mathrm{pH}$ 8.35, $1 \mathrm{mM}$ sorbitol, $3 \%$ ethylenglycol) and centrifuged again. After resuspension in each $1 \mathrm{~mL}$ Solution A the 4 samples were combined. Cells were frozen as $100 \mu \mathrm{L}$ aliquots at $-80^{\circ} \mathrm{C}$.

1-2 $\mu \mathrm{g}$ plasmid DNA and $50 \mu \mathrm{g}$ HSP DNA were added to frozen competent yeast cells (100 $\mu \mathrm{L}$ per sample). Cells were thawed for $3 \mathrm{~min}$ at $37^{\circ} \mathrm{C} .1 \mathrm{~mL}$ of Solution B (200 $\mathrm{mM}$ Bicine $\mathrm{pH} 8.35,40 \%$ PEG 1000) was added to each sample. Samples were mixed, incubated for $60 \mathrm{~min}$ at $30{ }^{\circ} \mathrm{C}$ and centrifuged $(10 \mathrm{~s}, 13000 \mathrm{rpm})$. After removal of supernatant cells were washed in $800 \mu \mathrm{L}$ Solution C (10 mM Bicine pH 8.35, $150 \mathrm{mM}$ $\mathrm{NaCl}$ ) and centrifuged again. Subsequently, cells were resuspended in $100 \mu \mathrm{L}$ Solution $\mathrm{C}$ and stroked out on selective SD plates.

\subsubsection{Gene transfer to A. tumefaciens}

Competent cells of Agrobacterium tumefaciens GV3101 were transformed by electroporation method. Cells were thawed on ice, mixed with respective plasmid DNA and transferred to an electroporation cuvette. Electric pulse $(2.5 \mathrm{kV}, 25 \mu \mathrm{F}, 400 \Omega)$ was applied for $\sim 5 \mathrm{~s}$. Subsequently, cells were incubated with $1 \mathrm{~mL} \mathrm{LB}$ medium for $2 \mathrm{~h}$ at $30^{\circ} \mathrm{C}$ and spread on selective YEB-plates. Incubation of plates was performed for 2-3 
days at $30^{\circ} \mathrm{C}$. Transformed cells from plates were grown in $25 \mathrm{~mL}$ selective YEB liquid medium $\mathrm{o} / \mathrm{n}$ at $30^{\circ} \mathrm{C}$. From $5 \mathrm{~mL}$ of this pre-culture plasmid-DNA was extracted (QIAprep kit) to control the transformed cells. The rest of the pre-culture was transferred into $400 \mathrm{~mL}$ selective YEB liquid medium and incubated o/n at $30^{\circ} \mathrm{C}$. Cells were harvested by centrifugation $(2500 \mathrm{rpm}, 30 \mathrm{~min})$ and resolved in $5 \%$ sucrose solution to an $\mathrm{OD}_{600}$ of 0.8 . Silvet-L77 $(0.05 \%)$ was added to this solution prior to $A$. thaliana transformation.

\subsubsection{Agrobacterium mediated gene transfer to $A$. thaliana}

Transformation of A. thaliana with Agrobacterium was performed after (Clough, 2000). Therefore, flowering plants were dipped into an Agrobacterium solution. Plants were subsequently cultured to seed development. Selection was performed with respective selection markers on the integrated transgenic DNA.

\subsubsection{Stress induction in A. thaliana}

\subsubsection{SA/ INA}

Arabidopsis plants were grown on soil under short-day conditions ( $8 \mathrm{~h}$ light) for five to six weeks. Plantlets were sprayed with $1 \mathrm{mM}$ SA (in water) or $1 \mathrm{mM}$ INA (in EtOH) and incubated under same conditions for additional 10 to 12 hours. Control plants were sprayed with water $+\mathrm{EtOH}(0.1 \%)$ and incubated for the same time spans or harvested before treatment. All controls are depicted as $0 \mathrm{~h}$.

\subsubsection{2,4-D}

Arabidopsis plants were grown on soil under long-day conditions ( $16 \mathrm{~h}$ light) for three to four weeks. Plantlets were washed out from the soil and floated in $50 \mathrm{mM}$ potassium phosphate buffer $\mathrm{pH} 5.8$ containing either $0.1 \mathrm{mM} 2,4-\mathrm{D}$ (in DMSO) or $0.1 \%$ DMSO. Incubation was performed under growing conditions for additional 10 hours. Control plants were floated in buffer + DMSO and incubated for the same time spans or harvested before treatment. All controls are depicted as $0 \mathrm{~h}$.

\subsubsection{TIBA}

Arabidopsis plants were grown on MS medium under long-day conditions (16 h light) for three weeks. Plantlets were sprayed with $0.1 \mathrm{mM}$ TIBA (in DMSO) and incubated under same conditions for additional 10 hours. Control plants were sprayed with water $+\operatorname{DMSO}(0.1 \%)$ and incubated for the same time spans or harvested before treatment. All controls are depicted as $0 \mathrm{~h}$. 


\subsubsection{Hydrogen peroxide}

Arabidopsis plants were grown on MS medium under long-day conditions (16 h light) for three weeks. Plantlets were transferred to $50 \mathrm{mM}$ potassium phosphate buffer $\mathrm{pH} 5.8$ containing $16 \mathrm{mM}$ hydrogen peroxide and floated under growing conditions for additional 8 hours. Control plants were floated on buffer only and incubated for the same time spans. All controls are depicted as $0 \mathrm{~h}$.

\subsection{Germination assays}

Germination assays were performed under long-day conditions (16 h light). Seeds from all genotypes were sterilized and directly sowed on MS medium lacking sucrose. MS medium contained either nothing, $0.1 \mathrm{mM}$ TIBA, $0.1 \mathrm{mM}$ INA or $0.05 \mathrm{mM}$ SA. Plants were grown for three weeks on these plates before pictures were taken and plantlets were weighted.

\subsubsection{Infection of Arabidopsis with B. cinerea}

Botrytis cinerea strains: $\mathrm{BH} / 1$ and $\mathrm{B} 1.26$

\subsection{Culturing}

Pieces of mycelium from a PDA plate (growing plate) or spores from glycerol stock ($80^{\circ} \mathrm{C}$ ) were transferred to fresh malt extract plates (sporulation plate). Growing of the fungi was carried out in darkness at $20-24^{\circ} \mathrm{C}$ for about $7-12$ days. Sporulation was initiated by UV irradiation of the plates (under a UV lamp) for $24 \mathrm{~h}$. The plates were subsequently incubated in darkness till full sporulation occurs (4-7 days). Collected spores (see below) were frozen as glycerol stocks $(30 \%)$ in aliquots $(50 \mu \mathrm{L})$ at $-80^{\circ} \mathrm{C}$.

\subsection{Collection of spores}

Five $\mathrm{mL}$ of PDB medium were dropped onto a plate with a full sporulating fungus. The fungal hyphes were scraped off with a Drygalski applicator and the medium containing the hyphes and spores was filtered through three layers of gauze bandage. Spores were counted under the microscope in a Thomma counting chamber (no. of spores in the whole chamber $\mathrm{x} 10,000=$ spores/mL medium) and diluted with PDB medium to $1 \mathrm{x}$ $10^{6}$ spores $/ \mathrm{mL}$. 


\subsection{Infection of plants}

The collected spores in the PDB medium were incubated in light at RT for 2-3 h. Plants with full expanded leaves were inoculated with $5 \mu \mathrm{L}$ of spore solution $\left(1 \times 10^{6}\right.$ spores $/ \mathrm{mL}$ ) on each leaf. The inoculated plants were kept under long day conditions for $24 \mathrm{~h}$. Optional: The inoculated plants were covered with plastic lids ( $24 \mathrm{hpi}$ ) to maintain a higher humidity to provide the fungi with optimized growing conditions. Pictures were taken and infected leaves were harvested during infection process every $24 \mathrm{~h}$.

\subsubsection{Transcriptome analysis}

\subsubsection{RNA extraction}

The extraction method based on TRIZOL extraction can be used to extract RNA, DNA and proteins from plants (Chomczynski, 1993). This method uses a Phenol/ Chloroform (dichloromethane) extraction to solve RNA in the aqueous phase while other parts like chlorophyll is solved in the hydrophobic chloroform phase. The two thiocyanates in the extraction buffer inhibit RNAses. After grinding of the plant material under liquid nitrogen $1 \mathrm{~mL}$ extraction buffer was added to $\sim 150 \mathrm{mg}$ plant material. After shaking for $15 \mathrm{~min}$ at RT, chloroform $(200 \mu \mathrm{L})$ was added to each sample. After an additional shaking step (15 min, RT) and centrifugation (12000 rpm, $\left.35 \mathrm{~min}, 4^{\circ} \mathrm{C}\right)$ the supernatant $(700 \mu \mathrm{L})$ was transferred to new microcentrifuge tubes. Precipitation buffer (HSPB) and 2-propanol (each $250 \mu \mathrm{L}$ ) were added and the samples were incubated for 10 min at RT and centrifuged $\left(12000 \mathrm{rpm}, 20 \mathrm{~min}, 4^{\circ} \mathrm{C}\right)$. After removing the supernatant, samples were dried at RT. The dried pellets were resolved in $50-100 \mu \mathrm{L}$ water (ultra pure). Concentration was measured as described in 2.2.1.2.

\subsubsection{Quantitative Realtime RT-PCR (qRT-PCR)}

RNA extraction of plant leaf material was performed as described above. DNaseI restriction was done before cDNA synthesis. $1 \mu \mathrm{g}$ of RNA, $1 \mu \mathrm{L}$ of $10 \mathrm{x}$ reaction buffer with $\mathrm{MgCl}_{2}$ (Fermentas, St. Leon-Roth, Germany) and desoxyribonuclease I (DNaseI), RNase-free was added with water to a final reaction volume of $10 \mu \mathrm{L}$. The mixture was incubated at $37^{\circ} \mathrm{C}$ for 30 minutes. To denatured the DNaseI $1 \mu \mathrm{L} 25 \mathrm{mM}$ EDTA was added and incubated at $65^{\circ} \mathrm{C}$ for 10 minutes. cDNA synthesis was performed with $1 \mu \mathrm{g}$ total RNA (DNA-free), 20 pmol of oligo-dT primer and 200 pmol of random nonamer oligonucleotides. Water was added to a final reaction volume of $12.5 \mu \mathrm{L}$. The mixture was heated to $70^{\circ} \mathrm{C}$ for $10 \mathrm{~min}, 20 \mathrm{nmol} \mathrm{dNTPs}, 4 \mu \mathrm{L} 5 \mathrm{x}$ reaction buffer (Fermentas, St. Leon-Roth, Germany) and $30 \mathrm{u}$ ribonuclease inhibitor (Eppendorf, Hamburg, Germany) were added and the mixture was heated to $37^{\circ} \mathrm{C}$ for $10 \mathrm{~min} .100 \mathrm{u}$ of RevertAid ${ }^{\mathrm{TM}} \mathrm{H}$ Minus M-MuLV reverse transcriptase (Fermentas, St. Leon-Roth, Germany) was added (final volume $20 \mu \mathrm{L}$ ) and the mixture was incubated at $42^{\circ} \mathrm{C}$ for $70 \mathrm{~min}$, then heated to $70^{\circ} \mathrm{C}$ for $10 \mathrm{~min}$. The iCycler System (Bio Rad, Hercules, CA, USA) was used for the 
amplification and quantification of cDNA using QuantiTect Primer Assays (Qiagen, //www1.qiagen.com/Products/Pcr/QuantiTect/PrimerAssays.aspx) for the respective genes and for the PDF2 subunit $P P 2 a$ as reference gene. The amplification mix consisted of 1x NH 4 -reaction buffer (Bioline, Luckenwalde, Germany); $2 \mathrm{mM} \mathrm{MgCl}$; $100 \mu \mathrm{M}$ of dNTPs; $0.4 \mu \mathrm{M}$ of primers, $0.25 \mathrm{u}$ BIOTaq DNA polymerase (Bioline Luckenwalde, Germany); 10 nM Fluoresceine (BioRad, Hercules, CA, USA); 100,000 times diluted SYBR Green I solution (Cambrex, Rockland, ME, USA); $1 \mu \mathrm{L}$ of a 1:10 dilution of cDNA as template and water (ultra pure) added to a total volume of $25 \mu \mathrm{L}$. PCR consisted of a 6 min initial denaturation step at $95^{\circ} \mathrm{C}$ followed by 40 cycles of $20 \mathrm{~s}$ at $95^{\circ} \mathrm{C}, 20 \mathrm{~s}$ at $55^{\circ} \mathrm{C}$ and $40 \mathrm{~s}$ at $72^{\circ} \mathrm{C}$.

\subsubsection{Micro array analysis}

Untreated plants were compared with TIBA-induced plants using pools of about 50 two week old plantlets in a square design comparing each possible condition and genotype combination (induced state comparing wildtype and scl14 mutant was doubled) with ten micro arrays (Landgrebe et al., 2004). Leaf material from induced plants harvested at 10 hpi was frozen and ground in liquid nitrogen. Total RNA was extracted according to the TRIZOL method (Invitrogen $\mathrm{GmbH}$, Karlsruhe, Germany) and purified using the RNeasyMini Kit (Qiagen, Hilden, Germany). Micro arrays spotted with the Arabidopsis Genome Oligo Set version 3.0 (Qiagen, Hilden, Germany) were obtained from D. Galbraith (University of Arizona, Tucson Arizona, USA). Slides were rehydrated at $60^{\circ} \mathrm{C}$ and UV-cross linked according to the supplier's web page. The Amino Allyl MessageAmp ${ }^{\mathrm{TM}}$ II aRNA Amplifcation Kit (Ambion, Darmstadt, Germany) was used for cDNA synthesis, in vitro transcription and Cy3/Cy5-labeling of the 5-(3aminoallyl)-UTP-containing aRNAs with the following modifications: Purification and concentration of double-stranded cDNA was done using the DNAclear ${ }^{\mathrm{TM}} \mathrm{Kit}_{\text {(Ambion, }}$ Darmstadt, Germany), and the large scale transcription reaction was purified with the MEGAclear ${ }^{\mathrm{TM}}$ Kit (Ambion, Darmstadt, Germany). Hybridization and washing was done as recommended on the supplier's web page (http://www.ag.arizona.edu/microarray/). The slides were scanned with a G2505B Micro array Scanner (Agilent Technologies, Böblingen, Germany). Non-linear loess regression was used to adjust the micro array data for technical and biological effects. To increase comparison of all slides, each normalized dataset was scaled by division with its standard deviation. The differences in gene expression were computed using a mixed model statistics in references to the applied design (ANOVA (Langrebe et al., 2006) allowing estimation of biological and technical variance. To estimate the significance, $t$-tests were applied for each feature. Multiplicity adjustment of the resulting p-values was done by the Benjamini-Hochberg procedure (Bretz et al., 2005). Normalization and statistic computation was done independently for a high and a low gain dataset, allowing the recovery of lost data from saturated spots. 


\subsubsection{Proteome analysis}

\subsubsection{Whole cell protein extracts}

The extractions of proteins were performed under denaturing conditions and on whole cell extract level. Extraction buffer containing urea (4 M urea, $16.6 \%$ glycerol, $5 \%$ SDS, $0.5 \% \beta$-mercaptoethanol) was used to extract the proteins. After grinding the plant material in liquid nitrogen, extraction buffer $(450 \mu \mathrm{L})$ was added to $\sim 150 \mathrm{mg}$ plant material. The samples were incubated at $65^{\circ} \mathrm{C}$ for $10 \mathrm{~min}$ and centrifuged $(13000 \mathrm{rpm}$, 20 min, RT). The supernatant was transferred to new microcentrifuge tubes and used for SDS-PAGE.

\subsubsection{Determination of concentrations of proteins}

Protein concentration was estimated by two different methods. A colorimetric assay was used to determine the concentration from proteins extracted without detergent usage according to (Bradford and Williams, 1976). The assay was conducted by pipetting equal amounts of protein extract into a microtiter plate containing $200 \mu \mathrm{L}$ of 5 -fold diluted Bradford reagent. The OD595 was measured with a MRX plate reader (Dynex). Protein concentrations were calculated with the help of a standard curve derived from different BSA protein amounts $(1,3$ and $6 \mu \mathrm{g})$ on the same plate. Proteins isolated using buffers containing detergents were either defined to equal amounts in a coomassie stained SDS gel (scanned and analysed with TINA2.0) or measured with the BCA protein assay kit (Thermo scientific) according to the instruction manual.

\subsubsection{SDS-PAGE}

In sodium dodecyl sulphate-polyacrylamide gel electrophoresis (SDS-PAGE), proteins are separated largely on the basis of polypeptide length. The electrophoresis of the protein was done using a discontinuous buffer system, in which a non-restrictive large pore gel, called a stacking gel, is layered on top of a separating gel called a resolving gel. The recipe for the resolving gel was consisting of: 7-8 \% (w/v) acrylamide/ bisacrylamide (37.5:1), $400 \mathrm{mM}$ Tris- $\mathrm{HCl} \mathrm{pH} 8.8,0.1 \%(\mathrm{w} / \mathrm{v})$ SDS, $0.1 \%(\mathrm{w} / \mathrm{v})$ TEMED and $0.1 \%(\mathrm{w} / \mathrm{v})$ APS. The stacking gel was consisting of: $5 \%(\mathrm{w} / \mathrm{v})$ acrylamide/bisacrylamide (37.5:1), $125 \mathrm{mM}$ Tris- $\mathrm{HCl} \mathrm{pH}$ 6.8, $0.1 \%(\mathrm{w} / \mathrm{v})$ SDS, $0.2 \%$ (w/v) TEMED and $0.1 \%(\mathrm{w} / \mathrm{v})$ APS. The denatured protein extract samples (each $\sim 10$ $\mu \mathrm{L}$, or defined equal amounts after a first coomassie stained gel) were boiled with $15 \mu \mathrm{L}$ 2x SDS sample buffer $(0.09 \mathrm{M}$ Tris, $20 \%$ glycerol, $2 \%$ SDS, $0.02 \%$ bromophenol blue, $0.1 \mathrm{M} \mathrm{DTT}$ ) at $95^{\circ} \mathrm{C}$ for 5 minutes, cooled on ice and loaded into the gel. The native extracted protein samples were mixed with $10 \mu \mathrm{L}$ of protein loading buffer and denatured at $95^{\circ} \mathrm{C}$ for 5 minutes, cooled on ice and then loaded onto the gel. The electrophoresis was performed at $120 \mathrm{~V}$ in 1x SDS running buffer $(250 \mathrm{mM}$ Tris, $2 \mathrm{M}$ Glycine, $1 \%$ SDS) until the bromophenol blue band reached the lower end of the gel. 6 
$\mu \mathrm{L}$ pre-stained protein ladder was loaded on each gel for the estimation of the size of the separated proteins.

\subsubsection{Coomassie staining of SDS gels}

The Coomassie Brilliant Blue G-250 dye was used to detect proteins separated on SDSPAGE. The gels were incubated with coomassie staining solution (colloidal coomassie) $\mathrm{o} / \mathrm{n}$. The gels were destained in water $\mathrm{o} / \mathrm{n}$.

Colloidal coomassie consists of $400 \mathrm{~mL}$ solution A (contain $40 \mathrm{~g}$ ammonium sulphate and $8 \mathrm{~mL}$ phosphoric acid) and $10 \mathrm{~mL}$ solution $\mathrm{B}$ (contain $0.5 \mathrm{~g}$ coomassie brilliant blue G250, this has to be solved shaking at least for $0.5 \mathrm{~h}$ ). Each gel was stained in $40 \mathrm{~mL}$ colloidal coomassie complemented with $10 \mathrm{~mL}$ methanol.

\subsubsection{Western blot}

The proteins separated in the SDS-PAGE were blotted onto a PVDF membrane using semi-dry blotting method in an electric field between two graphite plates. The PVDF membrane was activated before blotting using $\mathrm{MeOH}$. For the transfer of proteins from the gel to the membrane, the gel on top of the membrane was sandwiched between two 3- layers of Whatman papers (pre-soaked with transfer buffer). The whole arrangement was placed within a blot apparatus and transfer was performed under amperage of one $\mathrm{mA} / \mathrm{cm}^{2}$ for 1.4 hours. (Optional: Ponceau S staining was done to observe the success of the transfer. De-staining was done using $1 \mathrm{x}$ PBS.) After blotting the membrane was dried between two layers of Whatman paper. The standard was marked on the membrane with an iMark (pen containing pre-immune serum from rabbit) for later detection of standard bands with the second antibody and ECL kit to visualize them on the film. After $5 \mathrm{~min}$ the membrane was reactivated in $\mathrm{MeOH}$ and non-specific binding to the proteins on the membrane was prevented by blocking the membrane with non-fat dried milk powder ( $5 \%$ in $1 \mathrm{x}$ PBST) o/n at $4^{\circ} \mathrm{C}$ on a shaking platform. The detection of specific proteins on the membrane was performed using an antiserum directed against SCL14 or TGA2/5 in a 1:1000 dilution in $1 \mathrm{x}$ PBST (with $0.5 \%$ milk powder). The membrane was therefore incubated with the respective antiserum for $2 \mathrm{~h}$ at RT on a shaking platform. The incubation with the second antibody (anti-rabbit 1:25000 in 1x PBST) was performed for $1 \mathrm{~h}$ at RT on a shaking platform. This second antibody is conjugated to horseradish peroxidase (HRP). The HRP can utilize the enhanced chemiluminescent substrate (ECL, GE Healthcare, incubation of the membrane in ECL mix for $5 \mathrm{~min}$ ) emitting luminescence, which allows visualization of the membrane bound proteins on autoradiography films. The films were exposed to the membrane in detection cassettes for $30 \mathrm{~s}$ up to 10 min depending upon the strength of chemiluminescence signal generated by the respective amounts of bound protein. 


\subsubsection{ONPG assay}

Determination of transcriptional activation of reporter gene lacZ was done from its coded product, $\beta$-galactosidase catalyzed breakdown of substrate $o$-nitrophenyl- $\beta$-D galactopyranoside (ONPG). The $\beta$-galactosidase catalyzed the colourless substrate ONPG into the fluorescent $o$-nitrophenyle substance, which could be quantified at 420 $\mathrm{nm}$. Fresh clones were used to inoculate $2 \mathrm{ml}$ SD media with appropriate selection for the plasmid and supplemented with respective amino acids grown overnight at $30^{\circ} \mathrm{C}$ with 200-220 rpm shaking. Cells were harvested from $2 \mathrm{~mL}$ of overnight culture by centrifugation (13000 rpm, $1 \mathrm{~min}, \mathrm{RT})$ and resuspended in $675 \mu \mathrm{L} \mathrm{H}$ buffer $(100 \mathrm{mM}$ HEPES/KOH, pH 7.0; $150 \mathrm{mM} \mathrm{NaCl} ; 2 \mathrm{mM} \mathrm{MgCl}_{2} ; 1 \%$ (w/v) BSA) with one yeastlacking sample as control. From each sample $10 \mu \mathrm{L}$ aliquots were diluted with $190 \mu \mathrm{L}$ in a round-bottom 96-well plate for measuring the cell density at $\mathrm{OD}_{595}$. The rest $665 \mu \mathrm{L}$ cells were lysed by addition of $55 \mu \mathrm{L}$ chloroform and $55 \mu \mathrm{L} 0.1 \%(\mathrm{w} / \mathrm{v})$ SDS along with vigorous vortexing for $1 \mathrm{~min}$. $125 \mu \mathrm{L}$ of ONPG substrate $(4 \mathrm{mg} / \mathrm{ml}$ ONPG in $\mathrm{H}$ buffer) were added to the samples. All samples were incubated at $37^{\circ} \mathrm{C}$ until they turn yellow (15 min up to $2 \mathrm{~h}$ ). Necessary time required for the solution to become yellow was recorded. The reaction was stopped upon appearance of yellow colour with $400 \mu \mathrm{L}$ $1 \mathrm{M} \mathrm{Na}_{2} \mathrm{CO}_{3}$ and samples were centrifuged (13000 rpm, $5 \mathrm{~min}, \mathrm{RT}$ ). $200 \mu \mathrm{L}$ of the supernatant was transferred into microtiter plate for quantification at $420 \mathrm{~nm}$ in a spectrophotometer. The calculation of $\beta$-galactosidase activity was done according to the following formula:

$\beta$-galactosidase activity $=\left(1000 \times \mathrm{OD}_{420}\right) /\left(\mathrm{V} \times \mathrm{t} \times \mathrm{OD}_{600}\right)$

Where, $\mathrm{V}$ was the volume $(200 \mu \mathrm{L})$ and $\mathrm{t}$ was the reaction time. The $\beta$-galactosidase activity was expressed in Miller Units (MU).

\subsubsection{Localization of proteins: GFP-fusions in BY-2 protoplasts}

For the localization studies, BY-2 cells from tobacco liquid cell cultures were used. For each sample, $20 \mathrm{~mL}$ of the cell culture was transferred to a $50 \mathrm{~mL}$ centrifugation tube and centrifuged for $5 \mathrm{~min}$ (1550 rpm, RT, soft start and stop). After removal of the supernatant the cells were resuspended in the rest of the liquid phase. The cells were washed with $20 \mathrm{~mL}$ osmoticum $\left(0.5 \% \mathrm{BSA}, 0.01 \% \beta\right.$-mercaptoethanol, $0.05 \mathrm{M} \mathrm{CaCl}_{2}$, $0.01 \mathrm{M}$ sodium acetate, $0.25 \mathrm{M}$ mannitol, set to $\mathrm{pH} 5.8$ with $\mathrm{HCl}$ ) by centrifugation for 5 min (1550 rpm, RT, soft start and stop). The volume of the supernatant in the tubes was reduced to $5 \mathrm{~mL}$ and the cells were resuspended. After addition of $40 \mathrm{~mL}$ enzyme solution ( $1 \%$ cellulose onozuka RS, $0.5 \%$ macerozyme, $0.1 \%$ pectinase) the suspension was divided up to three Petri dishes. The dishes were closed with para-film and incubated in the dark $\mathrm{o} / \mathrm{n}$ at $25^{\circ} \mathrm{C}$. On the next day, protoplasts were transferred to centrifugation tubes and centrifuged (100 g, $5 \mathrm{~min}$, RT, soft start and stop). After removal of supernatant, protoplasts were resuspended in residual medium and washed in $20 \mathrm{~mL}$ osmoticum. Centrifugation and resuspension was done like before. Subsequently, $10 \mathrm{~mL}$ W5 solution (154 mM NaCl, $125 \mathrm{mM} \mathrm{CaCl}_{2}, 5 \mathrm{mM} \mathrm{KCl}, 5 \mathrm{mM}$ glucose, set to $\mathrm{pH} 5.8$ with $\mathrm{HCl}$ ) were added and centrifugation was repeated. This step was repeated with $5 \mathrm{~mL}$ W5 solution and the three protoplast samples were combined. 
Cell number was counted in a counting chamber (Fuchs-Rosenthal): counted cells per 4 squares x volume $(\mu \mathrm{L}) / 0,2 \mu \mathrm{L}$

Protoplasts were incubated at $4{ }^{\circ} \mathrm{C}$ for $30-60 \mathrm{~min}$ in the dark and centrifuged like before. After complete removal of supernatant, MMM solution (15 mM $\mathrm{MgCl}_{2}, 0.1 \% \mathrm{MES}$, $0.5 \mathrm{M}$ mannitol, set to $\mathrm{pH} 5.8$ with $\mathrm{KOH}$ ) was added to dilute the protoplasts to $2 \times 10^{6}$ cells/ mL. $30 \mu \mathrm{g}$ of DNA was added to $300 \mu \mathrm{L}$ of protoplast suspension. These samples were mixed with $300 \mu \mathrm{L}$ PEG solution (40\% PEG 4000, 0.4 M mannitol, $0.1 \mathrm{M}$ $\mathrm{Ca}(\mathrm{NO} 3)_{2}$, set $\mathrm{pH}$ to 8-9 with $\mathrm{KOH}$ ) and incubated for 20 min at RT. Subsequently 10 $\mathrm{mL}$ W5 solution were added and samples were centrifuged like before. After removal of supernatant $700 \mu \mathrm{L}$ MSF medium were added and samples were incubated o/n at $25^{\circ} \mathrm{C}$ in the dark. The next day protoplasts were analyzed under fluorescence microscope.

\subsubsection{Chromatin Immunoprecipitation (ChIP)}

An important method to study the regulation of transcription in living cells is the chromatin immunoprecipitation (ChIP) assay (Orlando, 2000). ChIP allows the analysis of the in vivo binding status of transcription factors or other DNA-associated proteins to certain DNA sequences (X-ChIP). Intact cells are treated with formaldehyde to crosslink promoter-associated proteins to the DNA. After isolation and shearing of the chromatin, protein-DNA complexes are immunoprecipitated with specific antibodies against the protein of interest. The precipitated DNA fragments are subsequently purified and analysed by polymerase chain reactions (PCR) using primers flanking the (putative) binding site of the protein. The amount of PCR product obtained is indicative for the relative amount of protein bound to the DNA when the tissue was harvested. The procedure allows detecting of quantitative differences in the relative amount of proteinDNA complexes, so that stimulus-induced binding can be detected.

If the binding site (cis element) of the transcription factor is not known, the promoters of putative target genes can be identified by ChIP followed by micro array analyses (ChIP-Chip, (Thibaud-Nissen et al., 2006)). In these experiments, new direct target genes can be identified, especially when whole genome tiling arrays are available (like for Arabidopsis thaliana). Alternatively, a library can be generated by cloning precipitated fragments after amplification by ligation mediated PCR (Wang et al., 2002).

In addition to the analysis of transcription factor binding, multi-protein complexes associated with the DNA can be studied using ChIP. As formaldehyde also crosslinks interacting proteins, multi-protein complexes (enhanceosome) can be mapped in vivo (Rochon et al., 2006). In this context, the so called SeqChIP can be used to address whether two proteins are simultaneously bound to a stretch of DNA (Geisberg and Struhl, 2004). As ChIP is also used to detect modifications at histones (for review see (Kuo and Allis, 1999)) a comprehensive snapshot of the events taking place during transcriptional activation can be obtained.

The following protocol describes a classical X-ChIP approach performed with leaves from Arabidopsis thaliana.

The protocol starts with infiltrating the material with a buffer containing formaldehyde. Formaldehyde is a very reactive bipolar compound that reacts with amino and imino groups of amino acids and DNA thus causing reversible crosslinks between proteins and 
DNA or between proteins (Orlando, 2000). Crosslinking is terminated by adding $0.3 \mathrm{M}$ glycine.

After the crosslinking, nuclei are prepared by two centrifugation steps of filtered whole cell extracts on Percoll ${ }^{\circledR}$ cushions. Afterwards, the nuclear envelope is solubilised with detergents. The chromatin is sheared into 500 to $1000 \mathrm{bp}$ fragments by sonication. After spinning down the insoluble debris, the supernatant is directly used for the immunoprecipitation. Immunoprecipitations can be either performed with affinitypurified antibodies or with the complete antiserum. When using unprocessed antisera, control precipitations with the respective pre-immune serum have to be done. Mutant plants lacking the transcription factor and/or amplification of a fragment lacking the putative binding site are also valuable tools to prove the specificity of the precipitation. After the immunoprecipitation, the DNA has to be purified for PCR analysis. A combination of de-crosslinking by heat treatment, protease A digestion and phenol extractions serves to remove the protein moiety of the complex. Chromatin that is not subjected to the immunoprecipitation is purified in the same way and serves to demonstrate that the same amount of chromatin is used for each sample (input control). Quantitative analysis of the so called IP-DNA by real-time PCR provides information to what extent a given transcription factor is occupying its target sequence within a promoter.

\subsection{Buffers and Materials}

\subsection{Preparation of Samples}

Approximately 3-5 g of Arabidopsis thaliana leaf material is needed.

\subsection{Crosslinking of Proteins to DNA}

(1) CLB1 (crosslink buffer 1): $50 \mathrm{mM} \mathrm{KH} \mathrm{PO}_{4} / \mathrm{K}_{2} \mathrm{HPO}_{4}, \mathrm{pH} 5.8,1 \%$ formaldehyde (see Note 1)

(2) CLB2 (crosslink buffer 2): $50 \mathrm{mM} \mathrm{KH} \mathrm{PO}_{4} / \mathrm{K}_{2} \mathrm{HPO}_{4}, \mathrm{pH}$ 5.8, $0.3 \mathrm{M}$ glycine

\subsection{Isolation of Nuclei}

(1) $25 \%$ Triton $\mathrm{X}-100$, stored at $4^{\circ} \mathrm{C}$.

(2) NEB (nuclei extraction buffer): $1 M$ hexylene glycol (2-methyl-2,4-pentanediol), 50 $\mathrm{mM}$ PIPES-KOH, pH 7.2, $10 \mathrm{mM} \mathrm{MgCl}$. Before use, $\beta$-mercaptoethanol has to be added to a final concentration of $5 \mathrm{mM}$ (see Note 2 ).

(3) GB (gradient buffer): $0.5 M$ hexylene glycol (ß-methyl-2.4-pentanediol), $50 \mathrm{mM}$ PIPES-KOH, pH 7.2, $10 \mathrm{mM} \mathrm{MgCl} 2,1 \%$ (w/v) Triton X-100. Before use, ßmercaptoethanol has to be added to a final concentration of $5 \mathrm{mM}$.

(4) Percoll cushions: $75 \%$ and $35 \%(\mathrm{w} / \mathrm{v})$ Percoll $^{\circledR}$ in GB.

(5) Miracloth (Calbiochem, Merck Chemicals Ltd., Nottingham, UK). 
(6) Nuclear stain: $300 \mathrm{nM}$ DAPI (4,6-diamidino-2-phenylindole) in water, to be stored at $-20^{\circ} \mathrm{C}$.

\subsection{Extraction of Chromatin}

(1) SB (sonic buffer): $10 \mathrm{mM}$ Tris- $\mathrm{HCl}, \mathrm{pH} 7.4,1 \mathrm{~m} M$ EDTA (ethylenediamine tetraacetic acid) containing either $0,0.25$ or $0.5 \%(\mathrm{w} / \mathrm{v})$ sodium dodecyl sulfate (SDS). The buffer is stored at room temperature.

(2) Protease inhibitor mix for plants (P-9599, Sigma-Aldrich, St. Louis, MO).

\subsection{Purification of DNA}

(1) PCI-Mix: phenol (equilibrated, $\mathrm{pH} 7.6$ - 8.0, AppliChem)/chloroform/isoamyl alcohol 25:24:1 (v/v/v). The mixture is stored at $4{ }^{\circ} \mathrm{C}$. All work involving phenol and chloroform should be done under a hood.

(2) CI-Mix: chloroform/isoamyl alcohol 24:1 (v/v).

(3) $3 M$ Na-Acetate

(4) Glycogen $10 \mathrm{mg} / \mathrm{mL}$ (G-8751, Sigma-Aldrich), store at $2-8^{\circ} \mathrm{C}$.

\subsection{Chromatin immunoprecipitation}

(1) RIPA-F: $50 \mathrm{mM}$ HEPES-NaOH, $\mathrm{pH} 7.4$ (see Note 3), $140 \mathrm{mM} \mathrm{NaCl}, 1 \mathrm{mM}$ EDTA, 1\% Triton X-100, 0.1\% sodium deoxycholate (DOC, minimum 97\%, Sigma-Adrich), $0.1 \%$ SDS; RIPA-F buffer without SDS is required for sample dilution prior to immunoprecipitation (see below). RIPA-F buffer may be used for up to 4 weeks when stored at $4^{\circ} \mathrm{C}$.

(2) Protein A Sepharose (from Staphylococcus aureus, Sigma-Aldrich), store at $2-8^{\circ} \mathrm{C}$.

(3) EB (elution buffer): $0.1 M$ glycine (adjust with $\mathrm{HCl}$ to $\mathrm{pH} 2.5$ ), $0.5 \mathrm{M} \mathrm{NaCl}, 0.05 \%$ Tween20. This buffer can be stored for up to 4 weeks at $4^{\circ} \mathrm{C}$.

(4) $10 \mathrm{mM}$ Tris- $\mathrm{HCl}, \mathrm{pH} 7.4$

(5) Proteinase $\mathrm{K}(20 \mathrm{mg} / \mathrm{mL})$. Aliquots $(100 \mu \mathrm{L})$ should be stored at $-20^{\circ} \mathrm{C}$.

\subsection{Plant Growth}

Grow Arabidopsis plants in a climate chamber under short day conditions (see Note 4) for about 4 to 5 weeks until they have developed enough biomass (about 3 - 5 g per sample).

Depending on the biological question to be asked, subject your plants to the appropriate treatment (e.g. pathogens, hormones, etc.).

Harvest 3 - $5 \mathrm{~g}$ of leaf material. 


\subsection{In vivo Crosslinking of Proteins to DNA}

Note: All steps for the crosslinking procedure are carried out at room temperature if not noted otherwise.

Put the leaves in a suitable device for subsequent vacuum-infiltration (see Note 5). This device should prevent floating of the leaves to the surface in order to make sure that the buffer, but not the air, is sucked in when the vacuum is released.

Put the device containing the leaf material into a beaker filled with CB1 so that the leaves are submerged.

Put the beaker in a desiccator and apply vacuum for 5 min using an oil pump. Release the vacuum, re-apply vacuum for additional $5 \mathrm{~min}$, release the vacuum and allow the crosslinking to proceed for $20 \mathrm{~min}$ (see Note 6).

Discard CB1 and wash the samples with CB2. Infiltrate CB2 into the leaves by applying vacuum for $5 \mathrm{~min}$, release the vacuum and incubate the samples for another $5 \mathrm{~min}$.

Discard CB2 and wash the samples twice with distilled water. After removing as much water as possible, the material can be frozen and stored in liquid nitrogen.

\subsection{Isolation of Nuclei}

Note: All steps are carried out at $4^{\circ} \mathrm{C}$. Working in a cooling chamber is recommended. Grind the plant material in liquid nitrogen.

Transfer the leaf powder into $50 \mathrm{~mL}$ tubes filled with $20 \mathrm{~mL}$ of NEB and mix with a glas pipette until the powder is completely submersed in the buffer.

Homogenize the sample with an electronic blender at low power (e.g. MiccraRT from

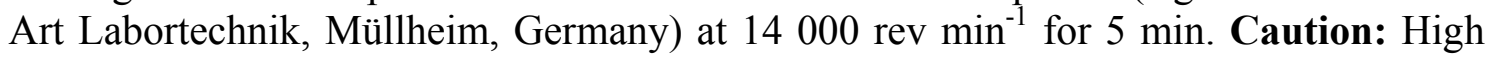
power mixers are not recommended as they will heat up the samples.

Filter the suspension through two sheets of Miracloth and collect the filtrate in $100 \mathrm{~mL}$ beakers (a small spoon can be used for careful mixing to accelerate the flow-through process). Add NEB to a total volume of $24 \mathrm{~mL}$.

Add $1 \mathrm{~mL}$ of Triton X-100 (25\%) dropwise to the filtrate on a magnetic stirrer. This step serves to lyse the organelles while leaving the nuclei intact. Caution: Add the Triton slowly to avoid high local concentrations of the detergent which might lead to disruption of the nuclear envelope.

Continue stirring for at least $30 \mathrm{~min}$ (this step can be extended up to $2 \mathrm{~h}$ ).

In the meantime, prepare the Percoll cushions in fresh $50 \mathrm{~mL}$ tubes. Overlay $6 \mathrm{~mL}$ of Percoll-cushion (75\%) carefully with $6 \mathrm{~mL}$ of Percoll-cushion $(35 \%)$.

Carefully place the resuspended nuclei on top of the Percoll cushions.

Centrifuge at $2100 \mathrm{~g}$ and $4^{\circ} \mathrm{C}$ for $30 \mathrm{~min}$ in a swinging bucket rotor (soft start and stop). The nuclei should appear as a greyish layer at the interface between the cushions.

Recover the nuclei with a blue tip $(1 \mathrm{~mL})$, transfer them into a fresh $50 \mathrm{~mL}$ tube and add GB to a total volume of $20 \mathrm{~mL}$. This step might work better when cut tips are used to recover the nuclei.

Add $6 \mathrm{~mL}$ Percoll-cushion (35\%) to fresh tubes

Overlay the Percoll-cushion $(35 \%)$ with the resuspended nuclei.

Centrifuge at $2100 \mathrm{~g}$ and $4^{\circ} \mathrm{C}$ for $10 \mathrm{~min}$ in a swinging bucket rotor (soft start and stop). 
Discard the supernatant, resuspend the nuclei in $1 \mathrm{~mL}$ GB and transfer them into $10 \mathrm{~mL}$ tubes. Take an aliquot to stain the nuclei with DAPI (see Note 7). The isolated nuclei appear under the fluorescent microscope as crescent shaped structures.

Centrifuge at $2100 \mathrm{~g}$ and $4^{\circ} \mathrm{C}$ for $10 \mathrm{~min}$ (soft start and stop) and discard the supernatant. Note: Nuclei can be stored for one day at $-80^{\circ} \mathrm{C}$.

\subsection{Preparation of Chromatin}

Note: All preparation steps should be carried out at $4^{\circ} \mathrm{C}$.

Resuspend the nuclei in $1 \mathrm{~mL}$ of SB, $0.5 \%$ SDS and add the protease inhibitor mix (1:100). Incubate under gentle agitation for $20 \mathrm{~min}$ at $4^{\circ} \mathrm{C}$. Dilute $(1: 1)$ with $1 \mathrm{~mL} \mathrm{SB}$ lacking SDS to get a final concentration of $0.25 \%$ SDS.

Sonicate 4 times for $20 \mathrm{~s}$ with a power of $100 \mathrm{~W}$ when using the MSE Soniprep 150 ultrasonic disintegrator (Sany-Gallen-Kamp, Loughboro, Leicestershire, UK; see Note 8). Cool the samples in ice/EtOH during and between the sonication pulses. If foaming is a problem, reduce the percentage of SDS in the sample.

Centrifuge at $11200 \mathrm{~g}$ and $4^{\circ} \mathrm{C}$ for $15 \mathrm{~min}$ to separate the soluble chromatin from the debris of the nuclei.

Freeze aliquots of $200 \mu \mathrm{l}$ in liquid nitrogen and store at $-80^{\circ} \mathrm{C}$. Take one aliquot of 50 $\mu \mathrm{L}$ for the quantification of the DNA content.

\subsection{Quantification of DNA in Chromatin Samples}

Add $200 \mu \mathrm{L} \mathrm{SB}, 0.25 \%$ SDS and $5 \mu \mathrm{L}$ of Proteinase $\mathrm{K}$ (from a $20 \mathrm{mg} / \mathrm{mL}$ stock solution) to $50 \mu 1$ of chromatin.

Incubate samples for $1 \mathrm{~h}$ at $37^{\circ} \mathrm{C}$ and $16 \mathrm{~h}$ at $42^{\circ} \mathrm{C}$ in a heating block to reverse the crosslinks. Note: Proteinase $\mathrm{K}$ treatment can also be done after the reversion of the crosslinks.

Extract with $250 \mu \mathrm{L}$ PCI, vortex rigorously for $30 \mathrm{~s}$ and separate the phases by centrifugation in a microcentrifuge (5 min at $13.000 \mathrm{rpm}, \mathrm{RT})$. Transfer the supernatant to a fresh microcentrifuge tube.

Extract with $250 \mu \mathrm{L} \mathrm{CI}$, vortex rigorously for $30 \mathrm{~s}$ and separate phases by centrifugation in a microcentrifuge (5 min at $13000 \mathrm{rpm}, \mathrm{RT}$ ). Transfer the supernatant to a fresh microcentrifuge tube.

Optional: Add $1 \mu \mathrm{L}$ RNaseA $(10 \mathrm{mg} / \mathrm{mL})$ to the supernatant and incubate at RT for 15 $\min$.

Add $1 / 10$ volumes of $3 M$ Na-Acetate, $1 \mu \mathrm{L}$ glycogen $(10 \mathrm{mg} / \mathrm{mL})$ and 2 volumes of absolute ethanol, mix by inverting the tubes for $6-8$ times and precipitate for $2-4 \mathrm{~h}$ at $80{ }^{\circ} \mathrm{C}$.

Pellet the DNA by centrifugation in a microcentrifuge ( $35 \mathrm{~min}$ at $13000 \mathrm{rpm}, 4^{\circ} \mathrm{C}$ ) and wash with $800 \mu \mathrm{L} \mathrm{70 \%} \mathrm{ethanol.}$

Pellet the DNA by centrifugation in a microcentrifuge (20 min at $13000 \mathrm{rpm}, \mathrm{RT}$ ) and discard the supernatant. Place the open microcentrifuge tube for $10 \mathrm{~min}$ at $37^{\circ} \mathrm{C}$ and resuspend the dried pellet in $50 \mu \mathrm{L}$ water (ultra pure). 
Measure the $\mathrm{OD}_{260}$ and analyze the size of the DNA fragments on a $1 \%$ agarose gel (see Note 9).

\subsection{Immunoprecipitation of Protein-DNA Complexes}

Thaw chromatin samples on ice (this will take some time).

Bring equal amounts of chromatin as measured by DNA content $(15 \mu \mathrm{g})$ to a total volume of $200 \mu 1$ with SB, $0.25 \%$ SDS and add $300 \mu 1$ RIPA-F lacking SDS.

Incubate for $1 \mathrm{~h}$ with $5 \mu \mathrm{L}$ PPI (pre-immune serum) with slow rotation at $4^{\circ} \mathrm{C}(\mathrm{e} . \mathrm{g}$. on a rotation platform like an Intelli-Mixer, LTF Labortechnik, Wasserburg, Germany).

In the meantime, add $1 \mathrm{~mL}$ RIPA-F to Protein A-Sepharose beads. You will need 2 x 50 $\mu 150 \%$ Protein A-Sepharose beads per sample: first, the complexes associated with the pre-immuneserum are captured, and afterwards the specific complexes are enriched with the immuneserum. To equilibrate the beads, let them sit for $15 \mathrm{~min}$ with slow rotation at $4^{\circ} \mathrm{C}$. Centrifuge in a microcentrifuge at $5000 \mathrm{rpm}$ for $3 \mathrm{~min}$, discard RIPA-F (works nicely with an insulin needle) and wash the beads once again with $1 \mathrm{~mL}$ RIPA-F (slowly rotate for $5 \mathrm{~min}$ at $4^{\circ} \mathrm{C}$ ). Discard the supernatant like before and dissolve the beads with RIPA-F to get a $50 \%$ beads solution.

Add $50 \mu \mathrm{L}$ of the equilibrated $50 \%$ Protein A-Sepharose beads to the samples and incubate them for $1 \mathrm{~h}$ at $4^{\circ} \mathrm{C}$ with slow rotation. This step serves to remove complexes from the chromatin that interact with the pre-immuneserum.

Centrifuge the samples in a microcentrifuge for $2 \mathrm{~min}$ at $13000 \mathrm{rpm}$. Take $50 \mu 1$ of the supernatant for later use as an input control (see 7) and use the remainder of the supernatant for the immunoprecipitation (see 8).

Add $400 \mu 1$ of SB, $0.25 \%$ SDS to the input control samples.

Transfer the remainder of the supernatant into a fresh microcentrifuge tube, add the antibody ( 1 to $5 \mu \mathrm{L}$ ) and incubate for $2 \mathrm{~h}$ at $4^{\circ} \mathrm{C}$ with slow rotation (see Note 10).

Add $50 \mu \mathrm{l}$ of the $50 \%$ Protein A-Sepharose beads and let the samples rotate for additional $2 \mathrm{~h}$ at $4^{\circ} \mathrm{C}$.

Centrifuge for $3 \mathrm{~min}$ at $5000 \mathrm{rpm}$ in a microcentrifuge and remove the supernatant with an insulin needle until the Sepharose is half-dry.

Wash the beads by adding $1 \mathrm{~mL}$ RIPA-F and let them rotate for $5 \mathrm{~min}$ at $4{ }^{\circ} \mathrm{C}$, centrifuge for $3 \mathrm{~min}$ at $5000 \mathrm{rpm}$ in a microcentrifuge and discard the supernatant with an insulin needle. Repeat this washing step for two more times.

Add $800 \mu 1$ RIPA-F and transfer the samples into a fresh microcentrifuge tube. Incubate for $5 \mathrm{~min}$ at $4{ }^{\circ} \mathrm{C}$ with slow rotation, centrifuge for $3 \mathrm{~min}$ at $5000 \mathrm{rpm}$ and discard the supernatant like before.

Add $150 \mu \mathrm{L}$ EB to the beads, vortex rigorously for $30 \mathrm{~s}$, centrifuge for $1 \mathrm{~min}$ at 13000 rpm in a microcentrifuge, transfer the supernatant with a yellow tip and into a microcentrifuge tube filled with $150 \mu \mathrm{L} 1 \mathrm{M}$ Tris-base, repeat the elution and combine the samples to a final volume of $450 \mu \mathrm{L}$.

Add $5 \mu \mathrm{L}$ Proteinase $\mathrm{K}(20 \mathrm{mg} / \mathrm{mL}$; also to input controls set aside in 7) and incubate samples for $1 \mathrm{~h}$ at $42^{\circ} \mathrm{C}$. Reverse the crosslinks for about $4 \mathrm{~h}$ at $65^{\circ} \mathrm{C}$. 


\subsection{Purification of DNA for PCR}

Extract with $450 \mu \mathrm{L}$ PCI, vortex rigorously for $30 \mathrm{~s}$ and separate the phases by centrifugation in a microcentrifuge (5 min at $13000 \mathrm{rpm}, \mathrm{RT})$. Remove the supernatant with a blue tip while holding the microcentrifuge tube in an angle of about $45^{\circ}$ and transfer the supernatant to a fresh microcentrifuge tube.

Add $450 \mu \mathrm{L} \mathrm{CI}$, vortex rigorously for $30 \mathrm{~s}$ and separate phases by centrifugation in a microcentrifuge $(5 \mathrm{~min}$ at $13000 \mathrm{rpm}, \mathrm{RT})$. Transfer the supernatant into a fresh microcentrifuge tube.

Optional: Add $1 \mu \mathrm{L}$ RNaseA $(10 \mathrm{mg} / \mathrm{mL})$ and incubate at RT for $15 \mathrm{~min}$.

Add $1 / 10$ volumes of $3 \mathrm{M}$ Na-Acetate, $1 \mu \mathrm{L}$ glycogen $(10 \mathrm{mg} / \mathrm{mL})$ and 2 volumes of absolute ethanol, mix by inverting the tubes $6-8$ times and precipitate for $2-4 \mathrm{~h}$ at $80^{\circ} \mathrm{C}$.

Pellet the DNA by centrifugation in a microcentrifuge ( $35 \mathrm{~min}$ at $13000 \mathrm{rpm}, 4^{\circ} \mathrm{C}$ ) and wash with $800 \mu \mathrm{L} 70 \%$ ethanol.

Pellet the DNA by centrifugation in a microcentrifuge (20 min at $13000 \mathrm{rpm}, \mathrm{RT})$ and discard the supernatant completely. Dry the pellet for $10 \mathrm{~min}$ at $37^{\circ} \mathrm{C}$ in an open microcentrifuge tube. Dissolve IP DNA in $35 \mu \mathrm{L}$ and input DNA in $175 \mu \mathrm{L}$ of water (ultrapure)

Resuspend the DNA at $65^{\circ} \mathrm{C}$ for 15 min while shaking at low speed. The purified DNA should be stored at $-20^{\circ} \mathrm{C}$.

\subsection{Analysis by PCR or real-time PCR}

The analysis of ChIP experiments by real-time PCR (qPCR) is recommended. If the PCR products are analyzed by agarose gel electrophoresis, different numbers of cycles have to be run for each sample in order to ensure that the reaction is in the linear range. The conditions for the PCR depend on the primers that are used for amplification of the promoter DNA sequence. It is recommended to use primers that amplify a fragment of about 250 bp (see Note 11).

For qPCR, use the following protocol as a start, some optimizations might be necessary depending on the sequence of the primers: Use $2.5 \mu \mathrm{L}$ of the purified IP-DNA and the input DNA, each. For a typical pipetting scheme see Fehler! Verweisquelle konnte nicht gefunden werden..

A typical qPCR program is:

$6 \mathrm{~min}$ at $95^{\circ} \mathrm{C}(+2 \mathrm{~min}$ when no fluoresceine measurement is performed)

40 cycles of $20 \mathrm{~s}$ at $95^{\circ} \mathrm{C}, 20 \mathrm{~s}$ at $60^{\circ} \mathrm{C}, 28 \mathrm{~s}$ at $72^{\circ} \mathrm{C}$

4 min at $72^{\circ} \mathrm{C}$

1 min at $95^{\circ} \mathrm{C}$

1 min at $55^{\circ} \mathrm{C}$

This program should be followed by a melting curve measurement to make sure that the primers have amplified a specific product.

Note: The initial denaturation time (in this case $6 \mathrm{~min}$ ) depends on the polymerase that is used. The annealing temperature has to be adapted to the primers used (see Note 12). Threshold cycles, which define the beginning of the exponential phase of the PCR, are used as units to indicate the relative amount of DNA in the samples. 


\subsection{Notes}

(1) Take special care when working with formaldehyde. It is highly toxic and has to be disposed separately. All work should be done under a hood. Wear protection clothes all the time.

(2) It is recommended to prepare NEB and GB freshly for each preparation. Add the $\beta$ mercaptoethanol just before you start the experiment. Work carefully with Bmercaptoethanol as it is harmful and causes damage to the environment. Waste should be disposed separately.

(3) The use of $\mathrm{NaOH}$ instead of $\mathrm{KOH}$ to adjust $\mathrm{pH}$ of the RIPA-F buffer is recommended as potassium forms precipitates with SDS in the buffer. RIPA-F contains a combination of denaturing and non-denaturing detergents (Triton, DOC, SDS) to solubilise the chromatin.

(4) Short day conditions are $8 / 16 \mathrm{~h}$ light/dark period, $22^{\circ} \mathrm{C}$. Grow the plants on soil with $\sim 20$ plants per pot. It is also possible to grow the plants under long day conditions, but the fraction containing the nuclei might be less clean as the cells accumulate starch under long day conditions.

(5) One possibility is to use nylon stockings.

(6) The incubation time with formaldehyde depends on the proteins which should be crosslinked. Shorter periods (of about 10 minutes) are sufficient for nucleosomal proteins, for crosslinking other proteins, the tissue should be treated for 20 minutes to 1 hour. The crosslinking should not be extended to longer periods as proteins get denatured or masked by formaldehyde. If problems (low yield of chromatin, or low yield of IP-DNA) occur, a time-course experiment should be performed.

(7) As DAPI (4,6-diamidino-2-phenylindole) moves slowly through membranes, an incubation time of $1.5 \mathrm{~h}$ for the samples (at $4^{\circ} \mathrm{C}$, in the dark) is recommended. The excitation wavelength is $358 \mathrm{~nm}$, emitted light has a wavelength of $461 \mathrm{~nm}$. Emission at $400 \mathrm{~nm}$ is due to binding of DAPI to RNA and should be subtracted by an appropriate filter.

(8) (9) The shearing of the chromatin by sonication should be controlled by gel electrophoresis on a $1 \%$ agarose gel after the precipitation of the DNA. The fragments should appear as a smear from $2 \mathrm{~kb}$ down to $300 \mathrm{bp}$. Depending on the sonication device, the power and the length and number of pulses need to be optimized.

(10) This so called "cleaning" step with the pre-immune serum is strongly recommended when an antiserum is used instead of a purified antibody.

(11) The performance of the ChIP largely depends on the antibody which is used. Some optimization is necessary to determine the best concentration for each antibody or antiserum.

(12) In this work real-time PCR quantification was performed using the SYBR Green technology in a MyiQ Single-Color Real-Time PCR Detection System (Bio-Rad, Munich, Germany). The SYBR Green stock is from Cambrex Bio Science, Rockland, USA and the Immolase DNA polymerase mix and the reaction buffer are from Bioline, Randolph, USA. Fluoresceine is added to calibrate for equal efficiency of fluorescence in each well. 
Table 3-1 Standard pipetting scheme for quantitative realtime PCR analyzing ChIP-DNA

\begin{tabular}{|l|c|c|c|}
\hline & stock & final conc. & $\mu \mathrm{L}$ \\
\hline Water & & & $\mathrm{X}^{*}$ \\
\hline Buffer & $10 \mathrm{x}$ & $1 \mathrm{x}$ & 2.5 \\
\hline dNTPs $1: 10$ & $10 \mathrm{mM}$ & $100 \mu \mathrm{M}$ & 0.25 \\
\hline 1. Primer & $10 \mu \mathrm{M}$ & $0.25 \mu \mathrm{M}$ & 0.625 \\
\hline 2. Primer & $10 \mu \mathrm{M}$ & $0.25 \mu \mathrm{M}$ & 0.625 \\
\hline SybrGreen $1: 1000$ & $100 \mathrm{x}$ & $1 \mathrm{x}$ & 0.25 \\
\hline MgCl $_{2}$ & $50 \mathrm{mM}$ & $\mathrm{X}^{*}$ & $\mathrm{X}^{*}$ \\
\hline Taq Polymerase & $5 \mathrm{U} / \mu \mathrm{l}$ & $1.25 \mathrm{U}$ & 0.25 \\
\hline Fluoresceine $1: 1000$ & $100 \mathrm{x}$ & $1 \mathrm{x}$ & 0.25 \\
\hline DNA & & & 2.5 \\
\hline Final volume & & $25 \mu 1$ & \\
\hline
\end{tabular}

*The $\mathrm{MgCl}_{2}$ concentration to be used depends on the type of Taq polymerase. In some cases, $\mathrm{MgCl}_{2}$ is included in the reaction buffer supplied with the enzyme or in commercially available master buffers for qPCR (which also contain SYBR Green or an alternative fluorophore and fluoresceine). 


\section{$4 \quad$ Results}

\subsection{The $\mathrm{N}$ terminus of SCL14 is required for TGA interaction}

In order to define the domain of SCL14 that interacts with TGA factors, a classical yeast-two-hybrid (YTH) system using TGA2 fused to the GAL4 DNA binding domain (GBD-TGA2) and SCL14 derivatives fused to the GAL4 activation domain (GADSCL14) was used. Different GAD-SCL14 deletion derivatives were co-transformed into yeast with GBD-TGA2.
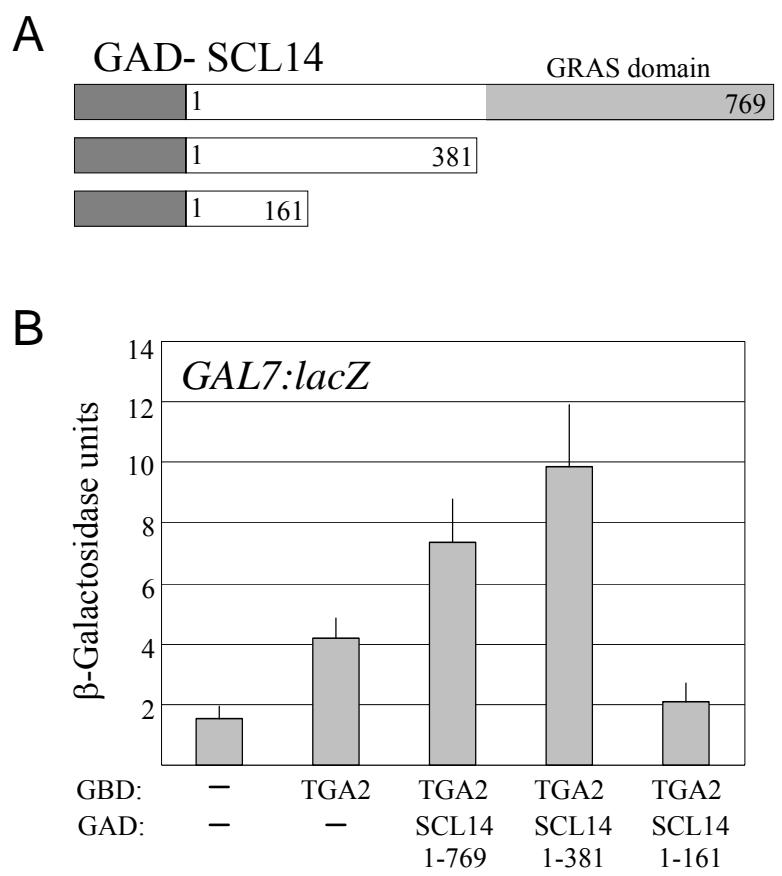

\section{Figure 4-1Yeast two hybrid analysis of SCL14 deletion derivatives}

(A) Schematic drawing of the tested SCL14 deletion derivatives. The GRAS domain (aa 391-765) is highlighted in grey. Numbers indicate the N-terminal and C-terminal amino acids of SCL14 in the respective constructs.

(B) Measurement of $\beta$-galactosidase activities in the yeast strain PJ69-4A, which contains the lacZ reporter gene under the control of the GAL7 promoter. Transformed effector plasmids encode TGA2 fused to the GAL4 DNA binding domain (GBD), SCL14 and deletion derivatives fused to the GAL4 activation domain (GAD) or non-fused GBD (vector pGBT9) or GAD (vector pGAD424). Four independent clones were taken for each combination of constructs. 
Complex formation between the two hybrid proteins was still possible, when only the variable N-terminal domain (aa 1-381) of SCL14 was used. However, the very first 161 N-terminal amino acids alone were not sufficient to support the interaction. Thus, the domain required for the interaction with TGA2 is located to the N-terminal region of SCL14 (Figure 4-1).

\subsection{Intracellular localization of SCL14-GFP fusion proteins}

The subcellular localization of SCL14 was assessed by microscopic analysis of a SCL14- green fluorescent protein (GFP) fusion protein that was transiently expressed in tobacco BY-2 protoplasts. As documented in Figure 4-2 (C), SCL14-GFP is localized both in the nucleus and in the cytosol. 


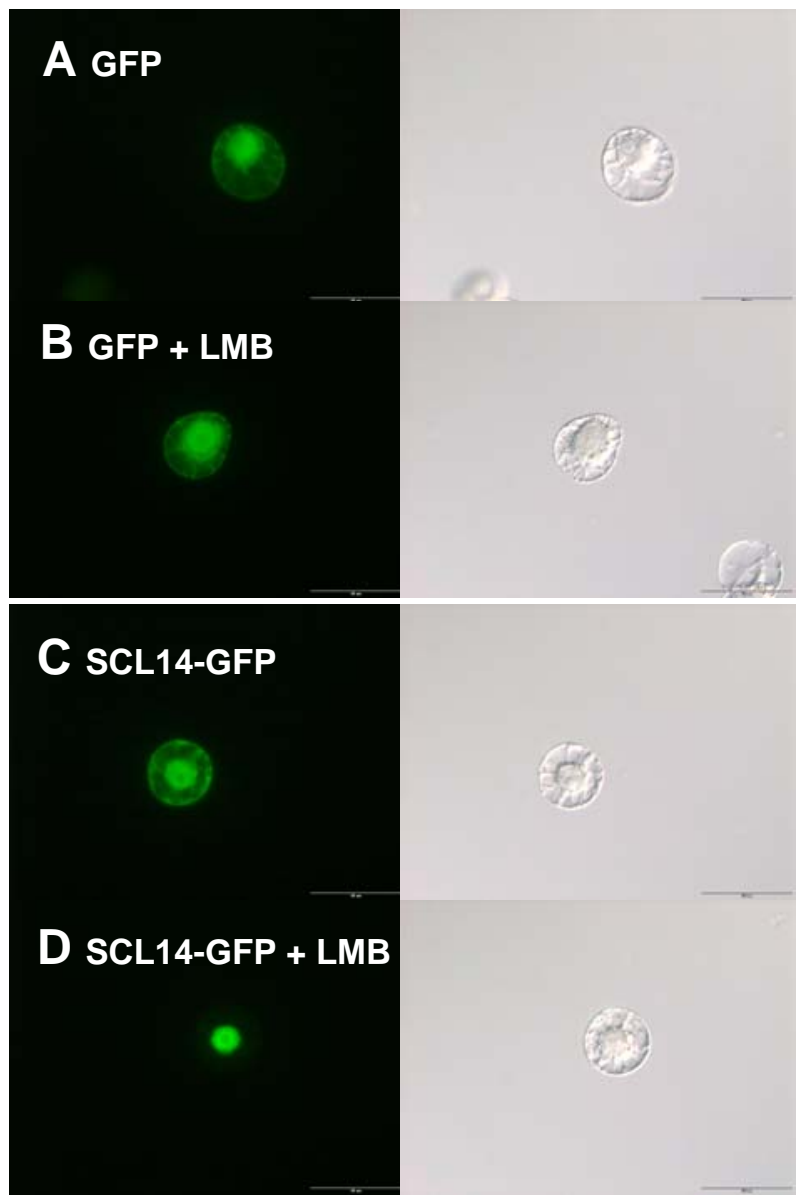

Figure 4-2 Localization of the SCL14-GFP fusion protein in protoplasts of tobacco BY-2 cells

Protoplasts were transfected with plasmids encoding GFP or SCL14-GFP and analyzed by fluorescence microscopy. In the right part bright field images are placed adjacent to the corresponding fluorescence pictures. BY-2 protoplasts transformed with GFP without LMB treatment (A) and with $2 \mu \mathrm{M}$ LMB (B); Protoplasts transformed with SCL14-GFP without LMB treatment (C) show localisation of SCL14 to cytoplasm and nucleus whereas SCL14 localizes only to the nucleus after treatment with $2 \mu \mathrm{M}$ LMB (D)

In order to assess whether the cytosolic localization of the protein is due to incomplete import or to active export, protoplasts were treated with Leptomycin B (LMB), which blocks the function of the exportin receptor XPO1 (Kudo et al., 1999). The GFP alone is distributed equally in the cytosol and the nucleus (A). Treatment with LMB shows no influence on the localization of the unfused reporter (B). In contrast, the LMB treatment led to the accumulation of the majority of SCL14-GFP in the nucleus (the original experiment was performed by Tanja Siemsen; Figure 4-2 shows the reproduction during this work). Thus, the cytosolic localization of SCL14 in the absence of LMB is most likely due to the XPO1-dependent nuclear export. 


\subsection{Sequence analysis of endogenous genes activated by SCL14}

Based on the results obtained in yeast the hypothesis was that SCL14 is recruited to the promoters of direct target genes by TGA factors bound to as-1-like elements. Therefore the promoter sequences of the genes identified by Tanja Siemsen were searched for putative as-1-like elements. Nine out of the 13 genes differentially regulated by SCL14 contain putative as-1-like elements within 250 bps from the transcriptional start site (Table 4-1). 
Table 4-1 Differentially expressed genes in as-1:GUS plants transformed with a CaMV 35S: $\mathrm{HA}_{3}-$ SCL14 construct $\left(\mathrm{HA}_{3}\right.$-SCL14) versus Scl14 mutant plants (log2 ratio >5.0)

\begin{tabular}{|c|c|c|c|c|}
\hline Gene & AGI code & $\begin{array}{c}\mathrm{HA}_{3} \text {-SCL14 } \\
\text { vs. scl14 } \\
\text { log2 ratio }\end{array}$ & $\begin{array}{c}\text { wildtype } \\
\text { vs. scl14 } \\
\log 2 \text { ratio }\end{array}$ & $\begin{array}{l}\text { as-1-like element } \\
\text { (-1000 bp promoter region) }\end{array}$ \\
\hline $\begin{array}{l}\text { SCARECROW-like transcription } \\
\text { factor } 14 \text { (SCL14) }\end{array}$ & At1g07530 & 11.2 & 7.5 & \\
\hline $\begin{array}{l}\text { Cytochrome P450 family protein } \\
\text { (CYP81D11) }\end{array}$ & At3g28740 & 10.8 & 8.4 & $-243 \overrightarrow{\text { TGACATATgcaaTGACGACA }}-224$ \\
\hline $\begin{array}{l}\text { UDP-glucoronosyl/UDP-glucosyl } \\
\text { transferase family protein }\end{array}$ & At1g05680 & 8.7 & 6.9 & \\
\hline Oxidoreductase & At2g37770 & 8.2 & 5.4 & \\
\hline MtN19-like protein & At5g61820 & 7.6 & 5.7 & $-121 \overrightarrow{\text { TGACGAGAgcgg }} \overrightarrow{T G A C G T C A}_{\longleftarrow}-102$ \\
\hline NADP-dependent oxidoreductase & At5g16980 & 6.3 & 4.6 & 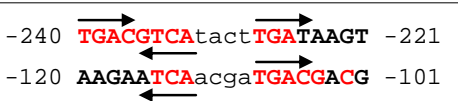 \\
\hline $\begin{array}{l}\text { 4-Methyl-5(B-hydroxyethyl)-thiazole } \\
\text { monophosphate biosynthesis protein }\end{array}$ & At3g14990 & 6.1 & 3.9 & - $71 \overrightarrow{\text { TTACGTCAtcgCACACGTCT }}$ \\
\hline Monooxygenase (MO1) & At4g15760 & 6.1 & 4.8 & -107 $\overrightarrow{\text { TGGCGTCAtaggcTTGCGTCA }} \quad-87$ \\
\hline Nitrilase 4 (NIT4) & At5g22300 & 5.8 & 4.0 & \\
\hline Glutathione S-transferase 25 (GSTU7) & At2g29420 & 5.5 & 3.3 & -64 GTTCGTCACtgg $\overrightarrow{\text { TGACGTCA }}-45$ \\
\hline $\begin{array}{l}\text { Short-chain dehydrogenase/ } \\
\text { reductase (SDR) family protein }\end{array}$ & At4g13180 & 5.5 & 3.4 & -134 ACACGTCACtgC $\underset{\longleftarrow T A C G A A A}{\longrightarrow}-115$ \\
\hline $\begin{array}{l}\text { Ubiquitin carboxyl-terminal hydrolase- } \\
\text { related }\end{array}$ & At5g61950 & 5.3 & 3.5 & \\
\hline $\begin{array}{l}\text { Arabidopsis NAC domain containing } \\
\text { protein } 2 \text { (ANAC002, ATAF1) }\end{array}$ & At1g01720 & 5.2 & 3.9 & $-179 \overrightarrow{\text { AGACGTAAgcaaTGACAACA }}-160$ \\
\hline $\begin{array}{l}\text { Arabidopsis NAC domain containing } \\
\text { protein } 32 \text { (ANAC032) }\end{array}$ & At1g77450 & 5.1 & 3.1 & 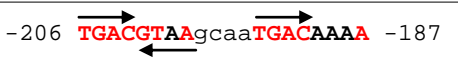 \\
\hline
\end{tabular}

\begin{tabular}{|l|c|}
\hline as-1:GUS & $-83 \overrightarrow{\text { TGACGTAAgggaTGACGCAC }}-64$ \\
\hline consensus & $\overrightarrow{\text { TGACGTCAnnnnTGACGTCA }}$ \\
\hline
\end{tabular}

On the right side of the table, sequences of as-1-like elements found in the respective promoter regions are shown. The numbers indicate their positions relative to the transcriptional start sites $(+1)$. Nucleotides corresponding to the $8 \mathrm{bp}$ palindromes within the as-1 consensus sequence (last row) are highlighted in bold capitals and written in red colour if they are conserved. Half sites of the palindromes which contain at least 3 of the 4 conserved TGAC nucleotides are marked by arrows. Additionally, the sequence and the position of the as-1 element within the as-1:GUS construct is shown.

\subsection{Recruitment of SCL14 and TGA2 to target promoters}

A powerful method to study the in vivo binding of transcription factors is the chromatin immunoprecipitation (ChIP) assay. Intact leaf tissue was treated with formaldehyde to crosslink promoter-associated proteins to the DNA. After isolation and shearing of the chromatin, protein-DNA complexes were immunoprecipitated with antiserum generated against SCL14 or TGA2,5. The precipitated DNA fragments were subsequently purified 
and analysed by quantitative real-time PCR using primers flanking the TGA binding site (as-1-like element) of the promoters (marked in Table 4-1). The amount of PCR product obtained is indicative for the relative amount of protein bound to the DNA when the tissue was harvested. Thus, ChIP allows detection of quantitative differences in the relative amount of SCL14-DNA and TGA2,5-DNA complexes. To confirm binding of TGA factors to the promoters identified by micro array analysis, chromatin immunoprecipitations (ChIP) of selected promoter fragments were performed with the antiserum against TGA2,5. TGA2,5 is recruited to the target promoters as shown for CYP81D11, MtN19-like and GSTU7 by ChIP analysis of chromatin from wildtype plants (Figure 4-3).

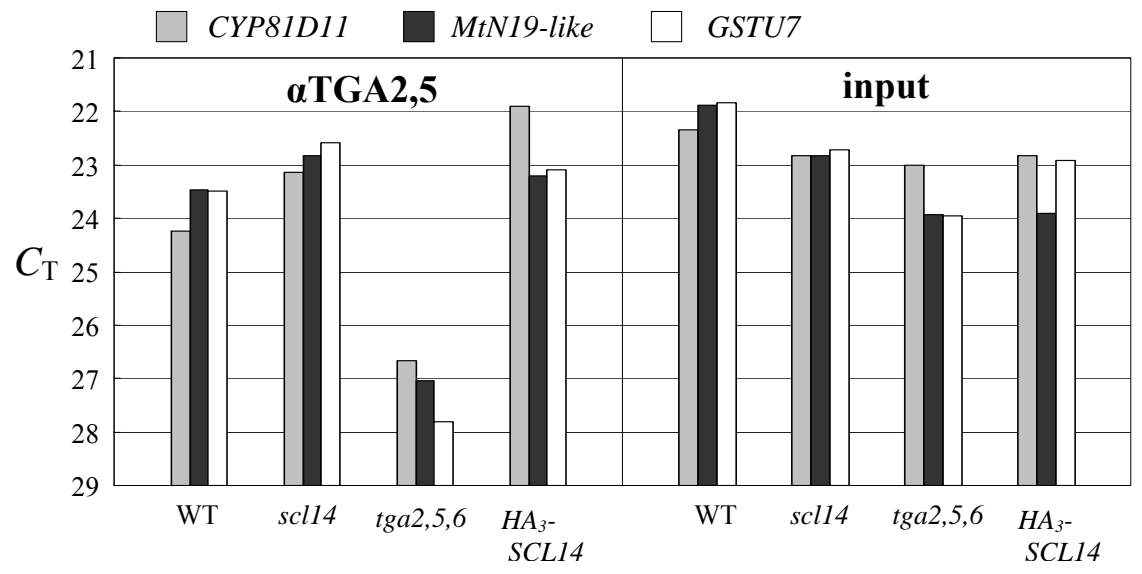

Figure 4-3 In vivo TGA factor binding to the promoters of CYP81D11, MtN19-like and GSTU7 as revealed by chromatin immunoprecipitation analysis

Leaves from five-week-old (short-day) as-1:GUS (WT) plants, plants transformed with the CaMV 35S:HA ${ }_{3}$-SCL14 construct $\left(\mathrm{HA}_{3}\right.$-SCL14), and scl14 and tga2 tga5 tga6 $(\operatorname{tga} 2,5,6)$ mutants were incubated in $1 \%$ formaldehyde before chromatin preparation. Chromatin samples were subjected to immunoprecipitation using $5 \mu \mathrm{l}$ of the $\alpha \mathrm{TGA} 2,5$ antiserum. The DNA was recovered after reversal of the cross-links and analyzed for the enrichment of promoter sequences by quantitative real-time PCR. $C_{\mathrm{T}}$ values are given as a parameter to quantify the amount of PCR products. $C_{\mathrm{T}}$-values obtained from the respective input controls are shown in the right part of the diagram. The amount of precipitated DNA in the tga2,5,6 mutant is strongly reduced compared to wildtype chromatin showing the specificity of the antiserum.

As expected, chromatin from wildtype plants yielded more immunoprecipitated promoter fragments than chromatin from tga2 tga5 tga6 plants, confirming the specificity of the antiserum. The amount of TGA factors at the three promoters tested was similar in wildtype, scl14 and $H A_{3}$-SCL14 plants, which corresponds with the 
amounts of protein detected by Western blot analysis in these plants (Figure 4-4). Thus, TGA factors bind to the as-1-like elements of target promoters independently of SCL14.

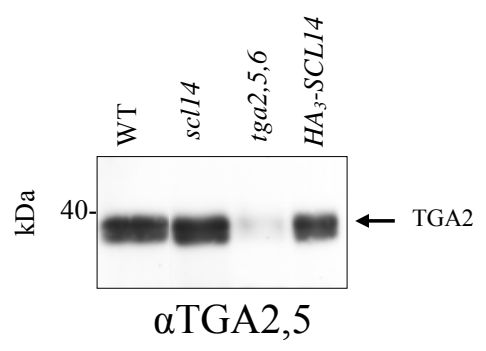

Figure 4-4 Western blot analysis of chromatin samples using the $\alpha$ TGA2,5 antiserum

Chromatin extracted from five-week-old plants grown under short-day conditions was used for Western blot analysis. $5 \mu \mathrm{g}$ of proteins in each sample (determined with BCA Kit) were separated on an $8 \%$ PAA gel. The genotype of the analyzed plants is indicated above the lanes. The $\alpha$ TGA2,5 antiserum was used in a 1:1000 dilution.

The same chromatin used for TGA2,5-ChIP was subjected to immunoprecipitation reactions with the $\alpha$ SCL14 antiserum. As crosslinking with formaldehyde prior to ChIP experiments can also crosslink interacting proteins, binding of SCL14 to TGA2-bound target promoters could be detected even though SCL14 has no own DNA binding ability. This ChIP experiment revealed recruitment of SCL14 to the promoters of CYP81D11, MtN19-like and GSTU7 in chromatin from wildtype plants (Figure 4-5). 


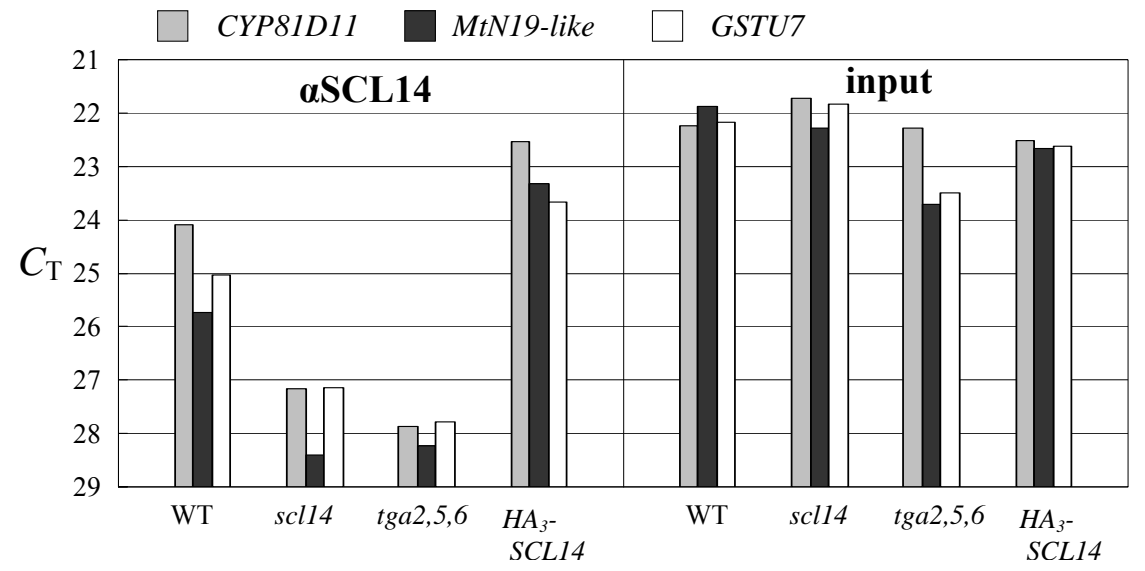

Figure 4-5 In vivo SCL14 binding to the promoters of CYP81D11, MtN19-like and GSTU7 as revealed by chromatin immunoprecipitation analysis

Leaves from five week old (short-day) as-1:GUS (WT) plants, plants transformed with the CaMV $35 S: H_{3}-S C L 14$ construct $\left(H_{3}-S C L 14\right)$, and scl14 and tga2 tga5 tga6 $($ tga2,5,6) mutants were incubated in $1 \%$ formaldehyde before chromatin preparation. Chromatin samples were subjected to immunoprecipitation using $5 \mu \mathrm{l}$ of the $\alpha \mathrm{SCL} 14$ antiserum. The DNA was recovered after reversal of the cross-links and analyzed for the enrichment of promoter sequences by quantitative real-time PCR. $C_{\mathrm{T}^{-}}$ values are given as a parameter to quantify the amount of PCR products. $C_{\mathrm{T}}$-values obtained from the respective input controls are shown in the right part of the diagram. The amount of precipitated DNA in the scl14 mutant is reduced compared to wildtype chromatin proving the specificity of the antiserum.

Chromatin prepared from the scl14 mutant yielded reduced amounts of PCR fragments documenting the specificity of the antiserum. The promoters were also less efficiently immunoprecipitated with the $\alpha$ SCL14 antiserum when chromatin was prepared from the tga2 tga5 tga6 triple mutant. As Western blot analysis proved wildtype levels of SCL14 in these plants (Figure 4-6), the conclusion can be made that TGA factors are required to recruit SCL14 to the target promoters analyzed here. When using the immunoprecipitated DNA from $\mathrm{HA}_{3}$-SCL14 plants, slightly increased amounts of immunoprecipitated promoter fragments were obtained in this experiment, which is consistent with slightly increased protein levels (Figure 2-3) and increased expression of as-1:GUS reporter construct. 


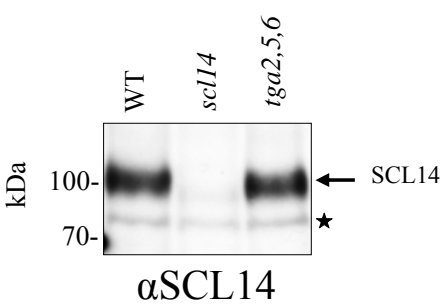

Figure 4-6 Western blot analysis of crude whole cell extracts using the aSCL14 antiserum

Five-week-old plants grown under short-day conditions were used. Amounts of proteins were normalized on a coomassie gel (scanned and quantified with TINA2.0) prior to Western blot analysis. The genotype of the analyzed plants is indicated above the lanes. The $\alpha$ SCL14 antiserum was used in a 1:1000 dilution. The asterisk marks a non-specific band.

\subsection{Expression pattern of SCL14 target genes}

The promoters of the three analyzed genes CYP81D11, MtN19-like and GSTU7 were targets for SCL14 and TGA2,5 binding. This binding occurs independently of any stress stimulus. Investigation of the expression pattern of the three target genes should reveal their possible function and whether binding of SCL14 and TGA2,5 is sufficient to activate their transcription. Tanja Siemsen (2005) showed the SCL14-dependent inducibility of the transgenic as-1:GUS reporter gene by SA and 2,4-D whereas increased GUS gene expression occurs in the SCL14 over-expressing plants. In order to analyze whether the endogenous target genes of SCL14 follow the same expression pattern as as-1:GUS, Arabidopsis plants were treated with 2,4-D (Figure 4-7) and SA (Figure 4-8). RNA from three week old plants treated for $0 \mathrm{~h}$ or $10 \mathrm{~h}$ and $0 \mathrm{~h}, 4 \mathrm{~h}$ or $8 \mathrm{~h}$ with the respective substance was analyzed in quantitative real-time RT-PCR (qRTPCR). This analysis revealed that expression of CYP81D11, MtN19-like and GSTU7 was induced by both chemicals, albeit with different selectivity: whereas expression of CYP81D11 was more responsive to SA than expression of MtN19-like and GSTU7, the latter two genes were more responsive to 2,4-D than CYP81D11. 


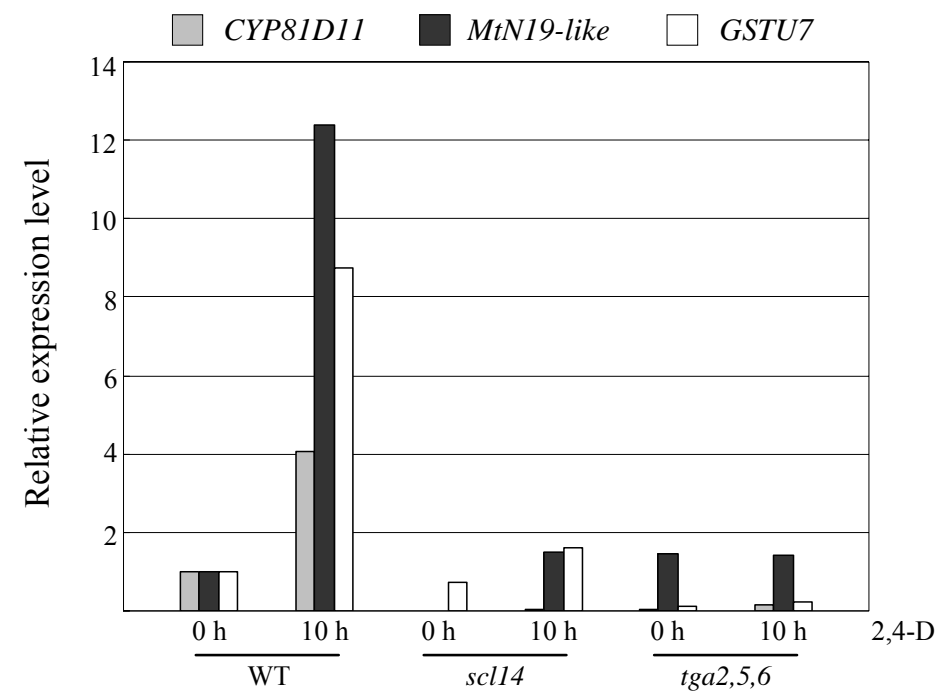

Figure 4-7 Expression of endogenous SCL14 target genes after 2,4-D treatment

Quantitative real-time RT-PCR analysis of relative CYP81D11-, MtN19-like- and GSTU7 transcript levels in as-1:GUS (WT), and scl14 and tga2 tga5 tga6 (tga2,5,6) mutant plants. Three-week-old plants were floated in $50 \mathrm{mM}$ potassium phosphate buffer $\mathrm{pH}$ 5.7, containing $0.1 \mathrm{mM} 2,4-\mathrm{D}$ for the indicated time spans. The values of the three genes in untreated as-1:GUS plants were set to " 1 ".

Overall, expression levels were lower in the scl14 and tga2 tga5 tga6 mutant plants confirming that these genes were regulated at least in part in an SCL14- and TGAdependent manner (Figure 4-7 and Figure 4-8).

Tanja Siemsen has shown previously that the NPR1-dependent $P R-1$ gene expression was unaltered in scl14 mutants and SCL14 over-expressing plants (Siemsen, 2005). In order to analyze the influence of NPR1 on the SCL14 target genes, their expression after SA stimulus in the $n p r 1-1$ was investigated. Induction of all three tested genes by SA was more efficient in npr1-1 mutants than in wildtype plants (Figure 4-8). This effect was most pronounced for CYP81D11, which correlates with its higher responsiveness to SA as compared to the two other genes. 


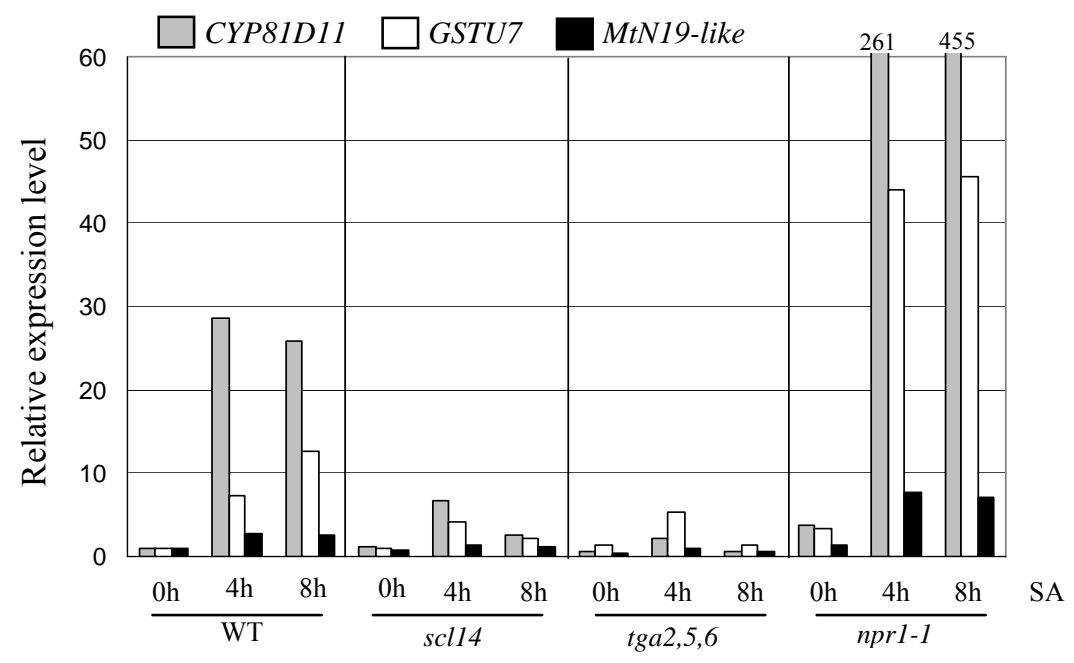

Figure 4-8 Expression of endogenous SCL14 target genes after treatment with SA

Quantitative real-time RT-PCR analysis of relative CYP81D11-, MtN19-like- and GSTU7 transcript levels in as-1:GUS (WT), and scl14, tga2 tga5 tga6 (tga2,5,6) and npr1-1 mutant plants. Three-week-old plants were treated with $1 \mathrm{mM}$ SA for the indicated time spans. The values of the three genes in untreated as1 :GUS plants were set to " 1 ".

To further elucidate the role of SCL14 target genes and to identify additional putative inducing stimuli a Genevestigator V3 Clustering Analysis of the genes that showed the highest difference in the expression levels between transgenic $H A_{3}-S C L 14$ plants and scl14 mutants was performed. This analysis revealed that seven of these genes including CYP81D11, MtN19-like and GSTU7 - belong to a cluster of genes that is upregulated after infection with Botrytis cinerea and Pseudomonas syringae and a variety of different chemicals including hydrogen peroxide $\left(\mathrm{H}_{2} \mathrm{O}_{2}\right)$, TIBA and 2,4-D (Figure 4-9). 


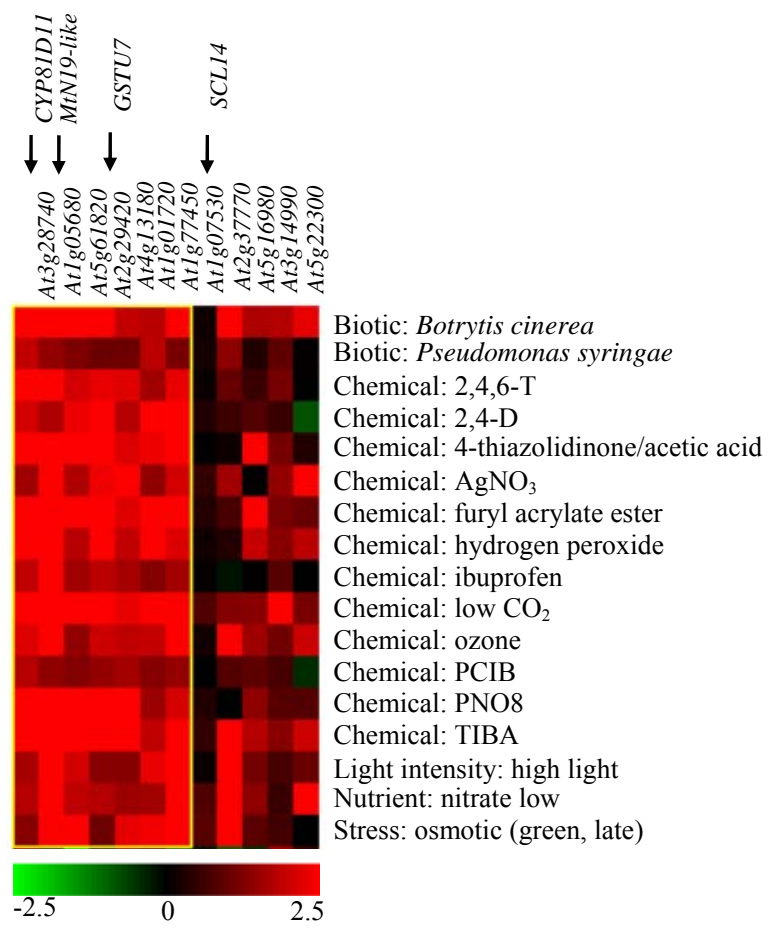

\section{Figure 4-9 Genevestigator V3 Clustering Analysis of genes listed in Table 4-1}

The Bicluster (BiMax algorithm) of genes and stimulus categories (at least 6 columns upregulated after stimulus) is marked by the yellow box. For the genes At4g15760 and At5g61950, no probe sets are available on the 22k Affymetrix array. 2,4,6-T, 2,4,6-trihydroxybenzamide (auxin inhibitor); 2,4-D, 2,4dichlorophenoxyacetic acid; 4-thiazolidinone/acetic acid (auxin signaling inhibitor); $\mathrm{AgNO}_{3}$ (ethylene inhibitor); furyl acrylate ester (auxin signaling inhibitor); ibuprofen (jasmonic acid biosynthesis inhibitor); PCIB: p-chlorophenoxyisobutyric acid (auxin inhibitor); PNO8, N-octyl-3-nitro-2,4,6trihydroxybenzamide (photosystem II inhibitor); TIBA, 2,3,5-triiodobenzoic acid (auxin transport inhibitor).

\subsubsection{The SA analogue 2,6-isonicotinic acid induces the SCL14 target genes in a TGA-dependent manner}

In order to investigate more putative inducers of SCL14 dependent target genes, 5 week-old plants were treated with $1 \mathrm{mM}$ 2,6-isonicotinic acid (INA) a functional homologue of SA often used to induce $P R$ gene expression. The expectation that INA exhibits the same inducing potential compared to SA was confirmed by analyzing RNA of the INA treated plants by qRT-PCR. The expression of the target genes was activated by INA in a SCL14 and TGA dependent manner (Figure 4-10). Moreover, a hyperinducibility of the genes in $H_{3}$-SCL14 expressing plants was observed. This in fact fits 
with the heightened levels of the as-1:GUS reporter transcript in those plants (Siemsen, 2005) after SA or 2,4-D treatment.

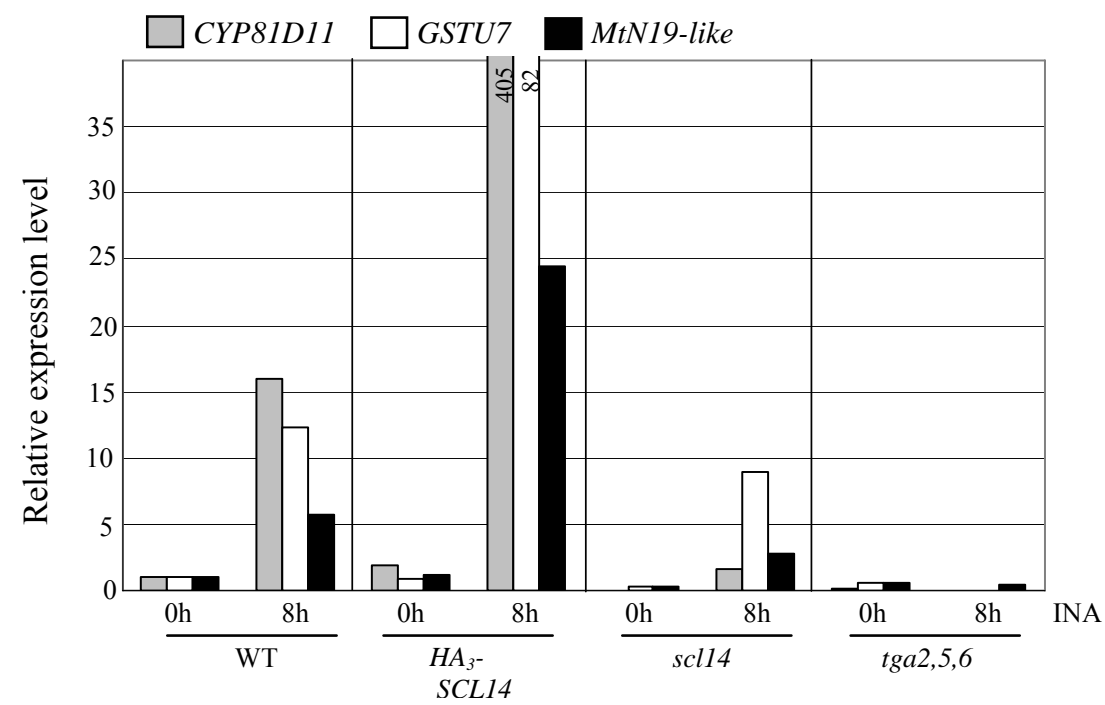

Figure 4-10 Expression of endogenous SCL14 target genes after INA treatment

Quantitative real-time RT-PCR analysis of relative CYP81D11-, MtN19-like- and GSTU7 transcript levels in as-1:GUS (WT), HA 3 -SCL14 expressing plants, scl14and tga2 tga5 tga6 (tga2,5,6) mutant plants. Fiveweek-old plants were sprayed with $1 \mathrm{mM}$ INA and incubated for the indicated time spans. The values of the three genes in untreated as-1:GUS plants were set to " 1 ".

However, these results could not clearly answer the question what kind of stimulus is needed for activation of SCL14 dependent target genes. The investigated substances SA, INA and 2,4-D all have phytohormonal (the latter one as auxin analogue) as well as xenobiotic character depending on their concentration and electrophilic character due to their reactive side groups.

\subsubsection{Hydrogen peroxide triggers the SCL14-dependent activation of CYP81D11, MtN19-like and GSTU7}

Next, hydrogen peroxide was analyzed for its inducing properties. RNA from plants floated $0 \mathrm{~h}$ or $8 \mathrm{~h}$ in potassium phosphate buffer containing $16 \mathrm{mM}$ hydrogen peroxide was analyzed in qRT-PCR. The target genes CYP81D11, MtN19-like and GSTU7 were induced by hydrogen peroxide in wildtype plants. This induction is independent of NPR1 (unaltered in npr1-1 mutants). In contrast to the induction with SA (Figure 4-8), 
transcript levels of target genes are not hyperinducible in the npr1-1 mutants. In the SCL14 over-expressing plants expression levels of the three genes are increased even under non-inducing conditions but only CYP81D11 transcript is hyperinducible by hydrogen peroxide in these plants. This constitutive expression was already observed for the GUS gene in those plants (Siemsen, 2005).

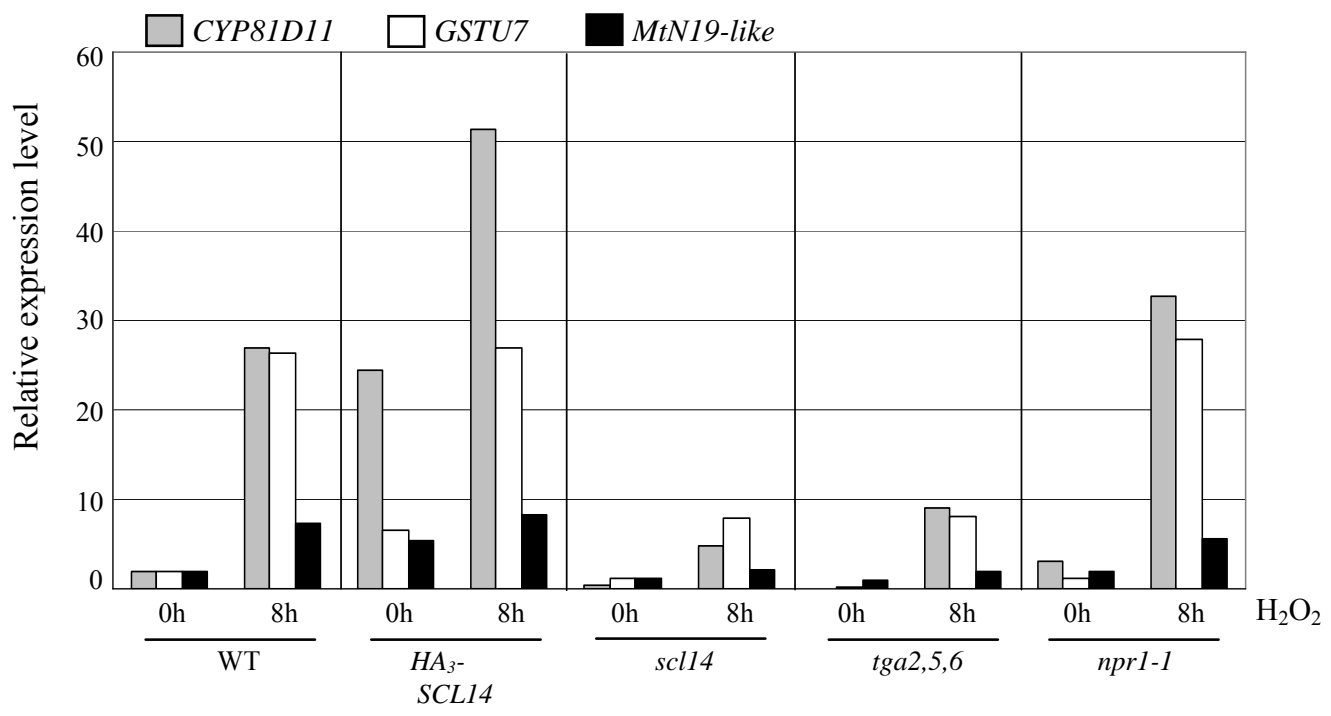

Figure 4-11 Expression of endogenous SCL14 target genes after treatment with hydrogen peroxide

Quantitative real-time RT-PCR analysis of relative CYP81D11-, MtN19-like- and GSTU7 transcript levels in as-1:GUS (WT), HA 3 -SCL14expressing plants, scl14, tga2 tga5 tga6 (tga2,5,6) and npr1-1 mutant plants. Three-week-old, MS-grown plants were floated in $50 \mathrm{mM}$ potassium phosphate buffer $(\mathrm{pH} 5,7)$ containing $16 \mathrm{mM} \mathrm{H}_{2} \mathrm{O}_{2}$ for the indicated time spans. The values of the three genes in untreated as-1:GUS plants were set to " 1 ".

The induction of the SCL14 target genes by hydrogen peroxide treatment depends at least partly on SCL14 and the TGA factors as their expression is reduced in the scl14 and the tga2,5,6 mutant.

\subsubsection{The chemical TIBA elicits SCL14 and TGA dependent expression of CYP81D11}

2,3,5-triiodobezoic acid (TIBA), a compound known to inhibit auxin transport, was one of the strongest inducers of the genes identified in the micro array experiment as revealed by Genevestigator analysis (Figure 4-9). RNA from three week old plants 
grown on MS-medium and treated for $0 \mathrm{~h}$ or $10 \mathrm{~h}$ with TIBA was analyzed by qRTPCR analysis. The genes CYP81D11, MtN19-like and GSTU7 were induced in wildtype plants. Similar to the results obtained with SA, INA and 2,4-D, induction of the three tested genes depends on SCL14 and TGA2, TGA5 or TGA6 (Figure 4-12).

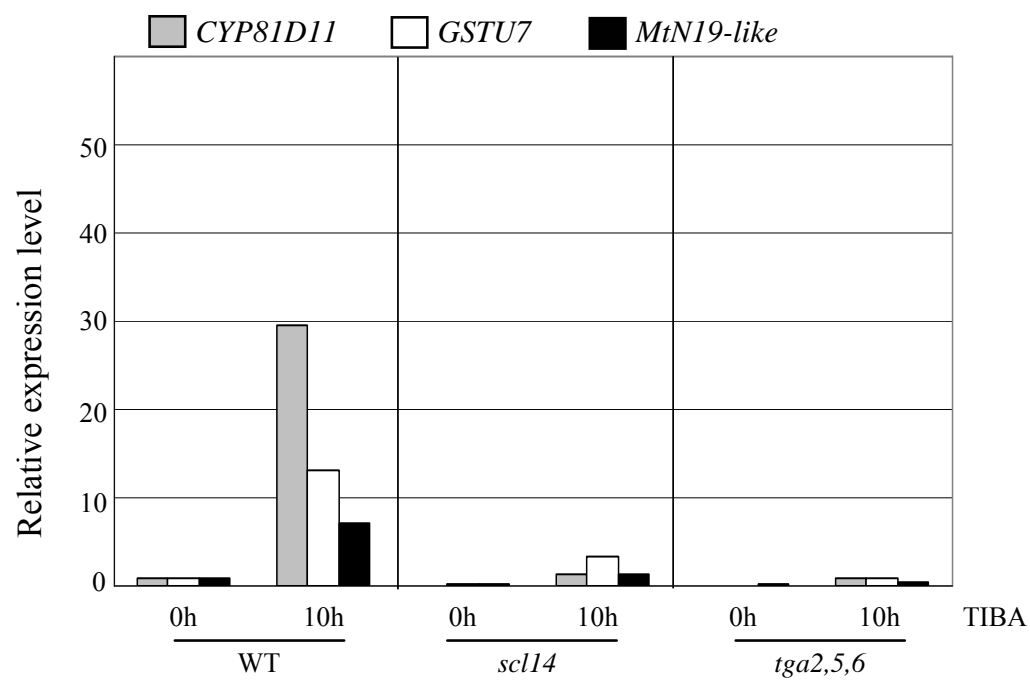

Figure 4-12 Expression of endogenous SCL14 target genes after treatment with TIBA

Quantitative real-time RT-PCR analysis of relative CYP81D11-, MtN19-like- and GSTU7 transcript levels in as-1:GUS (WT), scl14 and tga2 tga5 tga6 (tga2,5,6) mutant plants. Three-week-old plants grown on MS plates were treated with $0.1 \mathrm{mM}$ TIBA for 10 hours. The values of the three genes in untreated as$1: G U S$ plants were set to " 1 ".

\subsubsection{Complementation of the scl14 mutant}

Taken together, the three SCL14 target genes CYP81D11, MtN19-like and GSTU7 are inducible by a variety of substances (SA, INA, 2,4-D, $\mathrm{H}_{2} \mathrm{O}_{2}$ and TIBA). To control whether the observed differences in the relative expression levels of the SCL14 target genes between wildtype and scl14 mutants only refer to the loss of SCL14 protein, the scl14 mutant was complemented with ectopically expressed SCL14.

Expression of SCL14 (untagged) under the control of the CaMV $35 S$ promoter restored TIBA-dependent induction of CYP81D11 transcript in the scl14 mutants (Figure 4-13). Western blot analysis confirmed accumulation of SCL14 protein similar to wildtype levels in different transgenic lines (Figure 4-13). This experiment demonstrates that the defects of transcriptional activation in the scl14 mutants are due to the lack of SCL14. 


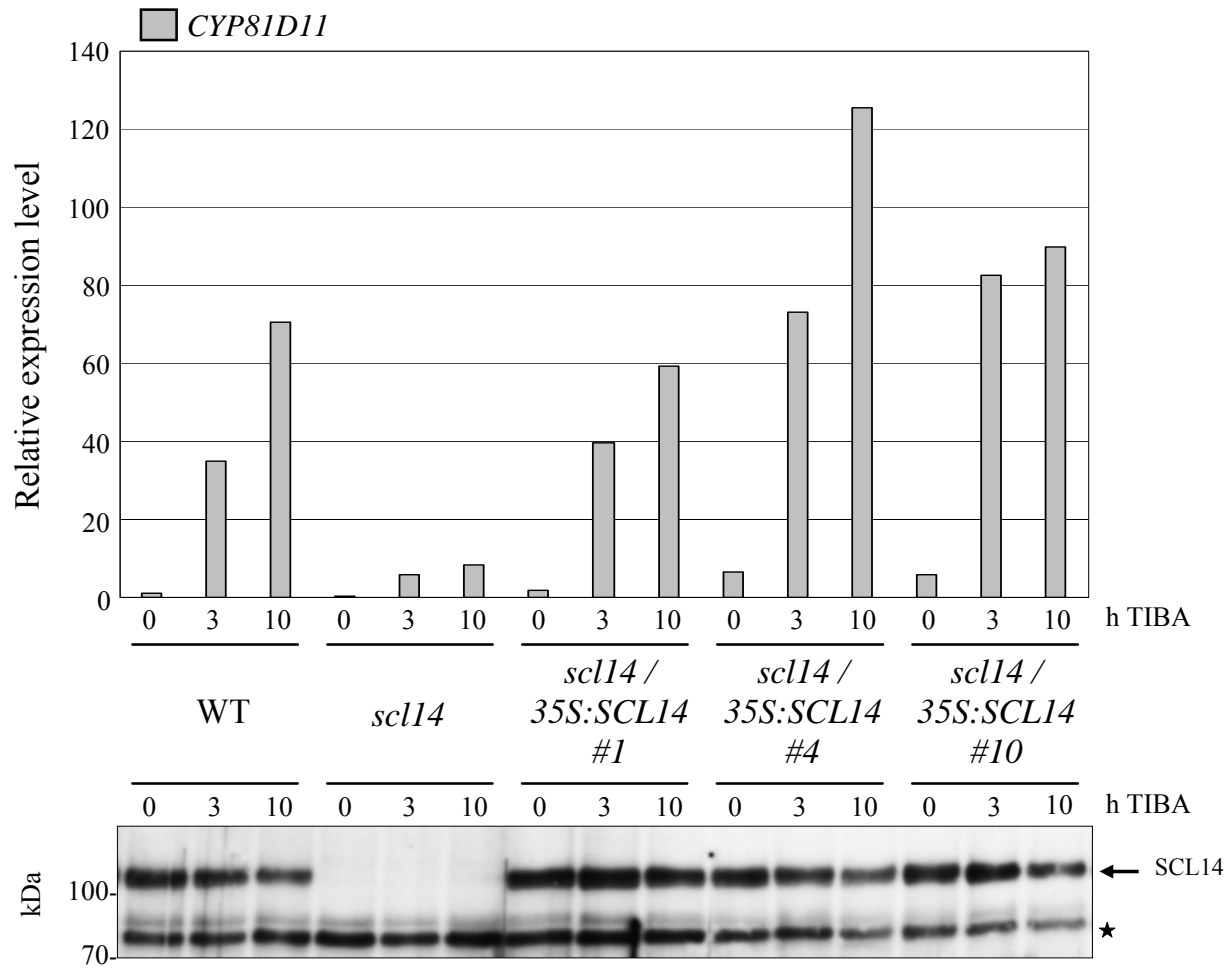

Figure 4-13 Complementation of the scl14 mutant phenotype

Quantitative real-time RT-PCR analysis (upper panel) of relative CYP81D11 transcript levels in as1:GUS (WT), as-1:GUS/scl14 (scl14), and three independent transgenic lines expressing SCL14 under the control of the CaMV 35S promoter in the as-1:GUS/scl14 mutant background (scl14/35S:SCL14). Three-week-old plants grown on MS plates were treated with $0.1 \mathrm{mM} \mathrm{2,3,5-triiodobenzoic} \mathrm{acid} \mathrm{(TIBA)}$ and incubated for further 10 hours. The expression value in untreated as-1:GUS plants was set to "1".

Crude protein extracts of the plants used for quantitative real-time RT-PCR analysis were subjected to Western blot analysis with the aSCL14 antiserum (lower panel). The antiserum was used in a 1:1000 dilution. The asterisk marks an unspecific band that serves as a loading control.

\subsubsection{SCL14 binding to DNA is not influenced by TIBA}

The auxin transport inhibitor TIBA efficiently increases the expression of SCL14dependent target genes like CYP81D11 (Figure 4-13). To study if this induction is reflected on the level of DNA binding of SCL14, ChIP experiments with chromatin from TIBA-treated wildtype plants were performed. The same wildtype plant material from the complementation experiment (Figure 4-13) was used in this experiment. The untreated scl14 mutant serves as a control for the specificity of the $\alpha$ SCL14 antiserum. 


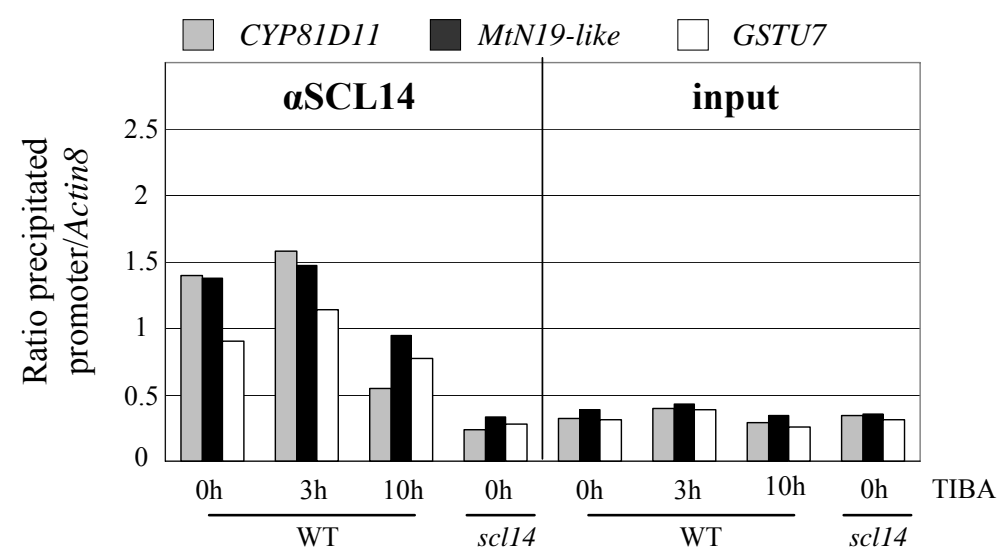

Figure 4-14 In vivo SCL14 binding to the promoters of CYP81D11, MtN19-like and GSTU7 after treatment with TIBA as revealed by chromatin immunoprecipitation analysis

Leaves from as-1:GUS (WT) plants treated 3 or 10 hours with $0.1 \mathrm{mM}$ TIBA and scl14 mutants were incubated in $1 \%$ formaldehyde before chromatin preparation. Chromatin samples were subjected to immunoprecipitation using $5 \mu \mathrm{l}$ of the $\alpha$ SCL14 antiserum. The DNA was recovered after reversal of the cross-links and analyzed for the enrichment of promoter sequences by quantitative real-time PCR. In this diagram the ratio between the respective precipitated promoter fragments and unspecifically precipitated Actin 8-DNA is depicted. Therefore, $C_{\mathrm{T}}$-values obtained from the real-time PCR for the target promoters were set off with $C_{\mathrm{T}}$-values for Actin8 with the $2^{-\Delta C_{\mathrm{T}}}$ method to normalize the amount of DNA in all preparations. Input controls are shown in the right part of the diagram.

The ratio between the specific promoter fragments and residual Actin8 DNA (this "contamination" should be equal in all samples prepared with the same antiserum) as depicted in Figure 4-14 reflects the amount of precipitated target promoter DNA. An increased ratio in the samples compared to the respective input controls demonstrates enrichment of specific promoter fragments by immunoprecipitation. The ratio in the scl14 mutant is equal to the input control, showing that $\alpha$ SCL14 antiserum failed to enrich specific promoter fragments in the mutants, thus showing the specificity of the antiserum. In contrast, the ratio of specific promoter fragments to Actin8 fragments is increased in aSCL14-precipitated chromatin from wildtype plants, demonstrating recruitment of SCL14 to the target promoters in the uninduced wildtype plants. The binding of SCL14 remains nearly unaltered during treatment with TIBA. After $10 \mathrm{~h}$ of treatment the amounts of DNA-bound SCL14 are slightly decreased. This observation correlates with detected protein levels of SCL14 (Figure 4-15). Nevertheless, transcription of the target genes is activated after $10 \mathrm{~h}$ of treatment with TIBA (Figure 4-12) suggesting that binding of SCL14 alone is not sufficient to activate target gene promoters. Regulation of transcriptional activation might be achieved on another level, 
e.g. modification of SCL14 or the TGA factors or removal of an additionally bound repressor protein.

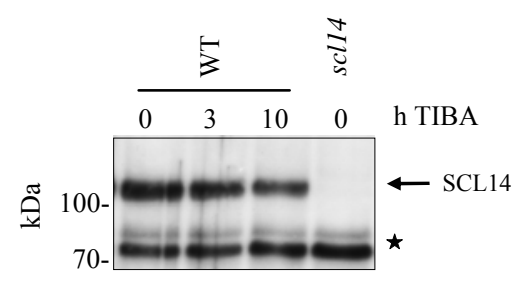

Figure 4-15 Abundance of SCL14 protein in TIBA-treated plants

Three-week-old plants grown on MS plates were treated with $0.1 \mathrm{mM}$ 2,3,5-triiodobenzoic acid (TIBA) and incubated for further 10 hours. Crude protein extracts of the plants indicated above the lanes were subjected to Western blot analysis with the $\alpha \mathrm{SCL} 14$ antiserum. The antiserum was used in a 1:1000 dilution. The asterisk marks an unspecific band that serves as a loading control.

\subsection{Influence of SCL14 protein levels on tolerance of Arabidopsis to xenobiotic stress}

The coding region of the SCL14 target genes imply that they might play a role in detoxification processes; this is consistent with the fact that transcription of these genes is efficiently induced by xenobiotic substances. To investigate whether this transcriptional activation can actually lead to resistance of plants to xenobiotics the performance of plants with different SCL14 protein levels and the tga,2,5,6 mutants on medium containing different xenobiotic stressors was assayed. Therefore seeds of the different plant genotypes were directly germinated on MS-plates containing SA, INA or TIBA.

The general growth and development was strongly affected for all plants germinating on MS-plates containing $0.05 \mathrm{mM} \mathrm{SA}$ (Figure 4-16). But, consistent with the loss of transcriptional activation of SCL14 target genes, growth of scl14 and tga2,5,6 mutants are affected more strongly. In addition, SCL14 overexpressing plants (HA $A_{3}$ SCL14) were more tolerant to SA, which correlates with hyper-inducibility of the SCL14/ TGAdependent target genes (Figure 4-10, Figure 4-11). 


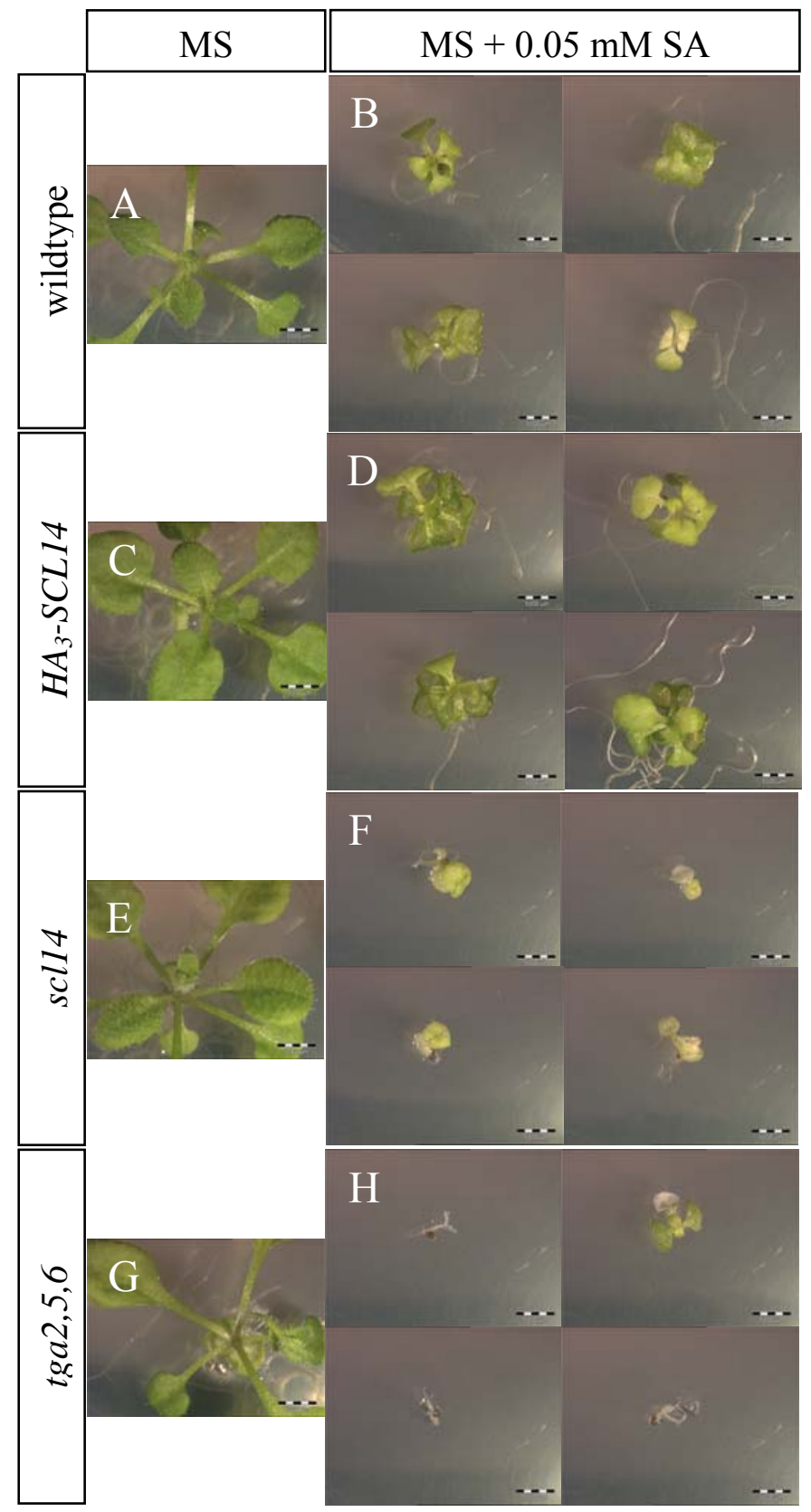

Figure 4-16 Seedling development on MS-plates containing SA

All plants on the right pictures were grown for 3 weeks on MS plates containing $0.05 \mathrm{mM}$ salicylic acid (SA). The pictures on the left show the respective plants on MS plates without SA. Wildtype plants (as1:GUS) show a reduction in growth (A, control; $\mathrm{B}$, grown on SA), 35S:HA 3 -SCL14 expressing plants are more resistant (C, control; D, grown on SA). Both mutants, scl14 and tga2,5,6 can hardly grow on plates containing SA (E,G, respective controls; F,H, respective mutants germinated on SA). The scale bar marks $2 \mathrm{~mm}$.

The observed differences in tolerance to chemical stress are even more pronounced when plants germinate on MS plates containing 0.1 mM INA (Figure 4-17). Actually, tolerance to INA also correlates with the ability of the different plants to activate 
transcription of SCL14/TGA dependent genes (Figure 4-8). The respective mutants fail to activate these genes and thus fail to tolerate the xenobiotic levels of INA.

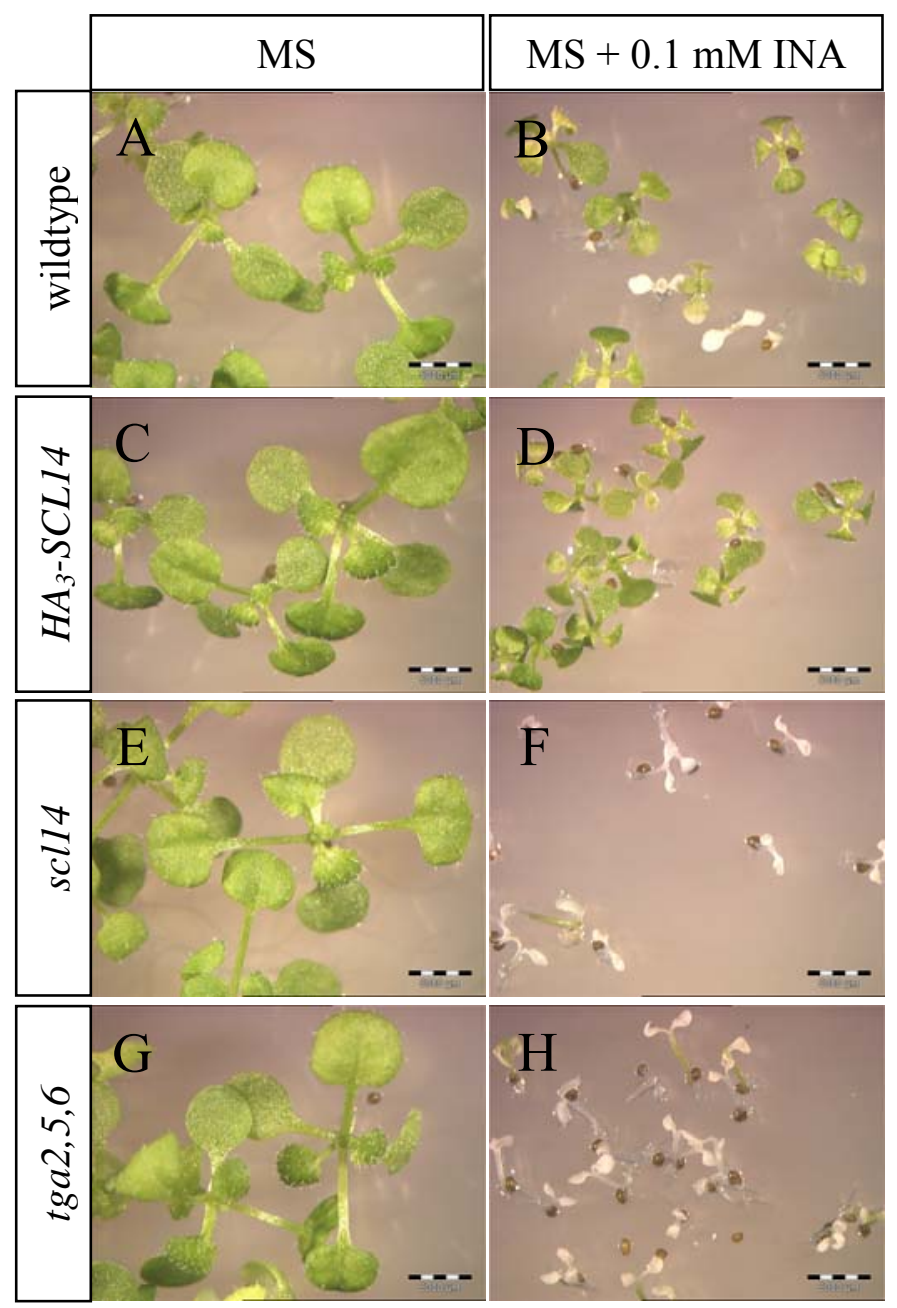

Figure 4-17 Seedling development on MS-plates containing INA

All plants on the right pictures were grown for 3 weeks on MS plates containing $0.1 \mathrm{mM}$ isonicotinic acid (INA). The pictures on the left show the respective plants on MS plates without INA. Wildtype plants (as1:GUS) show a reduction in growth (A, control; $\mathrm{B}$, grown on INA), 35S:HA 3 -SCL14 expressing plants are more resistant (C, control; D, grown on INA). Both mutants, scl14 and tga2,5,6 can not survive on INA (E,G, respective controls; F,H, respective mutants germinated on INA). The scale bar marks $5 \mathrm{~mm}$.

\subsubsection{Complementation of the growth defect of scl14 mutants on xenobiotics}

Consistent with the results for transcriptional activation, where TIBA elicits the strongest induction of SCL14 target genes, plants are most affected on MS plates containing $0.1 \mathrm{mM}$ TIBA. Even wildtype plants can hardly survive. The restriction of 
root elongation and general growth of the seedling only allows the plants to develop the first pair of leaves following the cotyledons (Figure 4-18 B). However, overexpression of SCL14 again leads to an increase in ability to cope with the xenobiotic stress, whereas, neither the scl14 mutants nor the tga2,5,6 mutants can survive on TIBA.

Ectopic expression of SCL14 (untagged) under the control of the $35 S$ promoter in the scl14 mutant (Figure 4-18 J, here shown for scl14/ 35S:SCL14 line \#10) led to a wildtype-like tolerance to TIBA, showing that SCL14 is sufficient to tolerate xenobiotic stress. 


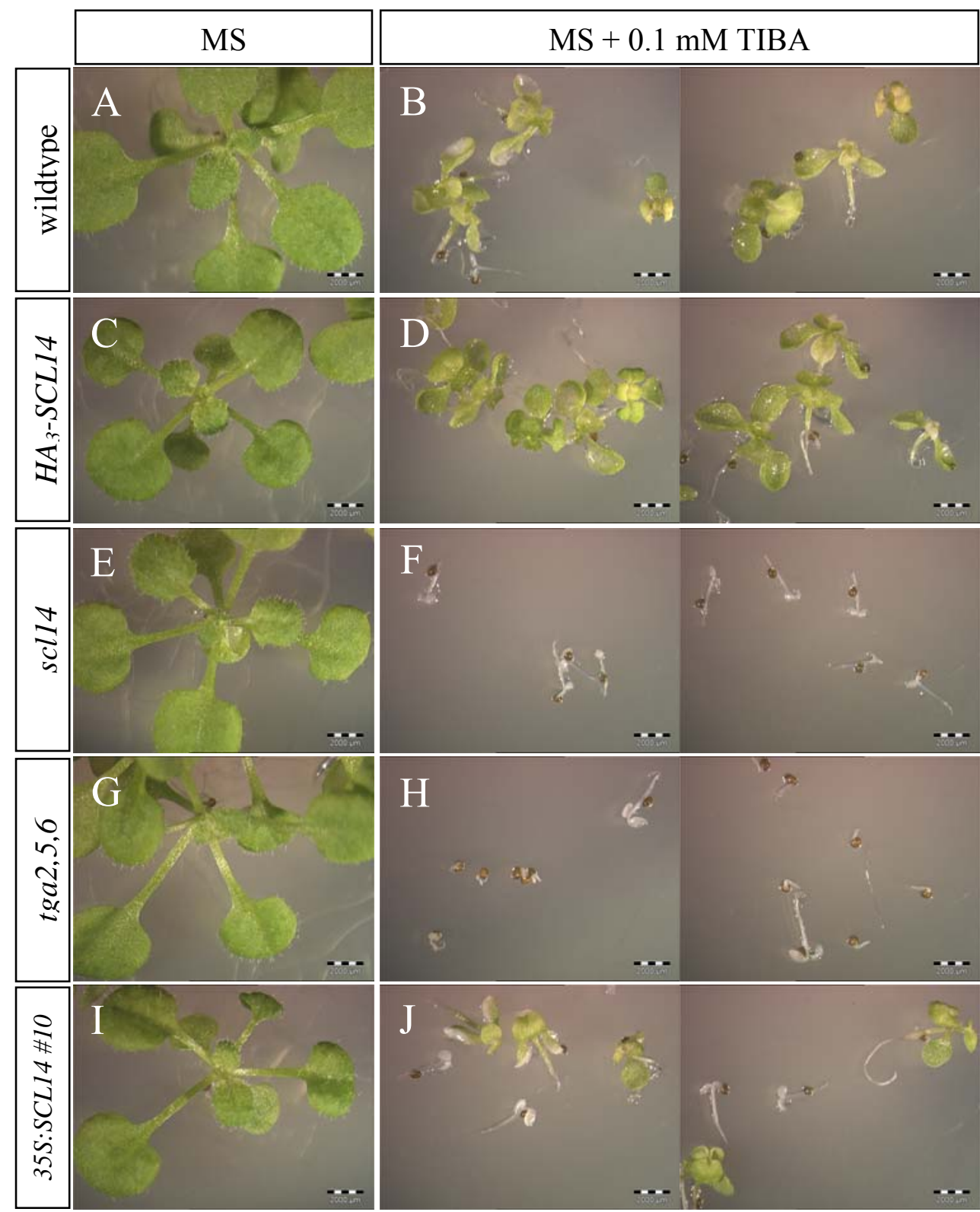

Figure 4-18 Seedling development on MS-plates containing TIBA

All plants on the right pictures (two plates are shown exemplarily for each genotype) were grown for 3 weeks on MS plates containing $0.1 \mathrm{mM}$ 2,3,5-triiodobenzoic acid (TIBA). The pictures on the left show the respective plants on MS plates without TIBA. Wildtype plants (as-1:GUS) show a strong reduction in growth but can survive (A, control; B, grown on TIBA), 35S:HA $-S C L 14$ expressing plants are more resistant to xenobiotics (C, control; D, grown on TIBA). Both mutants, scl14 and tga2,5,6 can not survive on TIBA (E,G, respective controls; F,H, respective mutants germinated on TIBA) but survival can be restored by expressing 35S:SCL14 in the scl14 mutant background (I, control; J, scl14/ 35S:SCL14 \#10 grown on TIBA). The scale bar in the pictures marks $5 \mathrm{~mm}$.

To quantify the observed differences in tolerance against xenobiotics 100 seeds per genotype were germinated on MS medium containing SA, INA or TIBA. Determination of the fresh weight of germinated plants after three weeks (not-germinated seeds were 
counted as $0 \mathrm{mg}$ ) confirmed that the mutants accumulated less biomass than the wildtype (Figure 4-19). Increased accumulation of biomass exhibited by the $\mathrm{HA}_{3}$-SCL14 plants was detected only after TIBA treatment.

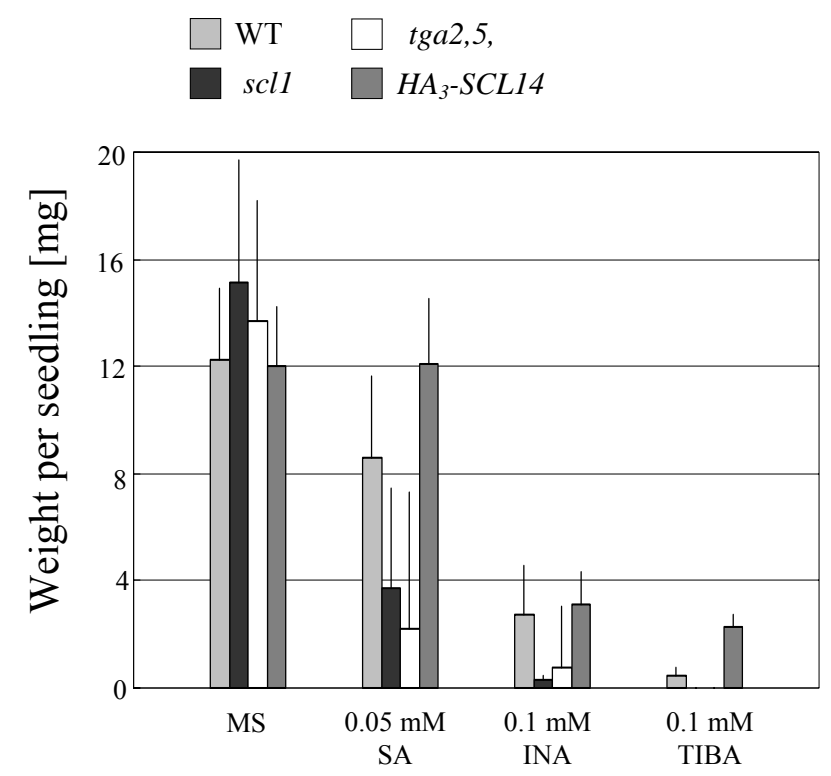

Figure 4-19 Determination of the fresh weight of seedlings grown on MS plates containing different xenobiotics

All indicated genotypes were grown for three weeks on MS plates containing either no xenobiotic (MS), $0.05 \mathrm{mM}$ SA, $0.1 \mathrm{mM}$ INA or $0.1 \mathrm{mM}$ TIBA. For each treatment and genotype 100 seeds from five individual plates were weighted.

\subsection{Identification of SCL14-dependent genes under inducing conditions}

As SCL14 contributes to tolerance of plants to xenobiotics like TIBA, micro array experiments comparing scl14 mutants and wildtype plants after TIBA treatment were performed to reveal additional target genes for SCL14 specifically regulated by xenobiotic stress.

RNA derived from about 50 plantlets of wildtype plants and scl14 mutants grown aseptically for 21 days on MS medium induced with TIBA for 10 hours was hybridized with Arizona whole genome micro arrays. 


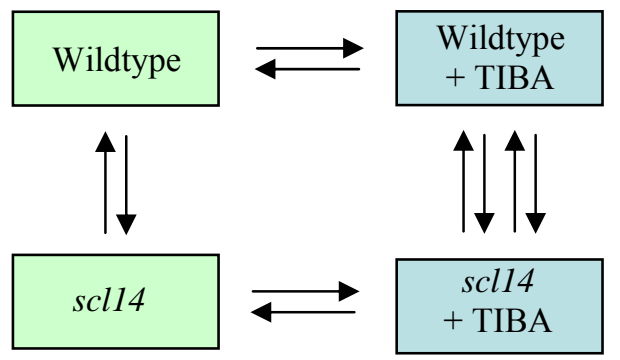

Figure 4-20 Scheme of the micro array analysis of TIBA-induced plants

RNA extracted from about 50 two week old, MS-grown plantlets for each genotype either uninduced or sprayed with $0.1 \mathrm{mM}$ TIBA for $10 \mathrm{~h}$ was hybridized with Arizona whole genome array slides. Each arrow stands for an independent micro array slide.

84 genes including SCL14 showed an over 2.5-fold $\left(\log _{2}\right)$ up-regulation in induced wildtype plants compared to scl14 mutants induced with TIBA. 37 genes were regulated in a reciprocal manner (see supplemental data for the complete list comparing all conditions). The genes were clustered (Table 4-2) for their differential expression under non-inducing conditions and their altered TIBA-inducibility in the scl14 mutants. Those marked in gold are the most promising candidates, because they are already reduced in the scl14 mutant under non-inducing conditions and TIBA treatment fails to induce those genes in scl14 mutants albeit strongly induces them if SCL14 is present. 
Table 4-2 Short list of the up-regulated genes in micro array analysis comparing wildtype (WT) and scl14 mutant (scl14) after TIBA treatment

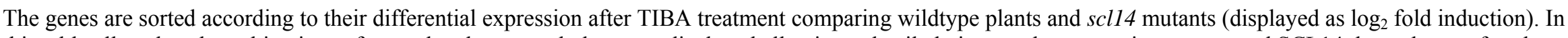
this table all analysed combinations of treated and untreated plants are displayed allowing a detailed view on the expression pattern and SCL14 dependency of each gene. Red marked AGI codes indicate genes also found to be SCL14-dependent in the initial micro array experiment using only uninduced plants. The complete micro array analysis is listed in supplemental data

\begin{tabular}{|c|c|c|c|c|c|}
\hline AGI code & Gene Description & $\begin{array}{c}\text { Wt (TIBA)I } \\
\text { scl14 (TIBA) }\end{array}$ & Wt/ scl14 & $\begin{array}{c}\text { scl14 (TIBA)I } \\
\text { scl14 }\end{array}$ & $\begin{array}{c}\text { Wt (TIBA)! } \\
\text { Wt }\end{array}$ \\
\hline At3g59140 & ATMRP14 & 4,57 & 1,69 & 0,04 & 2,92 \\
\hline At2g29490 & ATGSTU1 & 4,39 & 2,05 & 1,96 & 4,3 \\
\hline At4g08555 & unknown protein & 4,33 & 0,99 & 2,51 & 5,85 \\
\hline At1g77120 & $\mathrm{ADH} 1$ & 4,1 & 2,18 & 0,44 & 2,36 \\
\hline At3g28740 & CYP81D11 & 4,07 & 2,96 & 4,22 & 5,34 \\
\hline At5g53990 & glycosyl transferase & 3,87 & 3,57 & 0,38 & 0,69 \\
\hline At3g43190 & UDP-glycosyltransferase & 3,73 & 3,66 & $-0,06$ & 0,01 \\
\hline At1g77450 & ANAC032 & 3,7 & 2,47 & 0,51 & 1,75 \\
\hline At4g37290 & unknown protein, F6G17.7 & 3,59 & 0,07 & 0,05 & 3,57 \\
\hline At5g22140 & disulfide oxidoreductase & 3,52 & 1,81 & 2,72 & 4,42 \\
\hline At1g17170 & ATGSTU24 & 3,45 & 2,6 & 3,43 & 4,28 \\
\hline At5g61820 & MAC9.6 MtN19-like & 3,42 & 2,06 & 0,98 & 2,33 \\
\hline At3g50970 & XERO2 & 3,36 & 2,8 & 2,02 & 2,58 \\
\hline At4g34131 & UDP-glycosyltransferase & 3,33 & 1,46 & 2,31 & 4,19 \\
\hline At1g67810 & Fe-S metabolism associated domain-containing protein & 3,28 & 0,62 & 1,88 & 4,55 \\
\hline At1g05680 & UDP-glycosyltransferase & 3,26 & 1,01 & 3,3 & 5,54 \\
\hline At1g18970 & GLP4 & 3,25 & 2,25 & 0,87 & 1,86 \\
\hline At5g06090 & ATGPAT7/GPAT7 & 3,23 & 2,4 & 1,59 & 2,42 \\
\hline At1g17180 & ATGSTU25 & 3,22 & 1,35 & 0,52 & 2,38 \\
\hline At2g29420 & ATGSTU7 & 3,21 & 1,48 & 1,71 & 3,44 \\
\hline At1g07530 & SCL14 & 3,2 & 3,51 & $-0,16$ & $-0,46$ \\
\hline At1g62570 & disulfide oxidoreductase & 3,19 & 2,34 & 0,06 & 0,92 \\
\hline At1g14130 & oxidoreductase & 3,18 & 0,7 & 1,04 & 3,52 \\
\hline At3g10880 & unknown protein, T7M13.4 & 3,17 & $-0,02$ & 0,87 & 4,07 \\
\hline At3g04890 & unknown protein, T9J14.16 & 3,09 & 1,47 & 0,39 & 2,01 \\
\hline
\end{tabular}




\begin{tabular}{|l|l|r|r|r|r|}
\hline At2g34660 & ATMRP2 & 3 & 0,93 & $-0,55$ \\
At1g55020 & LOX1 & 2,98 & 1,53 & 1,76 & 0,22 \\
At1g05560 & UGT1 & 2,98 & 1,72 & 2,3 \\
At2g29480 & ATGSTU2 & 2,94 & 0,68 & 1,31 \\
At1g78340 & ATGSTU22 & 2,88 & 3,57 & 3,57 \\
At4g14630 & GLP9 & 2,86 & 2,39 & 1,05 \\
At2g02120 & LCR70/PDF2.1; protease inhibitor & 2,81 & 0,55 \\
\hline
\end{tabular}

in scl14 reduced, only inducible by TIBA in $\mathrm{Wt}$

in scl14 reduced, stronger inducible by TIBA in $\mathrm{Wt}$

in scl14 reduced, not inducible by TIBA (SCL14)

in scl14 unchanged 
TAIR based analysis (http:/wwww.arabidopsis.org) of the genes listed in Table 4-2 shows an over representation of transport related genes (Figure 4-21, 5), abiotic stimulus related genes (Figure 4-21, 8) and stress related genes (Figure 4-21, 11) in the array compared to the functional distribution of all genes in the Arabidopsis genome (Figure 4-21).

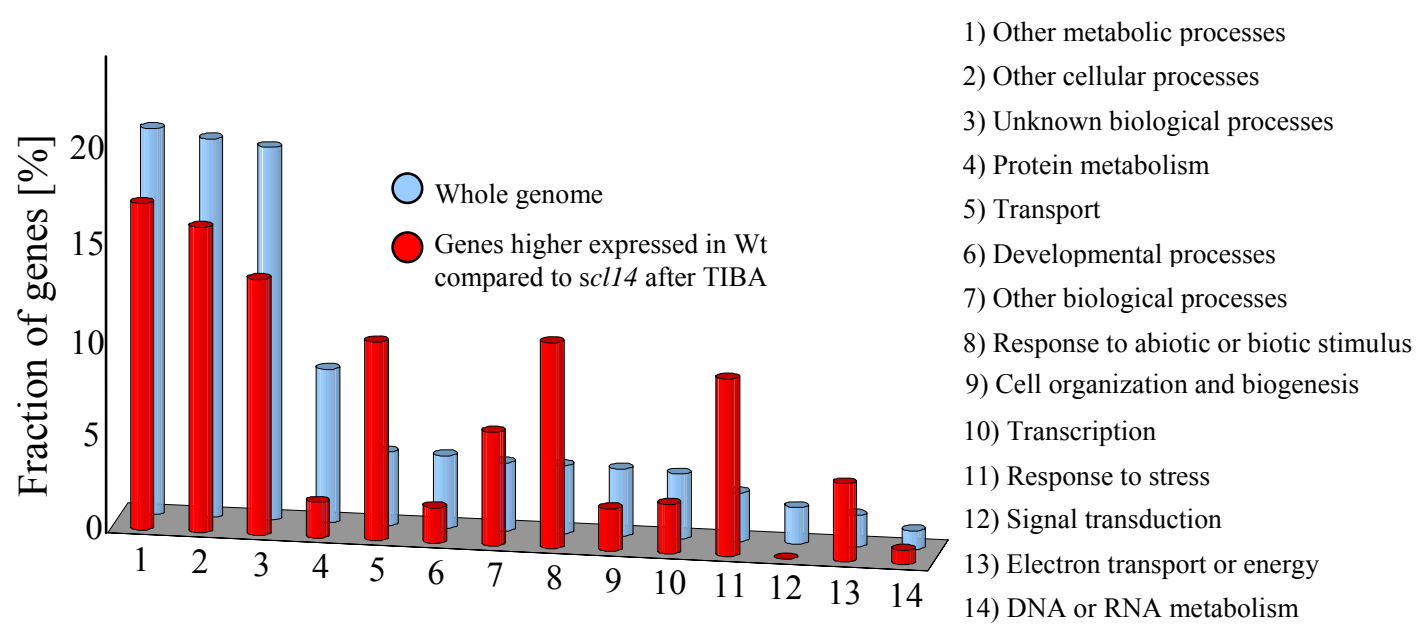

Figure 4-21 Functional distribution of genes higher expressed in wildtype plants compared to scl14 mutants after TIBA treatment

The functional distribution of genes in the whole Arabidopsis genome (blue) and the performed micro array based comparison between wildtype and scl14 mutants after TIBA treatment (red). Classification was performed with TAIR GO classification database tools.

Among these genes, a lot of stress related genes like cytochrome P450 family members or glutathione-S-transferases are induced (Figure 4-22). All of them showed an over 2.7-fold $\left(\log _{2}\right)$ difference when comparing the expression in wildtype plants versus expression in the scl14 mutant after TIBA treatment. 7 out of the up-regulated genes were originally identified as SCL14 dependent genes in the initial micro array experiment comparing uninduced conditions of wildtype and scl14 mutants (referring to the short list published by Tanja Siemsen, 2005). 


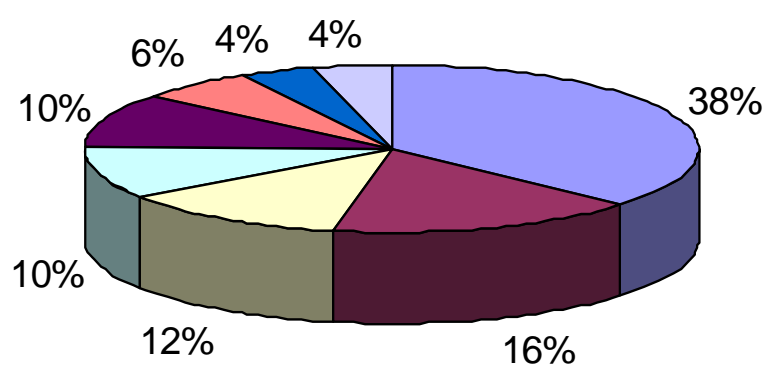

$\square$ others

$\square$ unknown

$\square$ glutathione-S-transferases

$\square$ cytochrome P450s

$\square$ glycosyltransferases

$\square$ oxidoreductases

$\square$ multidrug resistance proteins

$\square$ transcription factors

Figure 4-22 Distribution of up-regulated genes after TIBA induction comparing wildtype and scl14 mutants

The functional classification was performed by TAIR database analysis.

\subsubsection{Verification of TIBA-induced SCL14 target genes}

From the genes listed in Table 4-2 putative target genes were selected for quantitative real-time RT-PCR analysis. ATGSTU1 contains an as-1-like element in the promoter, thus represents a putative direct target gene for SCL14/ TGA dependent regulation. The ADH1 gene showed the greatest differences (beside ATMRP14 and ANAC032) in expression between wildtype and scl14 mutant plants under induced and non-induced conditions. ATMRP2 was also found to be induced by treatment with electrophile phytoprostanes $\mathrm{PPA}_{1}$ (Mueller et al., 2008) demonstrating association of this gene to electrophile/ xenobiotic stress responses. These three genes were analysed in an independently performed TIBA induction experiment to reproduce the achieved data from the micro array analysis (Figure 4-23). 


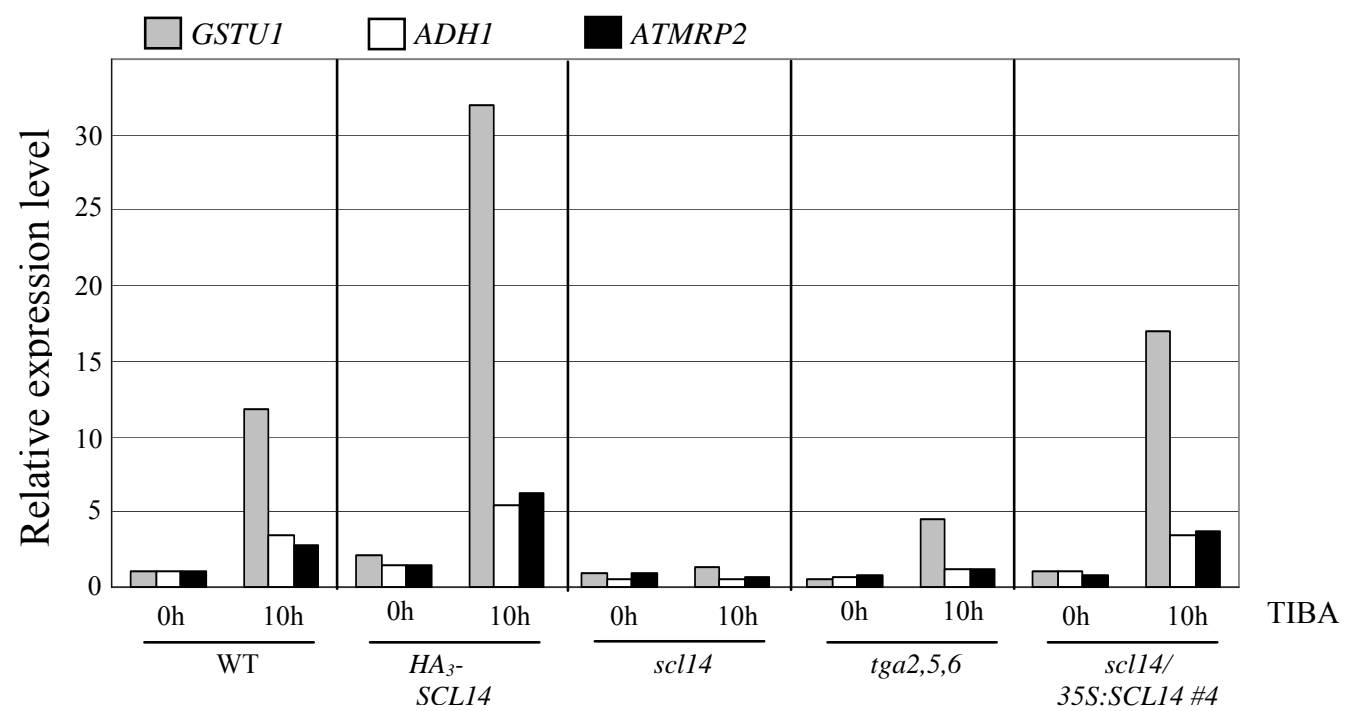

Figure 4-23 Expression of endogenous SCL14 target genes after TIBA treatment

Quantitative real-time RT-PCR analysis of relative GSTU1-, ADH- and ATMRP2 transcript levels in as1:GUS (WT), 35S:HA $\mathrm{H}_{3}$ SCL14 expressing plants, scl14 mutants, tga2 tga5 tga6 (tga2,5,6) mutants and scl14 mutants complemented with 35S:SCL14. Three-week-old plants grown on MS plates were treated with $0.1 \mathrm{mM}$ TIBA for 10 hours. The values of the three genes in untreated as-1:GUS plants were set to "1".

All three genes are induced in an SCL14- and TGA-dependent manner confirming the results from the micro array. Their altered expression in the scl14 mutant can be restored to wildtype levels by ectopic expression of SCL14 in the mutant background. Consistent with the results for CYP81D11, MtN19-like and GSTU7, the expression of the three genes is hyper-inducible in the $H A_{3}$-SCL14 expressing plants.

Chromatin immunoprecipitation experiments might reveal the direct regulation of the GSTU1 gene by SCL14 as it harbours a conserved as-1-like element in the promoter.

All data shown for the target genes propose a role for SCL14 in response to electrophilic/ xenobiotic substances. Whether this role also influences the tolerance of the plants against necrotrophic biological enemies like fungal pathogens, which elicit oxidative stress and the formation of RES, should be revealed by infection experiments with the fungus Botrytis cinerea, which also showed up as a strong inducer of SCL14 target genes in Genevestigator analysis (Figure 4-9). 


\subsection{Overexpression of SCL14 leads to resistance against the necrotrophic fungus Botrytis cinerea}

The grey mould causing fungus Botrytis cinerea is a major pathogen for a wide range of plant species. In Arabidopsis thaliana resistance against this necrotrophic pathogen is mainly mediated by jasmonates and ethylene and mostly depends on a functional COI1 and EIN2 protein. Beside the JA/ET response, camalexin synthesis (PAD3-dependent) is required for resistance. In addition, salicylic acid dependent genes are activated (e.g. $P R-1)$. In different microarray experiments the SCL14 target genes like CYP81D11 (Figure 4-9) were also found to be activated after B. cinerea infection. To investigate whether the SCL14 target genes show an influence on defence reaction the different transgenic plants and mutants were inoculated with spores of $B$. cinerea. The infection was carried out using different strains of Botrytis cinerea showing the results of two of them. The strains used are B1.26 (Thiedemann, Figure 4-26) and BH/1 (B. Mauch-Mani, Figure 4-30). Leaves of three week old plants were inoculated with $5 \mu \mathrm{L}$ of spores $(1 \mathrm{x}$ $10^{6}$ spores/ $\mathrm{mL}$ PDB) from the respective B. cinerea cultivar. Wildtype plants and coi11 mutants were inoculated with Botrytis cinerea $\mathrm{BH} / 1$ to investigate the degree of resistance against this fungal cultivar.
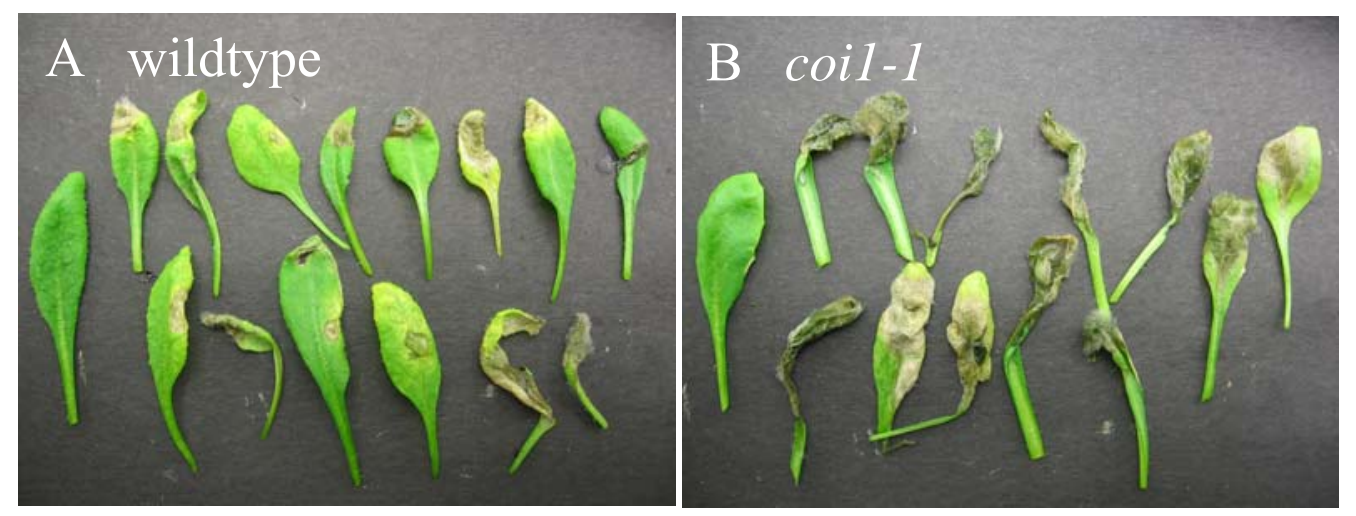

Figure 4-24 Infection of coi1-1 mutants with Botrytis cinerea $\mathrm{BH} / 1$

Pictures showing leaves of (A) wildtype plants (as-1:GUS) and (B) coi1-1 and the development of disease symptoms 96 hpi with Botrytis cinerea strain BH/1. Each leaf was inoculated with $5 \mu \mathrm{L}$ of spore solution ( 1 x $10^{6}$ spores/ mL PDB). As an uninfected control, the leftmost leaf was obtained from a non-infected plant grown side-by-side with the infected plants, respectively.

The F-box protein COI1 is essential for most of the aspects of JA dependent defence responses. As COI1 regulates activation of gene expression by targeting negative 
regulators for degradation the mutants fail to activate sufficient defences against necrotrophic pathogens like Botrytis cinerea. Actually, the degree of resistance is remarkably lower in coi1-1 mutants compared to wildtype plants (Figure 4-24). Compared to the coi1-1 mutants, tga2,5,6 mutants are more resistant to B. cinerea infection, although they show enhanced susceptibility when compared to wildtype plants (Figure 4-25).
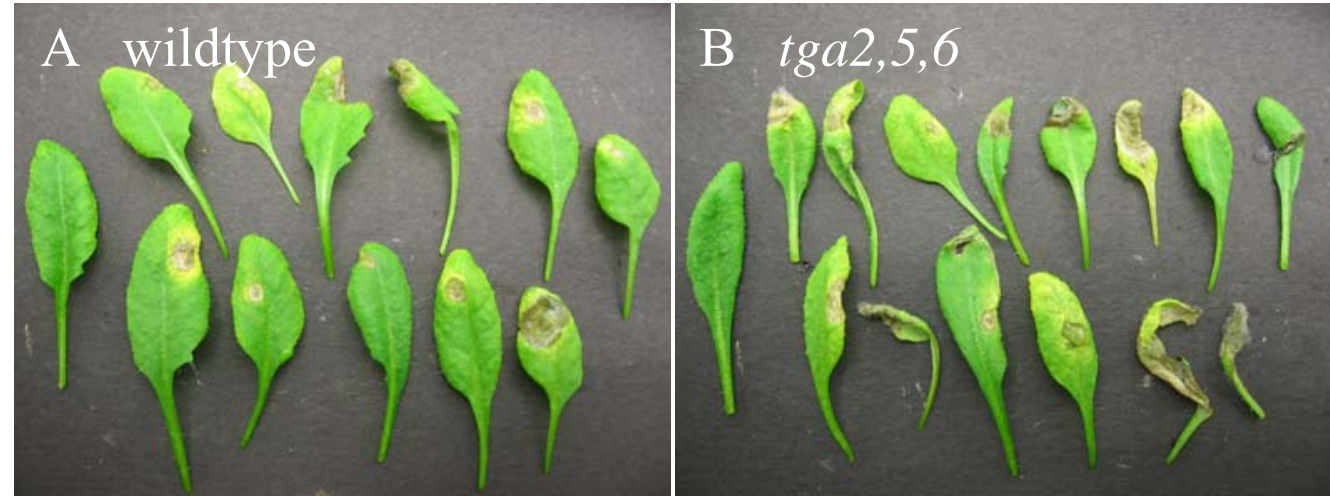

Figure 4-25 Infection of plants with Botrytis cinerea BH/1

Pictures showing leaves of (A) wildtype plants (as-1:GUS) and (B) tga2,5,6 mutants and the development of disease symptoms 96 hpi with Botrytis cinerea strain BH/1. Each leaf was inoculated with $5 \mu \mathrm{L}$ of spore solution $\left(1 \times 10^{6}\right.$ spores/ $\mathrm{mL}$ PDB $)$. As an uninfected control, the leftmost leaf was obtained from a non-infected plant grown side-by-side with the infected plants, respectively.

To investigate the influence of SCL14 on the resistance against B. cinerea, fungal propagation on wildtype plants was compared to propagation on scl14 mutants and SCL14 overexpressing plants $\left(H A_{3}-S C L 14\right)$. This infection was performed using the $B$. cinerea cultivar B1.26 on four week old plants. As indication for a susceptible phenotype, tga2,5,6 mutants were also infected with this cultivar (Figure 4-26). 

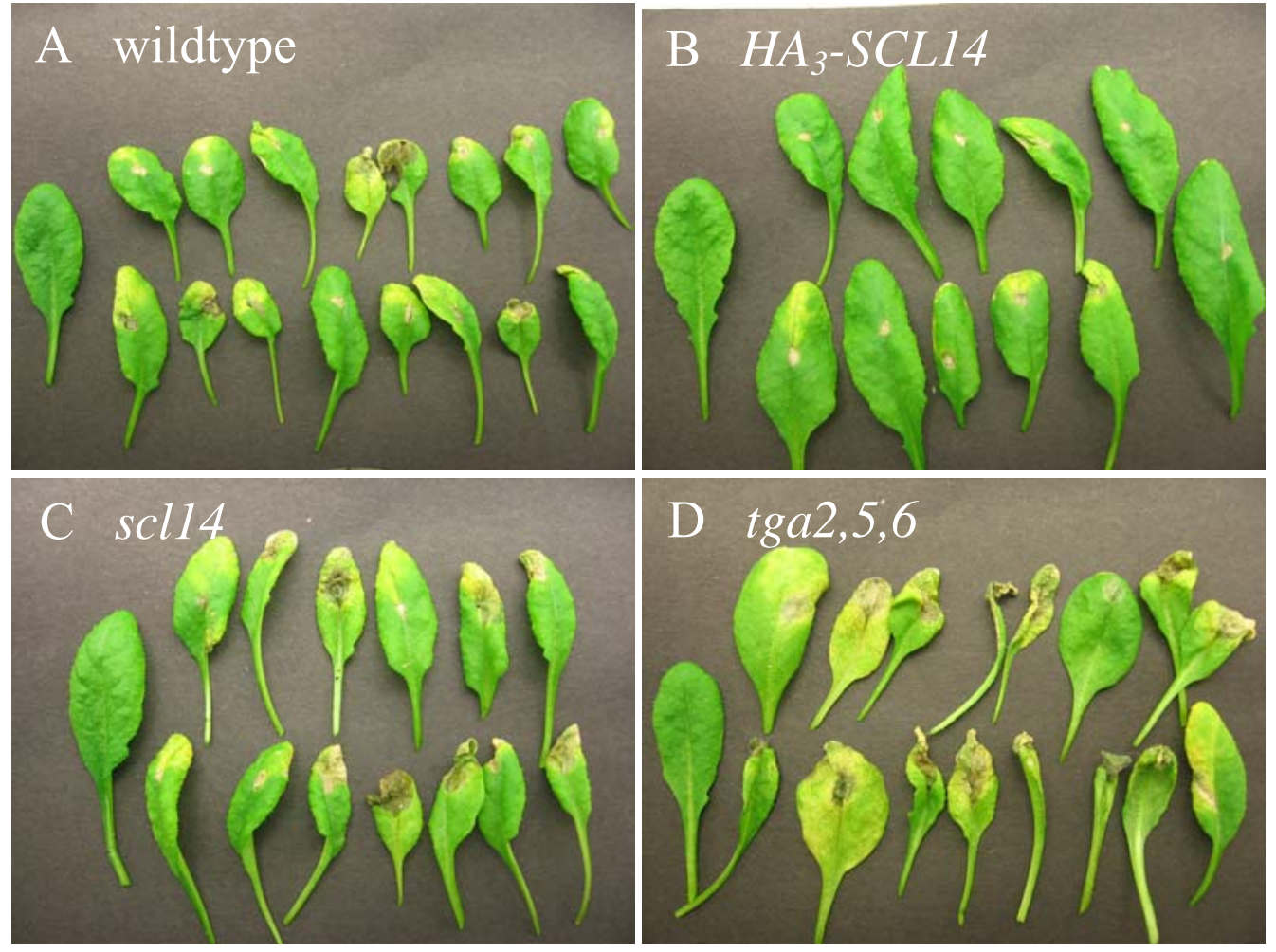

Figure 4-26 Infection of plants with Botrytis cinerea B1.26

Pictures showing leaves of (A) wildtype plants (as-1:GUS), (B) 35S:HA -SCL14 expressing plants, (C) scl14 mutants and (D) tga2,5,6 mutants and the development of disease symptoms 96 hpi with Botrytis cinerea strain 1.26. Each leaf was inoculated with $5 \mu \mathrm{L}$ of spore solution ( $1 \times 10^{6}$ spores/ mL PDB). As an uninfected control, the leftmost leaf was obtained from a non-infected plant grown side-by-side with the infected plants, respectively.

The infected leaves of wildtype plants and the scl14 mutants show no obvious differences in susceptibility to the fungus (Figure 4-26 A and C). The leaves of tga2,5,6 mutants show a higher susceptibility to this $B$. cinerea cultivar in consistence with the observed phenotype after BH/1 infection. However, overexpression of SCL14 leads to a high degree of resistance against Botrytis cinerea (Figure 4-26 B). Leaves of $H_{3^{-}}$ SCL14 plants only show small lesions at the direct site of infection.

The propagation of the fungus was measured by amplification of B. cinerea ActinA gene by qRT-PCR analysis. The relative expression levels of BcActinA gene reflect the observed phenotypes from the infected leaves (Figure 4-27). 


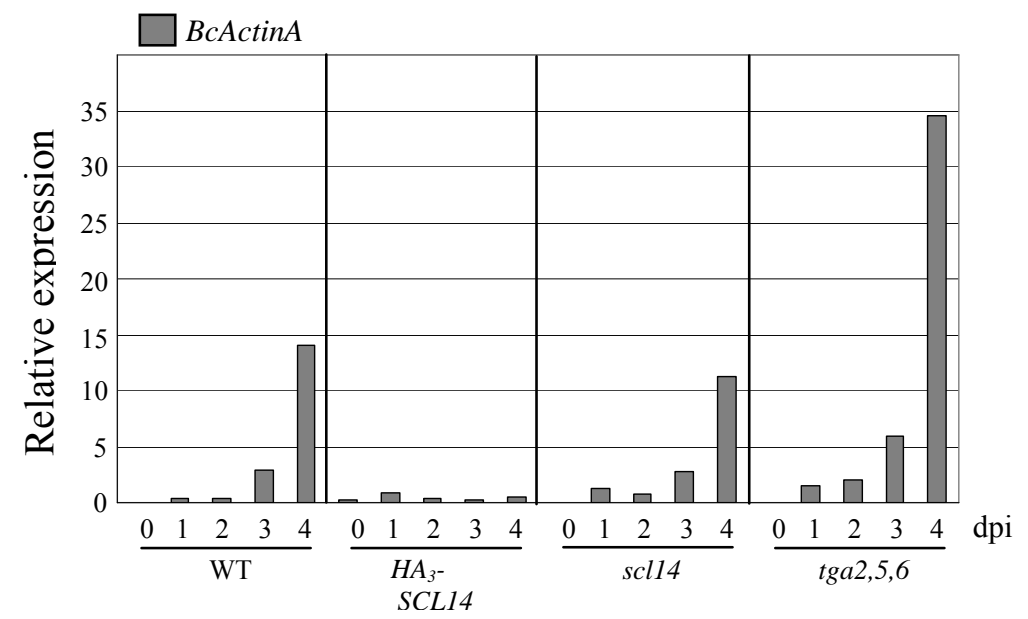

Figure 4-27 Quantitative RT-PCR analysis of fungal ActinA transcript levels in plants infected with Botrytis cinerea strain 1.26

The level of ActinA marks the degree of fungal propagation on the respective plants. Inoculated leaves were collected at the indicated time points (every 24 hours).

In $\mathrm{HA}_{3}$-SCL14 expressing plants the amount of detectable ActinA transcript is not increased during infection, reflecting the growth restriction of the fungus on these plants. In the wildtype and scl14 mutant plants ActinA transcript increases during infection reflecting spread of the fungus on the leaves. The tga2,5,6 mutants were more susceptible, thus, ActinA transcripts accumulate to higher levels especially in later stages of infection (96 hpi).

To elucidate whether the SA- and JA-dependent defence response pathways contribute to the observed phenotypes the expression of the PR-1 and PDF1.2 gene $96 \mathrm{~h}$ after $B$. cinerea infection was analyzed as markers for SA and JA signalling respectively. 


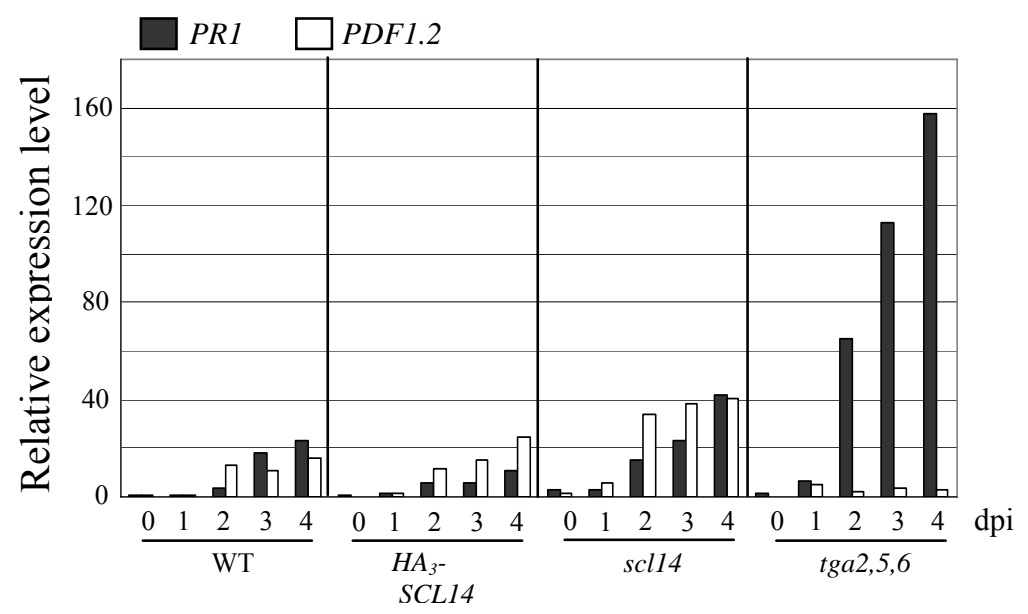

Figure 4-28 Quantitative RT-PCR analysis of PR-1 and PDF1.2 transcript levels in plants infected with Botrytis cinerea strain 1.26

The expression of PDF1.2 after B. cinerea infection depends on the TGA factors. In contrast expression of $P R-1$ after infection with Botrytis is enhanced in the tga2,5,6 mutant. Inoculated leaves were collected at the indicated time points (every 24 hours).

The Botrytis induced expression of the PDF1.2 gene is reduced in the tga2,5,6 mutants (Figure 4-28). Interestingly, the $P R-1$ transcript levels are increased in the mutants after fungal attack, pointing at an influence of the TGA factors in SA/JA and ET crosstalk during B. cinerea infection. Further studies are necessary to determine the exact role of the TGA factors in this regulation of resistance against Botrytis cinerea.

However, PR-1 and PDF1.2 transcript levels are both slightly increased in scl14 mutants whereas PDF1.2 transcript levels are slightly lower in the SCL14 overexpressing plants. This might due to the infection of more cells in the scl14 mutants in comparison with the SCL14 overexpressing plants.

In addition, Botrytis cinerea was found to be a good inducer of SCL14 target genes in Genevestigator analysis. However, induction of SCL14 target genes in B. cinerea infection experiments was not reproducible (here shown for CYP81D11 (Figure 4-29)). All analyzed transcript levels (CYP81D11, MtN19-like, GSTU7, GSTU1 and ATMRP2 were unchanged during infection (data not shown). 


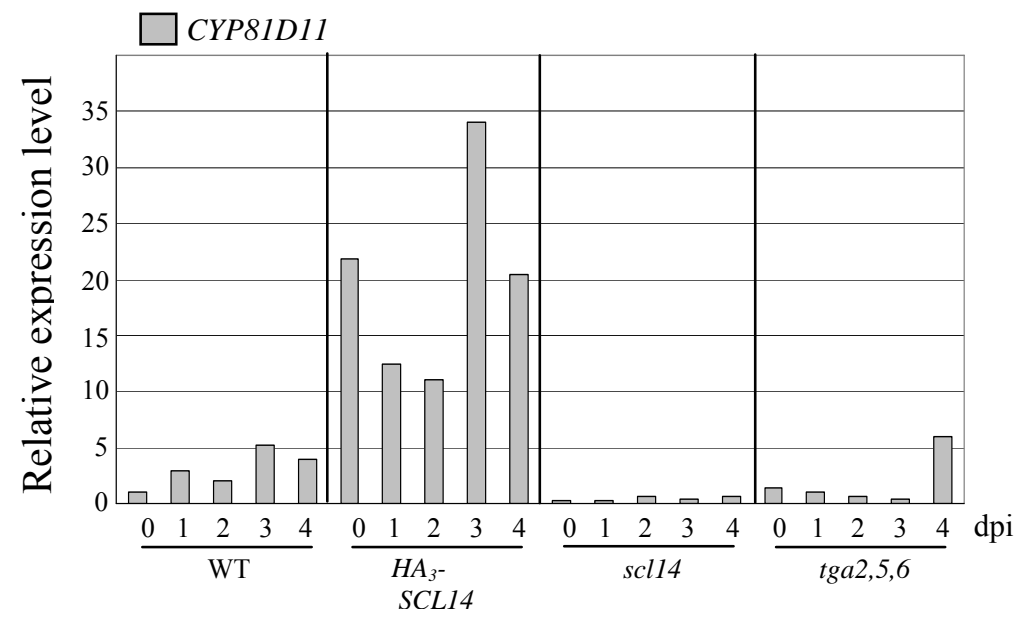

Figure 4-29 Quantitative RT-PCR analysis of CYP81D11 transcript levels in plants infected with Botrytis cinerea strain 1.26

The level of CYP81D11 depends on SCL14 and TGA factors. Expression in the tga2,5,6 mutant at 96 hpi possibly due to total maceration of the tissue. Inoculated leaves were collected at the indicated time points (every 24 hours). The relative levels of CYP81D11 transcript in uninfected wildtype plants were set to "1", all others are shown as "fold induction" over the uninfected wildtype.

Expression of CYP81D11 transcript is nearly unaffected in wildtype plants. Minimal induction of the gene depends on SCL14 and TGA factors (although transcript accumulates in tga2,5,6 mutants after 96 hpi). In contrast, transcript levels of CYP81D11 are constitutively higher in SCL14 overexpressing plants. This leads to the hypothesis of a more generally resistant phenotype of the $H A_{3}-S C L 14$ expressing plants due to constitutive active expression of genes associated with detoxification like CYP81D11 and GSTU7. This also resembles the phenotypes on MS-plates containing xenobiotic substances like TIBA, SA or INA (Figure 4-16, Figure 4-17 Figure 4-18).

To exclude an influence of the $\mathrm{HA}_{3}$-tag, infection experiments with a plant line overexpressing 35S:SCL14 (untagged) were performed. These plants also show a high degree of resistance against fungal attack (Figure 4-30). 

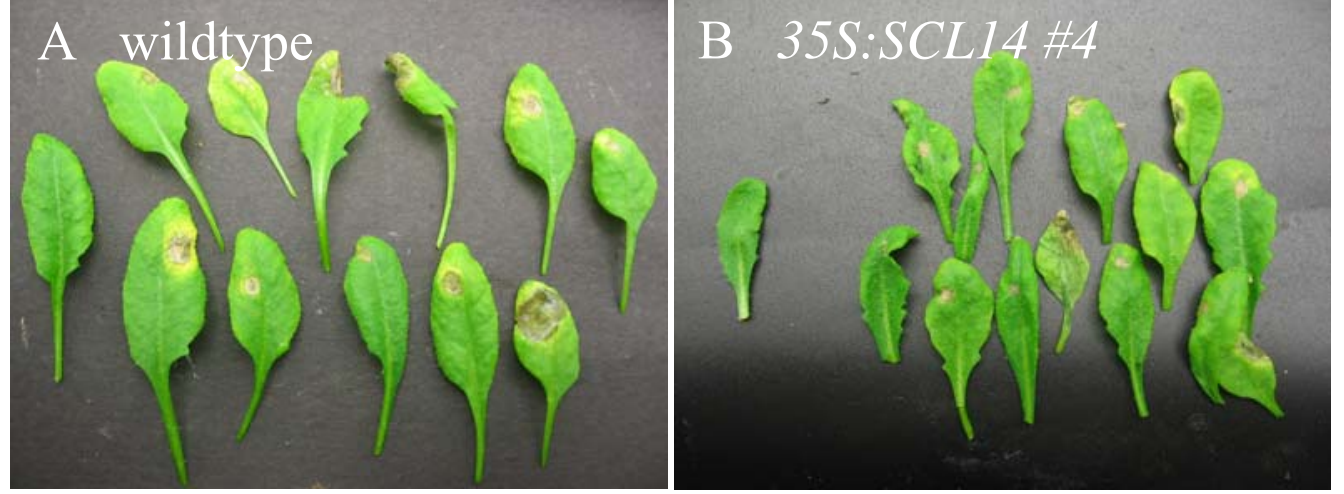

Figure 4-30 Infection of SCL14 overexpressing plants with Botrytis cinerea BH/1

Pictures showing leaves of (A) wildtype plants (as-1:GUS) and (B) 35S:SCL14 (untagged) expressing plants and their development of disease phenotypes 96 hpi with Botrytis cinerea strain BH/1. Each leaf was inoculated with $5 \mu \mathrm{L}$ of spore solution $\left(1 \times 10^{6}\right.$ spores/ mL PDB). As an uninfected control, the leftmost leaf was obtained from a non-infected plant grown side-by-side with the infected plants, respectively. 


\section{Discussion}

The TGA family of transcription factors and the corresponding target sequence as- 1 belong to the first experimental systems to be established for studying transcriptional control mechanisms in plants (Katagiri et al., 1989). The as-1 element was originally identified as the only regulatory cis element within the "truncated" CaMV $35 S$ promoter (Lam et al., 1989). This 90 bp promoter fragment confers transcriptional activation in response to high levels of SA and 2,4-D in tobacco (Liu and Lam, 1994; Qin et al., 1994) and Arabidopsis (Redman et al., 2002). The activating pathway is independent from NPR1 (Butterbrodt et al., 2006), a regulatory protein that interacts with TGA factors to confer expression of genes involved in systemic acquired resistance (Fan and Dong, 2002). In this work, chromatin immunoprecipitation assays present evidence that as-1bound TGA factors recruit the GRAS protein SCL14 to a number of endogenous promoters that are inducible by SA, 2,4-D and other chemicals. Activation of the corresponding genes helps to protect plants against at least certain types of xenobiotic stresses. In addition, overexpression of SCL14 leads to a high resistance against the necrotrophic fungus Botrytis cinerea.

\subsection{Functional role of the intracellular transport of SCL14}

In SCL14, the GRAS domain harbours a putative NES (aa 393 to 401: LRTLLVLC). This sequence might facilitate constant shuttling of the protein between the nucleus and the cytosol, which would explain its localization in both compartments (Figure 4-2). Studies from Thomas Merkle showed the interaction of SCL14 with the nuclear export receptor XPO1 in yeast, suggesting an active export of SCL14 from the nucleus. This active export can be disturbed by treatment with LMB. In fact, SCL14 only localizes to the nucleus after treatment of cells with LMB demonstrating that this export actually occurs in plant cells. Unfortunately, experiments with mutant versions of SCL14 protein with disturbed NES (L393A, L396A, V398A) were not successful as the expression of 
those mutant proteins was lethal at least for protoplasts in transient assays. Thus, the exact role of the transport remains to be elucidated but one possible function might be that SCL14 may receive modifications in the cytosol or act as carrier to import or export other regulatory proteins.

\subsection{Function of the N-terminal domain of SCL14}

Direct DNA binding has never been reported for any of the GRAS proteins, but a recent study reported association of DELLA proteins with selected GA-responsive promoters (Zentella et al., 2007). SCL14 cannot be detected at its target promoters in the absence of TGA2, TGA5 or TGA6 (Figure 4-5). As the N terminus of SCL14 provides the interface for the interaction with TGA2 (Figure 4-1), the conclusion is that this interaction recruits the protein to the respective promoter regions. It may be speculated that the DELLA proteins are also associated with their target promoters through the action of sequence-specific DNA-binding proteins.

Based on the occurrence of conserved amino acid sequences in the more variable $\mathrm{N}$ terminus of GRAS proteins, the GRAS gene family has been divided into eight subfamilies (Tian et al., 2004). SCL14 belongs to the L1SCL/SCL9-branch. Its best characterized member is LISCL (Lilium longiflorum SCARECROW-like) from lily, which is predominantly expressed in anthers during the premeiotic phase (Morohashi et al., 2003). In contrast, SCL14 is weakly expressed in all tissues, and shows 10-fold higher levels of gene expression in dry seeds (https://www.genevestigator.ethz.ch/). When fused to the GAL4 DNA binding domain, the N terminus of the L1SCL protein confers transcriptional activation in yeast as well as in plant cells. The activation domain was mapped to a stretch of 19 residues containing 7 acidic amino acids (motif I). This motif as well as the sequence DEDED (motif II) is conserved in SCL14 at positions aa 83 to 101 and 309 to 313 , respectively, and might be responsible for the transcriptional activation conferred by the TGA2/ SCL14 complex in yeast.

Screens in yeast for SCL14 interacting proteins failed until now because of its activation potential, which leads to auto activation in yeast, when SCL14 is fused to a DNAbinding domain (like GAL4-BD). Derivatives of SCL14 mutated in this possible 
activation domain showed no strong reduction in auto activation potential in yeast suggesting that additional domains confer activation.

\subsection{Genevestigator clustering analysis of SCL14 target genes}

In order to identify the conditions leading to activation of SCL14-dependent genes a Genevestigator clustering analysis was performed. This analysis revealed a variety of conditions, which induce SCL14 target genes (Figure 4-9). One common characteristic of the treatments is that they might create some sort of oxidative stress. For instance, reactive oxygen species (ROS) are generated after infection of plants with Botrytis cinerea or Pseudomonas syringae, hydrogen peroxide and ozone are ROS themselves and low $\mathrm{CO}_{2}$, treatment with the photosystem II inhibitor PNO8, and high light conditions enhance the ROS-forming potential of the chloroplasts (Apel and Hirt, 2004). Chemicals related to auxin action, like 2,4-D, 2,4,6-T, PCIB and TIBA, also induce SCL14 target genes. A common feature of these chemicals is that they consist of a halogen-substituted aromatic ring system that is likely to react with sulfhydryl groups. Therefore, they might activate the anti-xenobiotic genes by changing the redox state of the cell rather than by changing the auxin response. Consistently, the auxin transport inhibitor NPA (naphthylphthalamic acid), which does not contain strong electrondrawing substituents, does not induce expression of SCL14 target genes, supporting the hypothesis that the electrophilic character rather than the effects on auxin action are critical for eliciting the anti-xenobiotic stress response. Likewise, electrophilic phytoprostanes, which can damage cells by integrating into membranes and alter the selective permeability of the lipid bilayer (Mueller, 2004), are also capable of inducing an anti-xenobiotic stress response largely dependent on TGA2, TGA5 or TGA6 (Mueller et al., 2008). Thus, redox-dependent processes influencing the activity of bZIP transcription factors may constitute a common principle between mammals and plants.

Additionally, five of the genes listed as SCL14-dependent (CYP81D11 (At3g28740), UDP-glucosyl transferase (At1g05680), NADPH-dependent oxidoreductase (At5g16980), GSTU7 (At2g29420), AtNAC002 (At1g01720)) were identified in microarray experiments designed to monitor global changes in the Arabidopsis 
transcriptome after treatment with the allelochemical benzooxazolinone (BOA) (Baerson et al., 2005). The chemical warfare between neighbouring plants or other organisms that produce toxic compounds might have led to the evolution of mechanisms that allow the detoxification of a wide spectrum of harmful chemicals, irrespective of whether they occur in nature or whether they are synthetic.

Induction of the genes CYP81D11, MtN19-like and GSTU7 by these chemicals (TIBA, SA, INA, hydrogen peroxide) was strongly reduced in scl14 and tga2,5,6 mutants, showing the importance of both factors, SCL14 as well as the class II TGA transcription factors, for the regulation of the xenobiotic-induced genes. The lower performance of the scl14 and tga2,5,6 seedlings on medium containing harmful concentrations of SA, INA or TIBA (Figure 4-16, Figure 4-17, Figure 4-18) is consistent with the idea that these compounds are less efficiently detoxified because of insufficient induction of the corresponding genes. Actually, the levels of SCL14 transcript are about ten-fold higher in dry seeds suggesting a role of SCL14 in detoxification processes during germination.

\subsection{Functional role of SCL14 target genes}

SCL14 target genes were identified by Tanja Siemsen (2005) by comparing the transcriptome of plants with higher or lower levels of SCL14 $\left(H_{3}-S C L 14\right.$ transgenic plants versus scl14 mutant plants). Consistent with the idea that a subset of TGAregulated genes is related to defence responses against xenobiotic stress (Zhang and Singh, 1994; Pascuzzi et al., 1998; Klinedinst et al., 2000), genes with putative functions in the inactivation of toxic compounds were found. In plants and animals, the detoxification process starts with the introduction of functional groups by enzymes like P450 monooxygenases (phase I), which are subsequently conjugated to glucose of glutathione by enzymes such as UDP-glucosyl transferases and GSTs (phase II). Such modifications result in less toxic and/or more water-soluble conjugates which are subsequently deposited either in the vacuole or the apoplast (phase III) (Sandermann, 1992). Some of the SCL14 target genes are potentially involved in phase I (cytochrome P450 family protein CYP81D11 (At3g28740), monooxygenase MO1 (At4g15760)) or 
phase II (UDP-glucosyl transferase (AT1g05680), oxidoreductase (At2g37770), NADPH-dependent oxidoreductase (At5g16980), GSTU7 (At2g29420)).

Since the first micro array analysis only considers uninduced conditions a new micro array analysis was performed comparing the scl14 mutant with wildtype plants after treatment with the electrophilic substance 2,3,5-triiodobenzoic acid (TIBA) in order to find SCL14 target genes directly connected to xenobiotic stress. The main analysis focussed on the up-regulated genes after TIBA treatment comparing transcript levels of the wildtype with those found in the scl14 mutant (Table 4-2). Some of the previously found genes (CYP81D11, MtN19-like also named Mac9.6, GSTU7, one UDP-glycosyl transferase and the transcription factor ANAC032) also showed up in this second experiment. In addition, several new putative target genes for SCL14 were identified, reflecting the role of SCL14 for the regulation of genes associated with detoxification processes.

As expected, one major group of genes overrepresented in the "TIBA micro array" are involved in the response to general stress and abiotic stimuli including several glutathione-S-transferases. These genes putatively are involved in the detoxification of radicals and xenobiotics or in the balancing of the redox state of the cell.

Additionally, genes coding for proteins involved in transport are overrepresented in the micro array after TIBA. Among these transport related genes, two genes coding for transporters of the ABCC-type belonging to the family of multidrug-resistance associated proteins (MRPs) were induced (ATMRP2 and ATMRP14). Those transporters are mainly involved in the deposition of toxic compounds into the vacuole (Klein et al., 2006), thus playing a role in the phase III of detoxification processes. Likewise, ATMRP2 transcript was also found to be induced after treatment of plants with electrophilic phytoprostanes (Mueller et al., 2008).

To verify the genes identified in the micro array analysis being in fact SCL14dependent, some of the most promising candidates were chosen and confirmed as target genes (GSTU1, ADH1, ATMRP2, Figure 4-23) or false positives (LOX1, data not shown) using quantitative real-time RT PCR. Transcripts of GSTU1, ADH1 and ATMRP2 also responded in a SCL14 and TGA dependent manner in this independent TIBA induction experiment. However, promoter sequence analysis revealed an as-1-like element only for GSTU1 suggesting the others to be secondary SCL14-dependent genes. So far, ChIP 
experiments confirmed CYP81D11, GSTU7, MtN19-like (FX), the transcription factor ANAC032 and monooxygenase MO1 (data not shown) as genes directly regulated by the TGA/SCL14 complex.

\subsection{Regulation of genes involved in detoxification}

In mammalian systems, transcriptional responses of genes involved in phase I, II and III detoxification steps can be mediated by at least three different pathways. The first two involve receptor-xenobiotic ligand interactions: (1) After binding of the ligand, the aryl hydrocarbon nuclear receptor (AhR) is translocated to the nucleus and subsequently dimerizes with the co-activator Arnt to stimulate transcription (Denison and Nagy, 2003). (2) The pregnane $X$ receptor and the androstane receptor can bind promiscuously to structurally diverse xenobiotic ligands and activate gene expression after forming heterodimers with the 9-cis-retinoic acid receptor (Kliewer et al., 2002). (3) The third mammalian xenobiotic-sensing system involves the bZIP transcription factor Nrf2, which is retained in the cytosol by the protein Keap1. In the presence of a wide range of structurally diverse sulfhydryl-reactive electrophilic compounds, two critical cysteine residues in the Keap1 protein are oxidized. This releases Nrf2, which enters the nucleus and subsequently activates target promoters, possibly in association with small bZIP transcription factors of the Maf family (Nguyen et al., 2003).

In plants, the mechanisms leading to the activation of transcriptional responses to xenobiotic stress are far less elucidated. So far, only the TGA factors have been implicated in this response (Zhang and Singh, 1994; Pascuzzi et al., 1998; Klinedinst et al., 2000), and TGA1 has been shown recently to be redox-regulated after treatment of plants with SA (Fobert and Despres, 2005). As SCL14 target genes are potentially involved in detoxification steps, a role for TGA/ SCL14 in the regulation of detoxification steps was assumed. 


\subsection{Role of SCL14 during infection with Botrytis cinerea}

Botrytis cinerea is a necrotrophic fungus infecting a broad spectrum of host plants causing grey mould not only on plant leaves or stems but also on fruits before and after harvest. During infection, hydrogen peroxide and electrophilic compounds like phytoprostanes are generated in the plant cells. Plants react to the infection by a variety of defence responses including gene expression remodelling to accumulate anti-fungal proteins like plant defensins (including PDF1.2). The SCL14 target genes are also induced after B. cinerea attack as revealed by Genevestigator analysis (Figure 4-9). Unfortunately, this induction was not reproducable in the B. cinerea experiments done in this work. However, scl14 mutants showed no enhanced susceptibility (Figure 4-26), suggesting only a minor role for SCL14 target genes during infection. In addition, plants lacking SCL14 and the possibly redundant TGA-interacting SCL31 protein (Süthoff, 2006) are also not more susceptible to Botrytis infections than wildtype plants or scl14 mutants (data not shown), indicating that other plant responses are more important in determining the outcome of the interaction. In wildtype situation resistance against necrotrophic pathogens mostly depends on camalexin synthesis via PAD3 (cytochrome P450 family protein) (Ferrari et al., 2007) and JA/ ET-dependent defence responses mediated by ERF1 (Lorenzo et al., 2003). These pathways provide dominant resistances where loss of SCL14 has no influence.

In contrast, SCL14 overexpressing plants show a heightened resistance against $B$. cinerea (Figure 4-26). A model for the 35S:SCL14 expressing plants propose, that the constitutive activation of genes coding for detoxifying enzymes (Figure 4-11, Figure 4-29) leads to the heightened resistance. Other studies pointed out that the HR during attack of the pathogen lead to enhancement of fungal spread (Govrin and Levine, 2000) as necrotrophs like Botrytis utilise nutrients from dead cells. In 35S:SCL14 expressing plants, fast and constant removal of radicals by constitutively expressed detoxification proteins possibly limits cell death and so the supply of nutrients for the fungus. However, whether the 35S:SCL14 mediated resistance might overcome pad3, ein2 or coi1 susceptibility has yet not been elucidated.

In contrast, tga2,5,6 mutants are highly susceptible to $B$. cinerea, showing the importance of TGA factors during fungal attack. This lowered resistance probably due 
to TGA-function in JA/ET signalling. As the tga2,5,6 mutant fails to induce PDF1.2 gene expression after JA/ET stimulus (Mark Zander, personal communication), the interrupted JA/ET signalling most likely also contributes to the lack of induction of PDF1.2 transcript after B. cinerea infection (Figure 4-28). This lack of PDF1.2 correlates with susceptibility also in the bos3 (Botrytis-susceptible 3) mutant (Veronese et al., 2004). In addition, the JA signalling mutant coi1-1 shows severely reduced resistance (Figure 4-24) demonstrating the importance of JA signalling pathways during fungal attack.

\subsection{Direct regulation of target gene transcription by the TGA/ SCL14 complex at as-1-like elements}

Western blot analysis revealed that TGA factors and SCL14 are pre-existent in the cell and ChIP analysis indicated that the TGA/ SCL14/ as-1 complex is preformed at the promoter (Figure 4-5, Figure 4-3). However, this complex is less efficient to activate transcription under non-inducing conditions as compared to inducing conditions. Additionally, SCL14 protein levels and the degree of binding of SCL14 to the target promoters are only very slightly increased in 35S:SCL14 expressing plants (Figure 4-5) whereas transcription of target genes is constitutively active (Figure 4-11, Figure 4-29) even in uninduced situations. Moreover, under inducing conditions (TIBA treatment), complex formation of TGA/ SCL14 at as-1-like elements remains unchanged (Figure 4-14) suggesting another mechanism of transcriptional activation than recruitment of SCL14 to the respective promoters. It remains to be investigated how the different chemicals are perceived and how this leads to the activation of target promoters. The elucidation of this mechanism should also explain why even the three target genes (CYP81D11, GSTU7, MtN19-like) show a differential responsiveness towards SA versus 2,4-D (Figure 4-7, Figure 4-8). Whether the GRAS protein SCL14 is a direct target of the regulation or whether it is only needed for the activation process as soon as another compound is modified remains to be shown.

Another enigma that has to be solved is to define the characteristics that render as-1containing regulated promoters SCL14-dependent, NPR1-dependent or even independent from both proteins like e.g. GSTF8. A recent study suggested that NPR1 is 
recruited to the $P R-1$ promoter by a yet unknown protein (Rochon et al., 2006). The binding site of this unknown protein might be missing in the endogenous promoters that require SCL14 for their expression. It also remains to be investigated, why SCL14 target promoters are hyperinducible in the npr1 mutant after SA stimulus (Figure 4-8), a phenomenon that has been observed before for GSTU7 (Blanco et al., 2005). 


\section{Supplemental data}

\section{Table 6-1 Up-regulated genes after treatment with TIBA comparing wildtype and scl14 mutant}

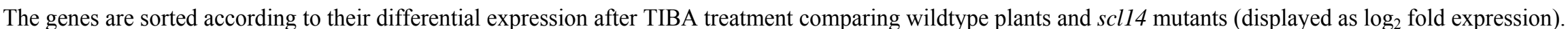
In this table all analysed combinations of treated and untreated plants are displayed allowing a detailed view on the expression pattern and SCL14 dependency of each gene. Genes listed were expressed with a false discovery rate of $10 \%$.

\begin{tabular}{|c|c|c|c|c|c|}
\hline AGI code & Gene Description & Wt/ scl14 & $\begin{array}{c}\text { scl14 } \\
(\mathrm{TIBA}) / \\
\text { scl14 }\end{array}$ & $\begin{array}{c}\text { Wt } \\
(\text { TIBA)/ } \\
\text { Wt }\end{array}$ & $\begin{array}{c}\text { Wt } \\
\text { (TIBA)/ } \\
\text { scl14 } \\
\text { (TIBA) }\end{array}$ \\
\hline At3g44980 & unknown protein & $-0,1$ & $-4,62$ & 0,41 & 4,92 \\
\hline At4g08530 & lipid binding & 0,73 & $-3,04$ & 0,95 & 4,72 \\
\hline At3g59140 & ATMRP14 & 1,69 & 0,04 & 2,92 & 4,57 \\
\hline At2g29490 & ATGSTU1 (GLUTATHIONE S-TRANSFERASE 19); glutathione transferase & 2,05 & 1,96 & 4,3 & 4,39 \\
\hline At4g08555 & - & 0,99 & 2,51 & 5,85 & 4,33 \\
\hline At1g77120 & ADH1 (ALCOHOL DEHYDROGENASE 1); alcohol dehydrogenase & 2,18 & 0,44 & 2,36 & 4,1 \\
\hline At3g28740 & CYP81D11 & 2,96 & 4,22 & 5,34 & 4,07 \\
\hline At3g44935 & - & 0,67 & $-6,39$ & -3 & 4,06 \\
\hline At5g53990 & transferase, transferring glycosyl groups & 3,57 & 0,38 & 0,69 & 3,87 \\
\hline At3g43190 & UDP-glycosyltransferase/ sucrose synthase/ transferase, transferring glycosyl groups & 3,66 & $-0,06$ & 0,01 & 3,73 \\
\hline At4g31950 & CYP82C3; heme binding / iron ion binding / monooxygenase/ oxygen binding & 2,3 & $-4,15$ & $-2,72$ & 3,72 \\
\hline At1g77450 & ANAC032; transcription factor & 2,47 & 0,51 & 1,75 & 3,7 \\
\hline At3g57010 & strictosidine synthase & 3,21 & $-3,33$ & $-2,9$ & 3,63 \\
\hline At4g37290 & unknown protein & 0,07 & 0,05 & 3,57 & 3,59 \\
\hline At5g22140 & disulfide oxidoreductase/ electron carrier & 1,81 & 2,72 & 4,42 & 3,52 \\
\hline At5g10830 & unknown protein & 1,69 & 0,53 & 2,31 & 3,48 \\
\hline At4g23700 & ATCHX17; monovalent cation:proton antiporter & 2,81 & 0,74 & 1,38 & 3,45 \\
\hline At1g17170 & - & 2,6 & 3,43 & 4,28 & 3,45 \\
\hline
\end{tabular}




\begin{tabular}{|c|c|c|c|c|c|}
\hline At5g61820 & unknown protein & 2,06 & 0,98 & 2,33 & 3,42 \\
\hline At4g31970 & CYP82C2; heme binding / iron ion binding / monooxygenase/ oxygen binding & $-0,96$ & $-0,77$ & 3,58 & 3,4 \\
\hline At3g50970 & XERO2 & 2,8 & 2,02 & 2,58 & 3,36 \\
\hline At5g62340 & enzyme inhibitor/ pectinesterase/ pectinesterase inhibitor & 1,24 & $-2,89$ & $-0,78$ & 3,34 \\
\hline At4g34131 & UDP-glycosyltransferase/ transferase, transferring hexosyl groups & 1,46 & 2,31 & 4,19 & 3,33 \\
\hline At3g06170 & unknown protein & 2,84 & $-1,02$ & $-0,55$ & 3,31 \\
\hline At3g50640 & unknown protein & 2,35 & $-2,31$ & $-1,37$ & 3,29 \\
\hline At1g67810 & unknown protein & 0,62 & 1,88 & 4,55 & 3,28 \\
\hline At1g05680 & UDP-glycosyltransferase/ transferase, transferring glycosyl groups / transferase & 1,01 & 3,3 & 5,54 & 3,26 \\
\hline At1g18970 & GLP4 (GERMIN-LIKE PROTEIN 4); nutrient reservoir & 2,25 & 0,87 & 1,86 & 3,25 \\
\hline At5g06090 & ATGPAT7/GPAT7; 1-acylglycerol-3-phosphate O-acyltransferase/ acyltransferase & 2,4 & 1,59 & 2,42 & 3,23 \\
\hline At1g17180 & ATGSTU25; glutathione transferase & 1,35 & 0,52 & 2,38 & 3,22 \\
\hline At2g29420 & ATGSTU7 (GLUTATHIONE S-TRANSFERASE 25); glutathione transferase & 1,48 & 1,71 & 3,44 & 3,21 \\
\hline At1g07530 & transcription factor & 3,51 & $-0,16$ & $-0,46$ & 3,2 \\
\hline At1g62570 & disulfide oxidoreductase/ monooxygenase/ oxidoreductase & 2,34 & 0,06 & 0,92 & 3,19 \\
\hline At1g14130 & oxidoreductase, acting on paired donors & 0,7 & 1,04 & 3,52 & 3,18 \\
\hline At3g25830 & ATTPS-CIN; myrcene/(E)-beta-ocimene synthase & 3,37 & $-2,43$ & $-2,67$ & 3,13 \\
\hline At3g04890 & unknown protein & 1,47 & 0,39 & 2,01 & 3,09 \\
\hline At4g22070 & WRKY31; transcription factor & 1,33 & $-0,89$ & 0,81 & 3,04 \\
\hline At2g34660 & ATMRP2 (MULTIDRUG RESISTANCE-ASSOCIATED PROTEIN 2); ATPase & 0,93 & $-0,55$ & 1,53 & 3 \\
\hline At2g30750 & CYP71A12; heme binding / iron ion binding / monooxygenase/ oxygen binding & 3,29 & 3,16 & 2,85 & 2,98 \\
\hline At1g55020 & LOX1; lipoxygenase & 1,76 & 0,22 & 1,44 & 2,98 \\
\hline At1g05560 & UGT1; UDP-glycosyltransferase/ transferase, transferring glycosyl groups & 1,72 & 2,3 & 3,57 & 2,98 \\
\hline At3g25820 & - & 3,42 & $-2,67$ & $-3,13$ & 2,96 \\
\hline At2g29480 & ATGSTU2 (GLUTATHIONE S-TRANSFERASE 20); glutathione transferase & 0,68 & 1,31 & 3,57 & 2,94 \\
\hline At1g78340 & ATGSTU22; glutathione transferase & 2,39 & 0,55 & 1,04 & 2,88 \\
\hline At4g14630 & GLP9 (GERMIN-LIKE PROTEIN 9); nutrient reservoir & 1,05 & 0,11 & 1,92 & 2,86 \\
\hline At2g02120 & LCR70/PDF2.1; protease inhibitor & 1,22 & 1,64 & 3,24 & 2,81 \\
\hline At4g37410 & CYP81F4; heme binding / iron ion binding / monooxygenase/ oxygen binding & 3,28 & $-0,72$ & $-1,23$ & 2,77 \\
\hline At3g54040 & unknown protein & 2,83 & 0,36 & 0,31 & 2,77 \\
\hline At5g63900 & DNA binding / protein binding / zinc ion binding & 1,91 & 2,53 & 3,39 & 2,77 \\
\hline
\end{tabular}




\begin{tabular}{|c|c|c|c|c|c|}
\hline At2g36380 & ATPase, coupled to transmembrane movement of substances & 1,28 & 0,29 & 1,77 & 2,76 \\
\hline At2g15490 & UDP-glycosyltransferase/ transferase, transferring glycosyl groups & 1,62 & 3,24 & 4,36 & 2,74 \\
\hline At2g33790 & unknown protein & 4,07 & $-0,86$ & $-2,2$ & 2,73 \\
\hline At5g05960 & lipid binding & 2,51 & $-1,68$ & $-1,46$ & 2,73 \\
\hline At2g39230 & unknown protein & 1,59 & $-0,97$ & 0,16 & 2,72 \\
\hline At5g42180 & - & 3,16 & $-1,04$ & $-1,5$ & 2,7 \\
\hline At1g75270 & glutathione dehydrogenase (ascorbate) & 1,57 & 1,33 & 2,46 & 2,7 \\
\hline At4g19810 & hydrolase, hydrolyzing O-glycosyl compounds & 2,06 & $-0,41$ & 0,23 & 2,69 \\
\hline At3g57510 & ADPG1; polygalacturonase & $-0,33$ & $-2,69$ & 0,33 & 2,69 \\
\hline At5g61950 & cysteine-type endopeptidase/ ubiquitin thiolesterase & 2,38 & 0,8 & 1,1 & 2,68 \\
\hline At4g29930 & DNA binding / transcription factor & 0,8 & $-3,78$ & $-1,89$ & 2,68 \\
\hline At3g13228 & - & 0,34 & 0,89 & 3,23 & 2,68 \\
\hline At5g45070 & ATPP2-A8; transmembrane receptor & 2,25 & $-0,56$ & $-0,15$ & 2,66 \\
\hline At3g66656 & - & 2,1 & $-1,23$ & $-0,67$ & 2,66 \\
\hline At2g31750 & UDP-glycosyltransferase/ transferase, transferring glycosyl groups / transferase & 0,38 & $-1,37$ & 0,9 & 2,65 \\
\hline At2g15220 & unknown protein & 1,97 & 0,11 & 0,77 & 2,62 \\
\hline At4g22235 & - & 1,85 & $-1,63$ & $-0,88$ & 2,6 \\
\hline At1g52060 & unknown protein & 3,3 & $-0,06$ & $-0,79$ & 2,58 \\
\hline At1g66700 & S-adenosylmethionine-dependent methyltransferase & 2,78 & 1,04 & 0,84 & 2,58 \\
\hline At3g28730 & - & 0,19 & 1,01 & 3,41 & 2,58 \\
\hline At3g05150 & carbohydrate transporter/ sugar porter & 2,45 & 1,11 & 1,24 & 2,57 \\
\hline At5g61070 & histone deacetylase & 1,76 & $-0,91$ & $-0,1$ & 2,57 \\
\hline At5g63790 & protein binding / ubiquitin-protein ligase/ zinc ion binding & 1,14 & 1,94 & 3,37 & 2,57 \\
\hline At5g40510 & unknown protein & 3,37 & $-2,01$ & $-2,81$ & 2,56 \\
\hline At5g38910 & nutrient reservoir & 0,64 & $-0,76$ & 1,16 & 2,56 \\
\hline At4g15390 & transferase & 3,6 & $-0,99$ & $-2,05$ & 2,54 \\
\hline At4g13180 & oxidoreductase & 1,46 & 1,21 & 2,29 & 2,54 \\
\hline At4g05020 & calcium ion binding / disulfide oxidoreductase & 1,38 & 0,13 & 1,28 & 2,53 \\
\hline At1g74590 & ATGSTU10; glutathione transferase & 1,74 & 0,67 & 1,46 & 2,52 \\
\hline At5g59510 & unknown protein & 0,81 & 0,88 & 2,59 & 2,52 \\
\hline
\end{tabular}


Table 6-2 Down-regulated genes after treatment with TIBA comparing wildtype and scl14 mutant

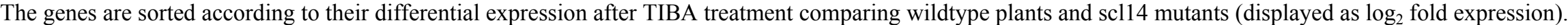
In this table all analysed combinations of treated and untreated plants are displayed allowing a detailed view on the expression pattern and SCL14 dependency of each gene. Genes listed were expressed with a false discovery rate of $10 \%$.

\begin{tabular}{|c|c|c|c|c|c|}
\hline AGI code & Gene Description & Wt/ sc/14 & $\begin{array}{c}\text { scl14 } \\
(\mathrm{TIBA}) / \\
\text { scl14 }\end{array}$ & $\begin{array}{c}\text { Wt }(\text { TIBA }) / \\
\text { Wt }\end{array}$ & $\begin{array}{c}\text { Wt (TIBA)/ } \\
\text { scl14 } \\
\text { (TIBA) }\end{array}$ \\
\hline At5g44420 & PDF1.2 & $-8,45$ & 1,33 & $-0,21$ & $-9,99$ \\
\hline At5g37130 & unknown protein & 2,01 & 12,36 & 0,74 & $-9,61$ \\
\hline At1g75830 & LCR67/PDF1.1 & $-6,92$ & 0,98 & $-0,39$ & $-8,29$ \\
\hline At5g44430 & PDF1.2c & $-7,07$ & 0,61 & $-0,43$ & $-8,11$ \\
\hline At3g01345 & - & $-7,41$ & $-0,85$ & 0,04 & $-6,52$ \\
\hline At2g26020 & PDF1.2b & $-5,14$ & 1,13 & $-0,23$ & $-6,5$ \\
\hline At5g02940 & unknown protein & $-0,12$ & 6,37 & 1,29 & $-5,2$ \\
\hline At2g26010 & PDF1.3 & $-2,89$ & 1,13 & $-0,39$ & $-4,41$ \\
\hline At5g46730 & unknown protein & $-1,11$ & 2,3 & $-0,92$ & $-4,33$ \\
\hline At5g54720 & protein binding & 0,65 & 3,1 & $-1,78$ & $-4,23$ \\
\hline At5g61160 & AACT1; transferase & $-3,29$ & 4,15 & 3,29 & $-4,15$ \\
\hline At2g14610 & PR1 (PATHOGENESIS-RELATED GENE 1) & $-5,84$ & $-1,6$ & 0,6 & $-3,64$ \\
\hline At5g24110 & WRKY30; transcription factor & $-1,23$ & 1,75 & $-0,42$ & $-3,41$ \\
\hline At1g72260 & THI2.1 (THIONIN 2.1); toxin receptor binding & $-2,55$ & $-0,26$ & $-1,05$ & $-3,35$ \\
\hline At3g49620 & DIN11 (DARK INDUCIBLE 11); iron ion binding / isopenicillin-N synthase & $-3,62$ & 3,1 & 3,45 & $-3,27$ \\
\hline At1g52400 & BGL1 (BETA-GLUCOSIDASE HOMOLOG 1); hydrolase & $-2,61$ & 0,36 & $-0,25$ & $-3,21$ \\
\hline At1g08630 & aldehyde-lyase & $-1,42$ & 2,4 & 0,65 & $-3,16$ \\
\hline At3g59930 & unknown protein & $-1,56$ & 1,21 & $-0,3$ & $-3,08$ \\
\hline At1g75750 & GASA1 & $-1,51$ & 0,84 & $-0,71$ & $-3,07$ \\
\hline At5g56550 & unknown protein & $-2,02$ & 0,85 & $-0,08$ & $-2,95$ \\
\hline At1g52410 & unknown protein & $-1,75$ & 0,98 & $-0,21$ & $-2,94$ \\
\hline At1g71270 & - & $-0,79$ & 2,85 & 0,7 & $-2,93$ \\
\hline At5g09610 & RNA binding & $-0,69$ & 2,01 & $-0,21$ & $-2,91$ \\
\hline At2g39330 & unknown protein & $-1,79$ & 0,28 & $-0,84$ & $-2,91$ \\
\hline At2g39320 & cysteine-type peptidase & $-0,14$ & 0,39 & $-2,37$ & $-2,9$ \\
\hline
\end{tabular}




\begin{tabular}{|c|c|c|c|c|c|}
\hline At2g20670 & unknown protein & $-1,89$ & $-0,1$ & $-0,97$ & $-2,76$ \\
\hline At4g26260 & MIOX4 & $-1,47$ & 3,45 & 2,18 & $-2,74$ \\
\hline At3g47340 & - & $-2,69$ & 0,65 & 0,62 & $-2,73$ \\
\hline At4g38680 & GRP2; nucleic acid binding & $-1,01$ & 1,3 & $-0,4$ & $-2,71$ \\
\hline At2g05530 & unknown protein & $-0,82$ & 3,47 & 1,59 & $-2,7$ \\
\hline At1g52040 & MBP1 (MYROSINASE-BINDING PROTEIN 1) & $-3,11$ & $-0,23$ & 0,19 & $-2,69$ \\
\hline At5g33355 & unknown protein & $-1,12$ & 1,06 & $-0,46$ & $-2,64$ \\
\hline At3g44970 & heme binding / iron ion binding / monooxygenase/ oxygen binding & $-1,49$ & $-0,12$ & $-1,22$ & $-2,6$ \\
\hline At3g28220 & unknown protein & $-1,68$ & $-1,46$ & $-2,37$ & $-2,6$ \\
\hline At2g21060 & ATGRP2B (GLYCINE-RICH PROTEIN 2B); DNA binding / nucleic acid binding & $-0,41$ & 1,98 & $-0,21$ & $-2,59$ \\
\hline At3g26230 & CYP71B24; heme binding / iron ion binding / monooxygenase/ oxygen binding & $-1,36$ & $-0,66$ & $-1,88$ & $-2,59$ \\
\hline At2g05520 & GRP-3 (GLYCINE-RICH PROTEIN 3) & $-0,77$ & 3,22 & 1,44 & $-2,56$ \\
\hline
\end{tabular}




\section{$7 \quad$ Bibliography}

Adie, B.A.T., Perez-Perez, J., Perez-Perez, M.M., Godoy, M., Sanchez-Serrano, J.J., Schmelz, E.A., and Solano, R. (2007). ABA is an essential signal for plant resistance to pathogens affecting JA biosynthesis and the activation of defenses in Arabidopsis. Plant Cell 19, 1665-1681.

Aerts, A.M., Thevissen, K., Bresseleers, S.M., Sels, J., Wouters, P., Cammue, B.P.A., and Francois, I.E.J.A. (2007). Arabidopsis thaliana plants expressing human beta-defensin-2 are more resistant to fungal attack: functional homology between plant and human defensins. Plant Cell Reports 26, 1391-1398.

Almeras, E., Stolz, S., Vollenweider, S., Reymond, P., Mene-Saffrane, L., and Farmer, E.E. (2003). Reactive electrophile species activate defense gene expression in Arabidopsis. Plant Journal 34, 202-216.

Alonso, J.M., Hirayama, T., Roman, G., Nourizadeh, S., and Ecker, J.R. (1999). EIN2, a bifunctional transducer of ethylene and stress responses in Arabidopsis. Science 284, 2148-2152.

Alvarez, M.E., Pennell, R.I., Meijer, P.J., Ishikawa, A., Dixon, R.A., and Lamb, C. (1998). Reactive oxygen intermediates mediate a systemic signal network in the establishment of plant immunity. Cell 92, 773-784.

Apel, K., and Hirt, H. (2004). Reactive oxygen species: Metabolism, oxidative stress, and signal transduction. Annual Review of Plant Biology 55, 373-399.

Baerson, S.R., Sanchez-Moreiras, A., Pedrol-Bonjoch, N., Schulz, M., Kagan, I.A., Agarwal, A.K., Reigosa, M.J., and Duke, S.O. (2005). Detoxification and transcriptome response in Arabidopsis seedlings exposed to the allelochemical benzoxazolin-2(3H)-one. J Biol Chem 280, 21867-21881.

Bailey-Serres, J., and Mittler, R. (2006). The roles of reactive oxygen species in plant cells. Plant Physiology 141, 311-311.

Benfey, P.N., and Chua, N.H. (1990). The Cauliflower Mosaic Virus-35s Promoter Combinatorial Regulation of Transcription in Plants. Science 250, 959-966.

Bernard, P., Kezdy, K.E., Vanmelderen, L., Steyaert, J., Wyns, L., Pato, M.L., Higgins, P.N., and Couturier, M. (1993). The F-Plasmid Ccdb Protein Induces Efficient Atp-Dependent DNA Cleavage by Gyrase. Journal of Molecular Biology 234, 534-541. 
Blanco, F., Garreton, V., Frey, N., Dominguez, C., Perez-Acle, T., Van der Straeten, D., Jordana, X., and Holuigue, L. (2005). Identification of NPR1-dependent and independent genes early induced by salicylic acid treatment in Arabidopsis. Plant Mol Biol 59, 927-944.

Bolle, C. (2004). The role of GRAS proteins in plant signal transduction and development. Planta 218, 683-692.

Bradford, M.M., and Williams, W.L. (1976). New, Rapid, Sensitive Method for Protein Determination. Federation Proceedings 35, 274-274.

Bretz, F., Landgrebe, J., and Brunner, E. (2005). Multiplicity issues in microarray experiments. Methods Inf Med 44, 431-437.

Butterbrodt, T., Thurow, C., and Gatz, C. (2006). Chromatin immunoprecipitation analysis of the tobacco PR-1a- and the truncated CaMV 35S promoter reveals differences in salicylic acid-dependent TGA factor binding and histone acetylation. Plant Mol Biol 61, 665-674.

Cao, H., Bowling, S.A., Gordon, A.S., and Dong, X.N. (1994). Characterization of an Arabidopsis Mutant That Is Nonresponsive to Inducers of Systemic AcquiredResistance. Plant Cell 6, 1583-1592.

Cao, H., Glazebrook, J., Clarke, J.D., Volko, S., and Dong, X. (1997). The Arabidopsis NPR1 gene that controls systemic acquired resistance encodes a novel protein containing ankyrin repeats. Cell. 88, 57-63.

Capelli, N., Diogon, T., Greppin, H., and Simon, P. (1997). Isolation and characterization of a cDNA clone encoding an osmotin-like protein from Arabidopsis thaliana. Gene 191, 51-56.

Chen, W., and Singh, K.B. (1999). The auxin, hydrogen peroxide and salicylic acid induced expression of the Arabidopsis GST6 promoter is mediated in part by an ocs element. Plant J 19, 667-677.

Chini, A., Fonseca, S., Fernandez, G., Adie, B., Chico, J.M., Lorenzo, O., GarciaCasado, G., Lopez-Vidriero, I., Lozano, F.M., Ponce, M.R., Micol, J.L., and Solano, R. (2007). The JAZ family of repressors is the missing link in jasmonate signalling. Nature 448, 666-U664.

Chomczynski, P. (1993). A Reagent for the Single-Step Simultaneous Isolation of Rna, DNA and Proteins from Cell and Tissue Samples. Biotechniques 15, 532-\&.

Clough, S., Bent, A. (2000). Vapor-Phase Sterilization of Arabidopsis Seed.

Denison, M.S., and Nagy, S.R. (2003). Activation of the aryl hydrocarbon receptor by structurally diverse exogenous and endogenous chemicals. Annual review of pharmacology and toxicology 43, 309-334. 
Despres, C., Chubak, C., Rochon, A., Clark, R., Bethune, T., Desveaux, D., and Fobert, P.R. (2003). The Arabidopsis NPR1 disease resistance protein is a novel cofactor that confers redox regulation of DNA binding activity to the basic domain/leucine zipper transcription factor TGA1. Plant Cell 15, 2181-2191.

Di Laurenzio, L., Wysocka-Diller, J., Malamy, J.E., Pysh, L., Helariutta, Y., Freshour, G., Hahn, M.G., Feldmann, K.A., and Benfey, P.N. (1996). The SCARECROW gene regulates an asymmetric cell division that is essential for generating the radial organization of the Arabidopsis root. Cell 86, 423-433.

Dill, A., Thomas, S.G., Hu, J., Steber, C.M., and Sun, T.P. (2004). The Arabidopsis F-box protein SLEEPY1 targets gibberellin signaling repressors for gibberellininduced degradation. Plant Cell 16, 1392-1405.

Dong, X.N. (2004). NPR1, all things considered. Current Opinion in Plant Biology 7, $547-552$.

Dower, W.J., Miller, J.F., and Ragsdale, C.W. (1988). High-Efficiency Transformation of Escherichia-Coli by High-Voltage Electroporation. Nucleic Acids Research 16, 6127-6145.

Fan, W., and Dong, X. (2002). In vivo interaction between NPR1 and transcription factor TGA2 leads to salicylic acid-mediated gene activation in Arabidopsis. Plant Cell 14, 1377-1389.

Ferrari, S., Galletti, R., Denoux, C., De Lorenzo, G., Ausubel, F.M., and Dewdney, J. (2007). Resistance to Botrytis cinerea induced in Arabidopsis by elicitors is independent of salicylic acid, ethylene, or jasmonate signaling but requires PHYTOALEXIN DEFICIENT3. Plant Physiology 144, 367-379.

Feys, B.J.F., Benedetti, C.E., Penfold, C.N., and Turner, J.G. (1994). Arabidopsis Mutants Selected for Resistance to the Phytotoxin Coronatine Are Male-Sterile, Insensitive to Methyl Jasmonate, and Resistant to a Bacterial Pathogen. Plant Cell 6, 751-759.

Fields, S., and Song, O. (1989). A novel genetic system to detect protein-protein interactions. Nature 340, 245-246.

Fobert, P.R., and Despres, C. (2005). Redox control of systemic acquired resistance. Curr Opin Plant Biol 8, 378-382.

Gao, M.J., Parkin, I., Lydiate, D., and Hannoufa, A. (2004). An auxin-responsive SCARECROW-like transcriptional activator interacts with histone deacetylase. Plant Mol Biol 55, 417-431. 
Gao, Z.Y., Chen, Y.F., Randlett, M.D., Zhao, X.C., Findell, J.L., Kieber, J.J., and Schaller, G.E. (2003). Localization of the Raf-like kinase CTR1 to the endoplasmic reticulum of Arabidopsis through participation in ethylene receptor signaling complexes. Journal of Biological Chemistry 278, 34725-34732.

Geisberg, J.V., and Struhl, K. (2004). Quantitative sequential chromatin immunoprecipitation, a method for analyzing co-occupancy of proteins at genomic regions in vivo. Nucleic Acids Res 32, e151.

Govrin, E.M., and Levine, A. (2000). The hypersensitive response facilitates plant infection by the necrotrophic pathogen Botrytis cinerea. Current Biology 10, $751-757$.

Gronover, C.S., Kasulke, D., Tudzynski, P., and Tudzynski, B. (2001). The role of G protein alpha subunits in the infection process of the gray mold fungus Botrytis cinerea. Molecular Plant-Microbe Interactions 14, 1293-1302.

Grun, C., Berger, S., Matthes, D., and Mueller, M.J. (2007). Early accumulation of non-enzymatically synthesised oxylipins in Arabidopsis thaliana after infection with Pseudomonas syringae. Functional Plant Biology 34, 65-71.

Hanahan, D. (1983). Studies on Transformation of Escherichia-Coli with Plasmids. Journal of Molecular Biology 166, 557-580.

Hayes, J.D., and McLellan, L.I. (1999). Glutathione and glutathione-dependent enzymes represent a Co-ordinately regulated defence against oxidative stress. Free Radical Research 31, 273-300.

Heinekamp, T., Kuhlmann, M., Lenk, A., Strathmann, A., and Droge-Laser, W. (2002). The tobacco bZIP transcription factor BZI-1 binds to G-box elements in the promoters of phenylpropanoid pathway genes in vitro, but it is not involved in their regulation in vivo. Molecular Genetics and Genomics 267, 16-26.

Howe, G.A., and Schilmiller, A.L. (2002). Oxylipin metabolism in response to stress. Current Opinion in Plant Biology 5, 230-236.

Imbusch, R., and Mueller, M.J. (2000). Analysis of oxidative stress and woundinducible dinor isoprostanes F-1 (phytoprostanes F-1) in plants. Plant Physiology 124, 1293-1303.

Jakoby, M., Weisshaar, B., Droge-Laser, W., Vicente-Carbajosa, J., Tiedemann, J., Kroj, T., Parcy, F., and Grp, b.R. (2002). bZIP transcription factors in Arabidopsis. Trends in Plant Science 7, 106-111.

James, P., Halladay, J., and Craig, E.A. (1996). Genomic libraries and a host strain designed for highly efficient two-hybrid selection in yeast. Genetics 144, 14251436. 
Johnson, C., Boden, E., Desai, M., Pascuzzi, P., and Arias, J. (2001). In vivo target promoter-binding activities of a xenobiotic stress-activated TGA factor. Plant Journal 28, 237-243.

Katagiri, F., Lam, E., and Chua, N.H. (1989). Two tobacco DNA-binding proteins with homology to the nuclear factor CREB. Nature 340, 727-730.

Kesarwani, M., Yoo, J.M., and Dong, X.N. (2007). Genetic interactions of TGA transcription factors in the regulation of pathogenesis-related genes and disease resistance in Arabidopsis. Plant Physiology 144, 336-346.

Klein, M., Burla, B., and Martinoia, E. (2006). The multidrug resistance-associated protein (MRP/ABCC) subfamily of ATP-binding cassette transporters in plants. Febs Letters 580, 1112-1122.

Klessig, D.F., Durner, J., Noad, R., Navarre, D.A., Wendehenne, D., Kumar, D., Zhou, J.M., Shah, J., Zhang, S.Q., Kachroo, P., Trifa, Y., Pontier, D., Lam, E., and Silva, H. (2000). Nitric oxide and salicylic acid signaling in plant defense. Proceedings of the National Academy of Sciences of the United States of America 97, 8849-+.

Kliewer, S.A., Goodwin, B., and Willson, T.M. (2002). The nuclear pregnane X receptor: a key regulator of xenobiotic metabolism. Endocrine reviews 23, 687702.

Klinedinst, S., Pascuzzi, P., Redman, J., Desai, M., and Arias, J. (2000). A xenobiotic-stress-activated transcription factor and its cognate target genes are preferentially expressed in root tip meristems. Plant Molecular Biology 42, 679688.

Koncz, C., and Schell, J. (1986). The Promoter of Tl-DNA Gene 5 Controls the Tissue-Specific Expression of Chimeric Genes Carried by a Novel Type of Agrobacterium Binary Vector. Molecular \& General Genetics 204, 383-396.

Krawczyk, S., Thurow, C., Niggeweg, R., and Gatz, C. (2002). Analysis of the spacing between the two palindromes of activation sequence-1 with respect to binding to different TGA factors and transcriptional activation potential. Nucleic Acids Res 30, 775-781.

Kudo, N., Matsumori, N., Taoka, H., Fujiwara, D., Schreiner, E.P., Wolff, B., Yoshida, M., and Horinouchi, S. (1999). Leptomycin B inactivates CRM1/exportin 1 by covalent modification at a cysteine residue in the central conserved region. Proc. Natl. Acad. Sci. USA 96, 9112-9117.

Kuo, M.H., and Allis, C.D. (1999). In vivo cross-linking and immunoprecipitation for studying dynamic Protein:DNA associations in a chromatin environment. Methods (San Diego, Calif 19, 425-433. 
Lam, E., Kato, N., and Lawton, M. (2001). Programmed cell death, mitochondria and the plant hypersensitive response. Nature 411, 848-853.

Lam, E., Benfey, P.N., Gilmartin, P.M., Fang, R.X., and Chua, N.H. (1989). Sitespecific mutations alter in vitro factor binding and change promoter expression pattern in transgenic plants. Proc Natl Acad Sci U S A 86, 7890-7894.

Landgrebe, J., Bretz, F., and Brunner, E. (2004). Efficient two-sample designs for microarray experiments with biological replications. In silico biology 4, 461-470.

Langrebe, J., Bretz, F., and Brunner, E. (2006). Efficient design and analysis of two colour factorial microarray experiments. . Computational Statistics and Data Analysis 50, 499-517.

Lebel, E., Heifetz, P., Thorne, L., Uknes, S., Ryals, J., and Ward, E. (1998). Functional analysis of regulatory sequences controlling $P R-1$ gene expression in Arabidopsis. Plant J 16, 223-233.

Liu, X., and Lam, E. (1994). Two binding sites for the plant transcription factor ASF-1 can respond to auxin treatments in transgenic tobacco. J Biol Chem 269, 668675.

Lorenzo, O., Piqueras, R., Sanchez-Serrano, J.J., and Solano, R. (2003). ETHYLENE RESPONSE FACTOR1 integrates signals from ethylene and jasmonate pathways in plant defense. Plant Cell 15, 165-178.

Minet, M., Dufour, M.E., and Lacroute, F. (1992). Complementation of Saccharomyces cerevisiae auxotrophic mutants by Arabidopsis thaliana cDNAs. Plant J. 2, 417-422.

Montillet, J.L., Chamnongpol, S., Rusterucci, C., Dat, J., van de Cotte, B., Agnel, J.P., Battesti, C., Inze, D., Van Breusegem, F., and Triantaphylides, C. (2005). Fatty acid hydroperoxides and $\mathrm{H} 2 \mathrm{O} 2$ in the execution of hypersensitive cell death in tobacco leaves. Plant Physiology 138, 1516-1526.

Morohashi, K., Minami, M., Takase, H., Hotta, Y., and Hiratsuka, K. (2003). Isolation and characterization of a novel GRAS gene that regulates meiosisassociated gene expression. J. Biol. Chem. 278, 20865-20873.

Mou, Z., Fan, W.H., and Dong, X.N. (2003). Inducers of plant systemic acquired resistance regulate NPR1 function through redox changes. Cell 113, 935-944.

Mueller, M.J. (2004). Archetype signals in plants: the phytoprostanes. Current Opinion in Plant Biology 7, 441-448. 
Mueller, S., Hilbert, B., Dueckershoff, K., Roitsch, T., Krischke, M., Mueller, M., and Berger, S. (2008). General Detoxification and Stress Responses Are Mediated by Oxidized Lipids through TGA Transcription Factors in Arabidopsis. Plant Cell.

Ndamukong, I., Al Abdallat, A., Thurow, C., Fode, B., Zander, M., Weigel, R., and Gatz, C. (2007). SA-inducible Arabidopsis glutaredoxin interacts with TGA factors and suppresses JA-responsive PDF1.2 transcription. Plant Journal 50, 128-139.

Nguyen, T., Sherratt, P.J., and Pickett, C.B. (2003). Regulatory mechanisms controlling gene expression mediated by the antioxidant response element. Annual review of pharmacology and toxicology 43, 233-260.

Nickolov, K.I. (2003). Subcellular Localization Of Nicotiana tabacum TGA Transcription Factors

(Göttingen: Georg-August-Universität).

Orlando, V. (2000). Mapping chromosomal proteins in vivo by formaldehydecrosslinked-chromatin immunoprecipitation. Trends Biochem Sci 25, 99-104.

Park, S.W., Kaimoyo, E., Kumar, D., Mosher, S., and Klessig, D.F. (2007). Methyl salicylate is a critical mobile signal for plant systemic acquired resistance. Science 318, 113-116.

Pascuzzi, P., Hamilton, D., Bodily, K., and Arias, J. (1998). Auxin-induced stress potentiates trans-activation by a conserved plant basic/leucine-zipper factor. Journal of Biological Chemistry 273, 26631-26637.

Prestera, T., Holtzclaw, W.D., Zhang, Y.S., and Talalay, P. (1993a). Chemical and Molecular Regulation of Enzymes That Detoxify Carcinogens. Proceedings of the National Academy of Sciences of the United States of America 90, 29652969.

Prestera, T., Zhang, Y.S., Spencer, S.R., Wilczak, C.A., and Talalay, P. (1993b). The Electrophile Counterattack Response - Protection against Neoplasia and Toxicity. Advances in Enzyme Regulation 33, 281-296.

Pysh, L.D., Wysocka-Diller, J.W., Camilleri, C., Bouchez, D., and Benfey, P.N. (1999). The GRAS gene family in Arabidopsis: sequence characterization and basic expression analysis of the SCARECROW-LIKE genes. Plant J. 18, 111119.

Qin, X.F., Holuigue, L., Horvath, D.M., and Chua, N.H. (1994). Immediate early transcription activation by salicylic acid via the cauliflower mosaic virus as-1 element. Plant-Cell. 6, 863-874. 
Rahman, A., Nakasone, A., Chhun, T., Ooura, C., Biswas, K.K., Uchimiya, H., Tsurumi, S., Baskin, T.I., Tanaka, A., and Oono, Y. (2006). A small acidic protein 1 (SMAP1) mediates responses of the Arabidopsis root to the synthetic auxin 2,4-dichlorophenoxyacetic acid. Plant Journal 47, 788-801.

Redman, J., Whitcraft, J., Gulam, H., and Arias, J. (2002). Abiotic and biotic stress differentially stimulate as-1 element activity in Arabidopsis. Plant Cell Rep. 21, 180-185.

Reymond, P., Bodenhausen, N., Van Poecke, R.M.P., Krishnamurthy, V., Dicke, M., and Farmer, E.E. (2004). A conserved transcript pattern in response to a specialist and a generalist herbivore. Plant Cell 16, 3132-3147.

Riechmann, J.L., Heard, J., Martin, G., Reuber, L., Jiang, C., Keddie, J., Adam, L., Pineda, O., Ratcliffe, O.J., Samaha, R.R., Creelman, R., Pilgrim, M., Broun, P., Zhang, J.Z., Ghandehari, D., Sherman, B.K., and Yu, G. (2000). Arabidopsis transcription factors: genome-wide comparative analysis among eukaryotes. Science 290, 2105-2110.

Rochon, A., Boyle, P., Wignes, T., Fobert, P.R., and Despres, C. (2006). The coactivator function of Arabidopsis NPR1 requires the core of its BTB/POZ domain and the oxidation of C-terminal cysteines. Plant Cell 18, 3670-3685.

Ryals, J., Weymann, K., Lawton, K., Friedrich, L., Ellis, D., Steiner, H.Y., Johnson, J., Delaney, T.P., Jesse, T., Vos, P., and Uknes, S. (1997). The Arabidopsis NIM1 protein shows homology to the mammalian transcription factor inhibitor I kappa B. Plant Cell 9, 425-439.

Sandermann, H., Jr. (1992). Plant metabolism of xenobiotics. Trends Biochem Sci 17, 82-84.

Sanger, F., Nicklen, S., and Coulson, A.R. (1977). DNA Sequencing with ChainTerminating Inhibitors. Proceedings of the National Academy of Sciences of the United States of America 74, 5463-5467.

Sattler, S.E., Mene-Saffrane, L., Farmer, E.E., Krischke, M., Mueller, M.J., and DellaPenna, D. (2006). Nonenzymatic lipid peroxidation reprograms gene expression and activates defense markers in Arabidopsis tocopherol-deficient mutants. Plant Cell 18, 3706-3720.

Siemsen, T. (2005). Die Bedeutung des Proteins Scarecrow-like 14 bei der Regulation der Transkription von Stressgenen (Göttingen: Georg-August-Universität).

Silverstone, A.L., Ciampaglio, C.N., and Sun, T. (1998). The Arabidopsis RGA gene encodes a transcriptional regulator repressing the gibberellin signal transduction pathway. Plant Cell 10, 155-169. 
Staswick, P. (2008). JAZing up jasmonate signaling. Trends Plant Sci.

Stintzi, A., Weber, H., Reymond, P., Browse, J., and Farmer, E.E. (2001). Plant defense in the absence of jasmonic acid: The role of cyclopentenones. Proceedings of the National Academy of Sciences of the United States of America 98, 12837-12842.

Subramaniam, R., Desveaux, D., Spickler, C., Michnick, S.W., and Brisson, N. (2001). Direct visualization of protein interactions in plant cells. Nature Biotechnology 19, 769-772.

Süthoff, U. (2006). Analyse der Interaktion von TGA 2 und Scarecrow - ähnlichen Regulationsfaktoren (Göttingen: Georg-August-Universität).

Thibaud-Nissen, F., Wu, H., Richmond, T., Redman, J.C., Johnson, C., Green, R., Arias, J., and Town, C.D. (2006). Development of Arabidopsis whole-genome microarrays and their application to the discovery of binding sites for the TGA2 transcription factor in salicylic acid-treated plants. Plant J 47, 152-162.

Thines, B., Katsir, L., Melotto, M., Niu, Y., Mandaokar, A., Liu, G.H., Nomura, K., He, S.Y., Howe, G.A., and Browse, J. (2007). JAZ repressor proteins are targets of the SCFCO11 complex during jasmonate signalling. Nature 448, 661U662.

Thomma, B.P.H.J., Eggermont, K., Penninckx, I.A.M.A., Mauch-Mani, B., Vogelsang, R., Cammue, B.P.A., and Broekaert, W.F. (1998). Separate jasmonate-dependent and salicylate-dependent defense-response pathways in Arabidopsis are essential for resistance to distinct microbial pathogens. Proceedings of the National Academy of Sciences of the United States of America 95, 15107-15111.

Tian, C., Wan, P., Sun, S., Li, J., and Chen, M. (2004). Genome-wide analysis of the GRAS gene family in rice and Arabidopsis. Plant Mol Biol 54, 519-532.

Ton, J., and Mauch-Mani, B. (2004). beta-amino-butyric acid-induced resistance against necrotrophic pathogens is based on ABA-dependent priming for callose. Plant Journal 38, 119-130.

Uquillas, C., Letelier, I., Blanco, F., Jordana, X., and Holuigue, L. (2004a). NPR1independent activation of immediate early salicylic acid-responsive genes in Arabidopsis. Molecular Plant-Microbe Interactions 17, 34-42.

Uquillas, C., Letelier, I., Blanco, F., Jordana, X., and Holuigue, L. (2004b). NPR1independent activation of immediate early salicylic acid-responsive genes in Arabidopsis. Mol Plant Microbe Interact 17, 34-42. 
van Hulten, M., Pelser, M., van Loon, L.C., Pieterse, C.M.J., and Ton, J. (2006). Costs and benefits of priming for defense in Arabidopsis. Proceedings of the National Academy of Sciences of the United States of America 103, 5602-5607.

Verburg, J.G., and Huynh, Q.K. (1991). Purification and Characterization of an Antifungal Chitinase from Arabidopsis-Thaliana. Plant Physiology 95, 450-455.

Veronese, P., Chen, X., Bluhm, B., Salmeron, J., Dietrich, R., and Mengiste, T. (2004). The BOS loci of Arabidopsis are required for resistance to Botrytis cinerea infection. Plant Journal 40, 558-574.

Vollenweider, S., Weber, H., Stolz, S., Chetelat, A., and Farmer, E.E. (2000). Fatty acid ketodienes and fatty acid ketotrienes: Michael addition acceptors that accumulate in wounded and diseased Arabidopsis leaves. Plant Journal 24, 467476.

Wagner, U., Edwards, R., Dixon, D.P., and Mauch, F. (2002). Probing the diversity of the Arabidopsis glutathione S-transferase gene family. Plant Mol Biol 49, 515-532.

Wang, H., Tang, W., Zhu, C., and Perry, S.E. (2002). A chromatin immunoprecipitation (ChIP) approach to isolate genes regulated by AGL15, a MADS domain protein that preferentially accumulates in embryos. Plant $\mathbf{J}$ 32, 831-843.

Weigel, R.R., Pfitzner, U.M., and Gatz, C. (2005). Interaction of NIMIN1 with NPR1 modulates PR gene expression in Arabidopsis. Plant Cell 17, 1279-1291.

Weigel, R.R., Bauscher, C., Pfitzner, A.J.P., and Pfitzner, U.M. (2001). NIMIN-1, NIMIN-2 and NIMIN-3, members of a novel family of proteins from Arabidopsis that interact with NPR1/NIM1, a key regulator of systemic acquired resistance in plants. Plant Molecular Biology 46, 143-160.

Xiang, C.B., Miao, Z.H., and Lam, E. (1997). DNA-binding properties, genomic organization and expression pattern of TGA6, a new member of the TGA family of bZIP transcription factors in Arabidopsis thaliana. Plant Molecular Biology 34, 403-415.

Xie, D.X., Feys, B.F., James, S., Nieto-Rostro, M., and Turner, J.G. (1998). COI1: An Arabidopsis gene required for jasmonate-regulated defense and fertility. Science 280, 1091-1094.

Yan, Y.X., Stolz, S., Chetelat, A., Reymond, P., Pagni, M., Dubugnon, L., and Farmer, E.E. (2007). A downstream mediator in the growth repression limb of the jasmonate pathway. Plant Cell 19, 2470-2483. 
Zentella, R., Zhang, Z.L., Park, M., Thomas, S.G., Endo, A., Murase, K., Fleet, C.M., Jikumaru, Y., Nambara, E., Kamiya, Y., and Sun, T.P. (2007). Global analysis of della direct targets in early gibberellin signaling in Arabidopsis. Plant Cell 19, 3037-3057.

Zhang, B., and Singh, K.B. (1994). ocs element promoter sequences are activated by auxin and salicylic acid in Arabidopsis. Proc Natl Acad Sci U S A 91, 25072511.

Zhang, Y.L., Tessaro, M.J., Lassner, M., and Li, X. (2003). Knockout analysis of Arabidopsis transcription factors TGA2, TGA5, and TGA6 reveals their redundant and essential roles in systemic acquired resistance. Plant Cell 15, 2647-2653.

Zimmerli, L., Metraux, J.P., and Mauch-Mani, B. (2001). beta-aminobutyric acidinduced protection of Arabidopsis against the necrotrophic fungus Botrytis cinerea. Plant Physiology 126, 517-523. 


\section{Acknowledgement:}

Zunächst möchte ich mich ganz herzlich bei allen bedanken, die mir diese Arbeit überhaupt erst ermöglicht haben.

Von all jenen hat Christiane Gatz den größten Anteil an dieser Arbeit. Durch Ihre Unterstützung zu jeder Zeit und Ihre innovativen Ideen haben Sie meine Arbeit und mich persönlich sehr viel weiter gebracht als ich das ohne Sie geschafft hätte. Auch für das große Vertrauen in mich möchte ich mich wirklich sehr bedanken. Außerdem möchte ich mich für die vielen Möglichkeiten der Darstellung meiner Arbeit auf Kongressen bedanken. Das hat mich auch persönlich sehr gestärkt.

Auch Wolfgang Dröge-Laser möchte ich sehr herzlich danken. Du hast nicht nur meine Diplomarbeit und meine Dissertation korreferiert, sondern hattest auch immer gute Ratschläge für mich zur Verfügung. Für deine ermutigenden Kommentare zu meinen Arbeitsberichten möchte ich dir sehr danken.

Detlef Doenecke und Gerhard Braus möchte ich für die ausgezeichneten Ratschläge und Hilfestellungen als Mitglieder meines Thesis Committees danken. Außerdem danke ich dem Graduiertenkolleg 521 für die finanzielle Unterstützung meiner Arbeit und für die Möglichkeit des wissenschaftlichen und privaten Austausches mit Mitgliedern des eigenen und anderen Graduiertenkollegs. Besonders unseren Sprechern Detlef Doenecke und Pawel Burkhardt gebührt der Dank für die Organisation der vielfältigen und interessanten Seminare und Praktika.

Ivo Feussner möchte ich herzlich für die bereitwillige Beteiligung an meiner Prüfungskommission und für die Ratschläge zu elektrophilen Substanzen danken.

Ernst Wimmer möchte ich für die Beteiligung an meiner Prüfungskommission danken. Ein ganz besonderer Dank geht an Corinna Thurow. Du hast mich erst davon überzeugt meinen weiteren wissenschaftlichen Weg in der Pflanzenphysiologie zu gehen. Das war mit Sicherheit die beste Entscheidung, die ich in meinem bisherigen Leben getroffen habe. Vielen Dank auch für die unglaubliche Geduld und Gewissenhaftigkeit mit der du mir bei so manchem Problem geholfen hast.

Meiner SCL14-Vorgängerin Tanja Siemsen möchte ich für die tolle Einweisung und Starthilfe in das SCL14-Feld danken. Ich hoffe ich konnte mit dieser Arbeit dein angefangenes Werk würdig fortsetzen. 
Thomas Butterbrodt und Steffi Krawczyk möchte ich danken für die hervorragende wissenschaftliche Anleitung. Danke, Steffi, für das tolle GPII, was mich überzeugt hat, dass dieses wissenschaftliche Feld das richtige für mich ist. Thomas, dir möchte ich für die Einweisung in die ChIP und für die vielen kleinen Tipps und Tricks im Laboralltag danken. Mit dir zusammen zu arbeiten hat mir auch immer sehr viel Spaß bereitet. Euch beiden wünsche ich für die gemeinsame Zukunft zu dritt (bisher) alles Gute.

Meinem Diplomarbeitsbetreuer und gutem Freund Marco Herde möchte ich für die tolle Zeit und großartige wissenschaftliche Anleitung während meiner Diplomarbeit danken. Auch für die vielen sehr spaßigen gemeinsamen Freizeitaktivitäten danke ich dir sehr. Ralf Weigel möchte ich für die vielen, unglaublich hilfreichen Ratschläge zu meinem Projekt danken und für die hinterlassenen Laborhilfsmittel.

Ein riesiger Dank geht auch an Guido Kriete. Danke Guido, für deine stete Hilfestellung bei jedem noch so kleinen Problem.

Ich möchte auch Björn Willige (Uni Tübingen) und Carina Behringer (Bayer CropScience) für die fruchtbare Zusammenarbeit am RGA-Projekt und am SCL14Safener-Projekt danken. Ebensolcher Dank gebührt Stefan Müller und Susanne Berger (Uni Würzburg) für die Zusammenarbeit am SCL14-Phytoprostan-Projekt.

Ein herzliches Dankeschön auch an Brigitte Mauch-Mani (Uni Neuchatel) und Andreas von Tiedemann (Uni Göttingen) fürs zur Verfügung stellen von B. cinerea Kultivaren und einen lieben Dank an Yuelin Zhang für die Zusendung von tga2,5,6 Samen.

Als nächstes möchte ich meinen großartigen Laborkollegen danken, die mich die ganze oder auch nur Teile der Zeit hier begleitet haben und das Laborleben abwechslungsreich und angenehm gestaltet haben.

Katrin Gärtner möchte ich besonders danken für die vielfältige Hilfe im Labor. Du bist wirklich meine beste Freundin. Ich danke dir, dass ich mit dir über wirklich alles reden konnte und dass du meine Macken so gut ertragen hast. Mein (Einsiedler-) Leben und das Laborleben war durch dich sehr viel bunter und abwechslungsreicher. Vielen herzlichen Dank auch dafür, dass ich dir meine Experimente anvertrauen konnte, wenn ich selbst verhindert war. Ich wünsche dir und Marco in den USA und im weiteren Leben alles Gute. 
Katja Rindermann möchte ich danken für die vielen gemeinsamen Freizeitaktivitäten. Auf dich Katja, konnte ich mich immer verlassen und du hattest immer gute Ratschläge für mich.

Ich danke Hella Tappe für ihre Hilfe gerade in schwierigen Situationen. Du hast es wie keine andere verstanden andere wieder aufzubauen und mit Rat und Tat auf beste Weise zu unterstützen. Ich danke dir auch sehr für die vielen, netten gemeinsamen Koch-, Cocktail- und DVD-Abende.

Mark "Schilt" Zander möchte ich sehr für die lockere und angenehme Arbeitsatmosphäre danken. Es war und wird mir auch in Zukunft ein Vergnügen sein mit dir am Botrytis-Projekt zu arbeiten. Auch für die entspannten Poker-Runden möchte ich dir sehr danken.

Ein ganz herzlicher Dank geht auch an meine Lieblingsdiplomandin Ulli Süthoff. Du hast mir die Betreuung wirklich sehr leicht gemacht mit deiner liebenswerten und lockeren Art. Ich wünsche dir für deinen weiteren Weg alles Gute (deine treulose Tomate).

Meinem SCL14-Praktikanten Simon von Berlepsch möchte ich für seine ruhige und besonnene Arbeit an den SCL14-Deletionen danken. Die Ergebnisse der HefeInteraktionsdaten sind auch von ihm erarbeitet worden.

Unseren TAs Ronald Scholz, Anna Hermann, Larissa Kunz und Anette Gunkel möchte ich für die zuverlässige und gewissenhafte Hilfe im Labor danken. Durch ihre beständige Bereitstellung von Medien, Antibiotika-Stocks und kompetenten E. coliZellen habt ihr mir meine Arbeit unglaublich erleichtert. Ronald und Anna, euch gebührt der besondere Dank, dass ihr auch kurzfristig für jede erdenkliche Hilfe zur Verfügung gestanden habt.

Auch unseren Gärtnern Uwe Wedemeyer und Feli Glasenapp möchte ich sehr danken. Besonders die Bereitstellung von fertigen Pflanzentabletts war mir eine enorme Hilfe. Danke auch für die Bereitstellung von „ungewöhnlichen“ Samen, wie Tomatensamen. Ehemaligen Laborkollegen, mit denen ich sehr gerne zusammen gearbeitet habe, sei hier auch gedankt. Gerade Iris Camehl und Mathias Zopf möchte ich für die gemeinsame Zeit danken. 
An dieser Stelle möchte ich noch meinen Dank an diejenigen ausrichten, die mir zwar nicht direkt bei der Arbeit helfen konnten, aber umso wichtiger für mich persönlich sind. Besonders möchte ich mich bei meinen liebenswerten und fantastischen Eltern, Harald und Renate bedanken. Ich liebe euch beide sehr. Ihr seid wirklich die besten Eltern der Welt. Ihr seid meine Kraft in schwierigsten Situationen. "Schrank" und "Mächen" bleibt so wie ihr seid.

Meinen großartigen Geschwistern Dominik und Ines danke ich einfach dafür, dass es sie gibt. Ihr seid für mich die wichtigsten Menschen in meinem Leben. Danke dass ihr immer für mich da seid. Ich wünsche auch Bianka, Hanna Lea und Liam Emil alles Gute im Leben.

Einen ganz lieben Dank möchte ich auch meinem Cousin Jonathan Weggen und meiner Tante Susanne Weggen sagen. Ihr seid für mich wie ein zweiter Bruder und eine zweite Mutter. Danke für all die schönen Zeiten, die wir gemeinsam erlebt haben und das ich immer bei euch „reinschneien“ konnte.

Ein großer Dank geht auch an meine Freunde, mit denen ich immer sehr viel Spaß hatte und die auch meine schlechten Sprüche (fast) ohne murren ertragen haben. Danke Jan, Bennet, Sven und Freddi.

Die letzten Zeilen dieser Danksagung und meine Arbeit möchte ich meinem verstorbenen Onkel Joachim Weggen widmen. Danke Joe für die Zeit, die wir gemeinsam auf dieser Welt verbracht haben. Du warst wie ein zweiter Vater für mich und ich werde die Erinnerung an dich immer in meinem Herzen bewahren. 


\section{Curriculum Vitae:}

Seit 01/2005 Dissertation "The GRAS Protein SCL14 and TGA Transcription Factors interact to regulate Stress-Inducible Promoters"

11/2003-11/2004: Diplomarbeit "Analyse des Terpensynthase28-Promotors in transienten und stabilen Transformationen von Arabidopsis thaliana"

11/2003: mündliche Diplomprüfung Botanik: Ausreichend, Mikrobiologie: Sehr Gut, Geologie: Gut

02/2001: $\quad$ Vordiplom Gesamtnote: Befriedigend

WS 1998/1999: Beginn des Diplomstudiengangs Biologie an der Universität Göttingen

08/1997-09/1998: Zivildienst beim TSV Buxtehude: Kindergarten und Kinderturnen

1988-1997: Orientierungsstufe und Halepaghen-Gymnasium, Buxtehude; Abitur in den Fächern Mathematik, Gemeinschaftskunde, Biologie und Deutsch: Note 2,9

1984-1987: $\quad$ Grundschule Altkloster, Buxtehude 